\title{
ADOLESCENTS' RESPONSES TO THE DISTRESS OF OTHERS: THE INFLUENCE OF MULTIPLE ATTACHMENT FIGURES VIA EMPATHIC CONCERN
}

\section{WADE BYRON PROFE}

\section{PRFWAD001}

A dissertation submitted in partial fulfilment of the requirements for the Master of Arts specialising in Psychological Research

Department of Psychology

Faculty of Humanities

University of Cape Town

Supervisor: Associate Professor Lauren Wild

2016

\section{DECLARATION \\ This work has not been previously submitted in whole, or in part, for the award of any degree. It is my own work. Each significant contribution to, and quotation in, this dissertation from the work, or works, of other people has been attributed, and has been cited and referenced.

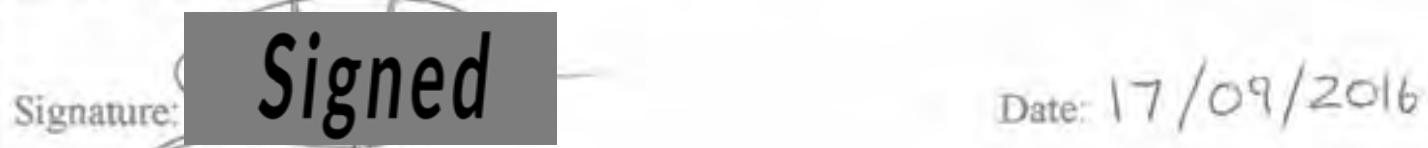


The copyright of this thesis vests in the author. No quotation from it or information derived from it is to be published without full acknowledgement of the source. The thesis is to be used for private study or noncommercial research purposes only.

Published by the University of Cape Town (UCT) in terms of the non-exclusive license granted to UCT by the author. 


\section{ACKNOWLEDGEMENTS}

My thanks must go first and foremost to my God, Jesus the Christ, who is the giver of the resources, intelligence and time I needed to complete this dissertation.

To my supervisor, Associate Professor Lauren Wild: Your ever-present assistance with my work is greatly appreciated. Thank you for placing your trust in me to produce a work that you can believe in.

Thank you to the schools, principals and teachers who went out of their way to accommodate my research and allowed me to collect data from their learners. My thanks also go to the Western Cape Education Department for permitting me to collect data in schools.

Thank you to my research assistants: Tasneem, Alexandra, Jarren, Brent, Isabella, Petro, and Jennifer. You all went out of your way to help, and were willing to go the extra mile when the research process yielded unexpected demands.

To Professor Colin Tredoux, who patiently, selflessly and graciously endured my constant barrage of statistics questions: Thank you! My gratitude also goes to Michelle and Alicia for always being willing to lend a hand with my statistics questions.

Thank you to Andrew Lewis from the UCT HPC team, who provided consistent, patient and timely support while I tried to figure out Linux commands and how to use the HPC cluster.

Thank you to the University of Cape Town for kindly granting me a scholarship in order to pursue my Masters degree.

Finally, thank you to all those family and friends who supported me, encouraged me, and took an interest in my work. 


\begin{abstract}
Despite its importance for the successful maturation of adolescents, relatively little is known about the development of prosocial behaviour during this life period. Attachment theory, although largely absent from the literature in this area, provides an informative theoretical description of how prosocial behaviours in response to the distress of others may be socialized. The aim of this study was to investigate the relative influence of attachment security to mothers, fathers, closest grandparents, and friends on the response to others' distress among early adolescents, via the mediation of empathic concern. Cross-sectional, quantitative survey data from 520 adolescents (aged 11-14) from 9 schools in Cape Town were used in the analyses. Zero-order correlations confirmed the expected positive relationships between attachment security to all four figures and empathic concern, as well as self-reported prosocial behaviour, but not for teacher-reported prosocial behaviour. Structural Equation Modelling revealed that empathic concern completely mediated the relation between attachment security and both self- and teacher-reported prosocial behaviour. Furthermore, when controlling for attachment security to mothers, fathers, closest grandparents and friends simultaneously, peer attachment emerged as the only significant indirect influence on self-reported prosocial behaviour. For teacher-reported prosocial behaviour, however, the indirect effect of friend attachment failed to reach significance. The results of this study provide theoretical insight into the influence of secure attachments on prosocial behaviour, and highlight the importance of supportive same-age peer relationships in adolescence.
\end{abstract}

Keywords: Attachment, prosocial behaviour, empathic concern, mother, father, grandparent, friend 
TABLE OF CONTENTS

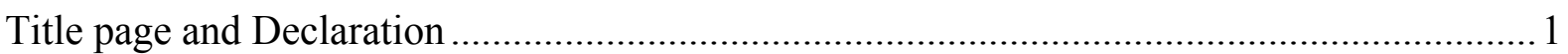

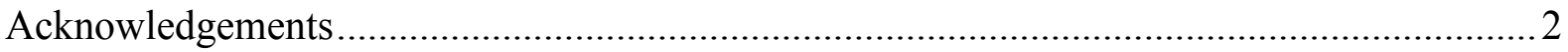

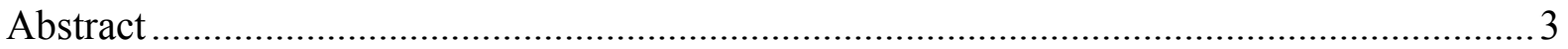

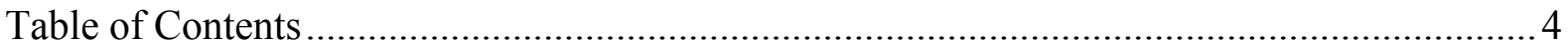

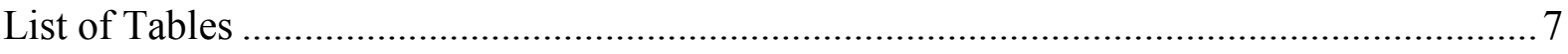

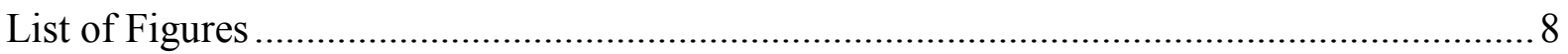

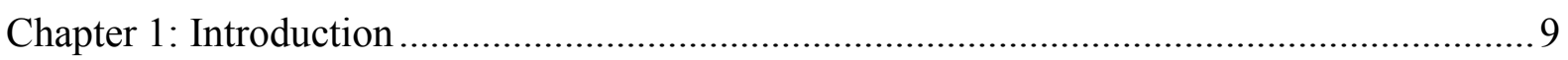

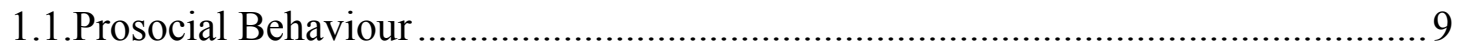

1.1.1. The importance of prosocial development.......................................... 9

1.1.2. The multi-dimensionality of prosocial behaviour.............................. 10

1.1.3. Socializing influences on prosocial development............................. 11

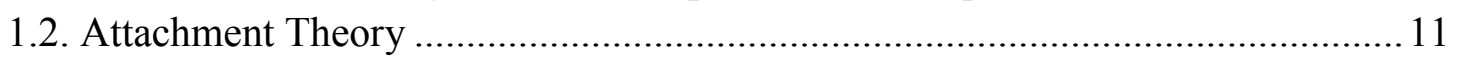

1.2.1. The attachment behavioural system ................................................ 11

1.2.2. Attachment throughout life ............................................................. 12

1.2.3. Systematic differences in attachment-related behaviour ..................... 13

1.2.4. Attachment working models ........................................................ 14

1.2.5. Attachment working models as emotion regulation strategies ............ 15

1.2.5.1. Strategies of secure working models ....................................... 16

1.2.5.2. Strategies of anxious-ambivalent working models .................. 16

1.2.5.3. Strategies of avoidant working models .................................. 17

1.3.Emotion Regulation and Empathic Concern...................................................... 18

1.3.1. The expected prosocial outcome of attachment security .................... 18

1.3.2. Empathic concern and personal distress ............................................ 18

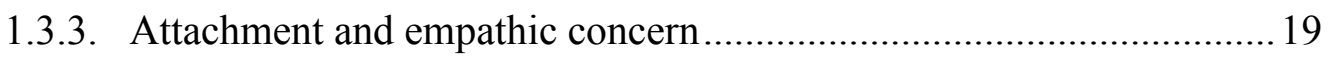

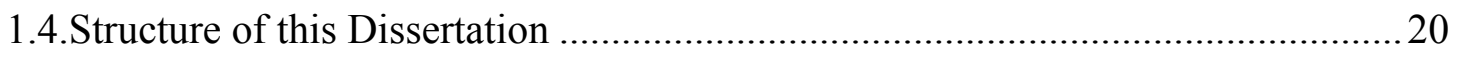

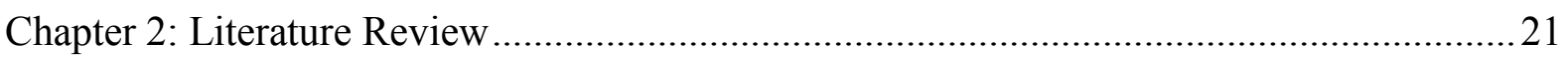

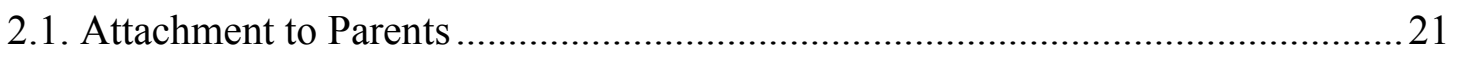

2.1.1. Differentiating between mother and father attachment ........................2 21

2.1.2. Limitations of previous research.................................................... 23

2.2. Moving Beyond Parent Attachment................................................................. 24

2.2.1. Attachment to friends.......................................................................... 24

2.2.2. Attachment to grandparents ............................................................. 25

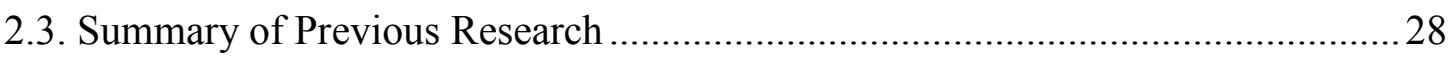

2.4. Aims and Hypotheses of the Current Study ......................................................29

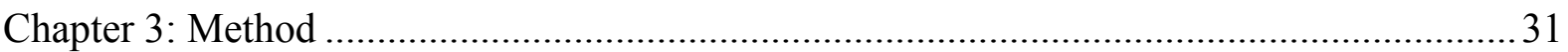

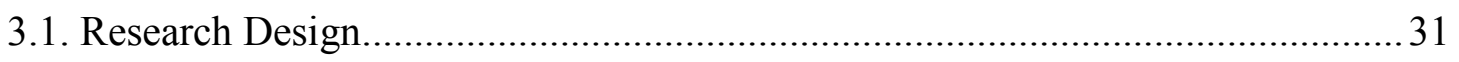

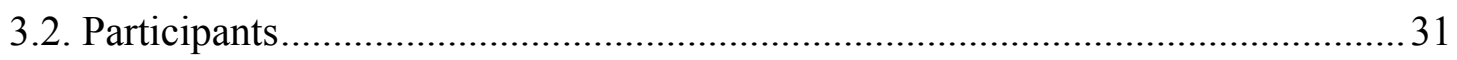




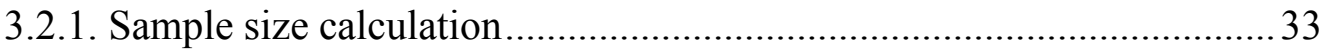

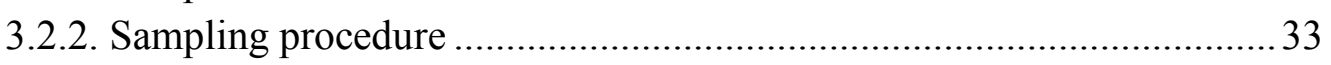

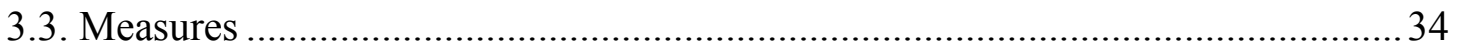

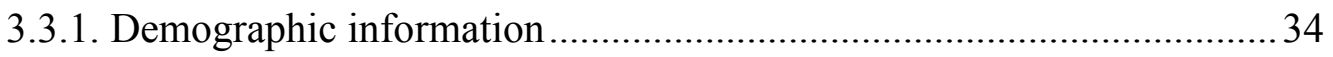

3.3.2. Mother, father, friend and closest grandparent attachment................... 34

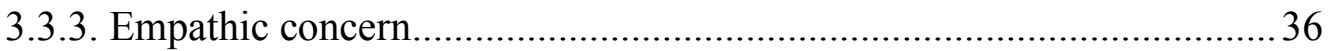

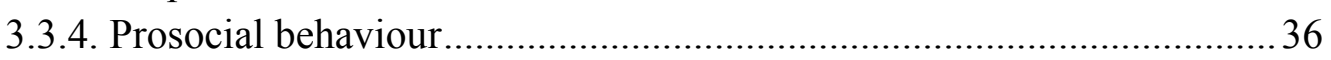

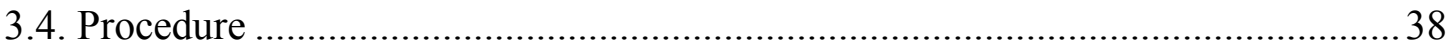

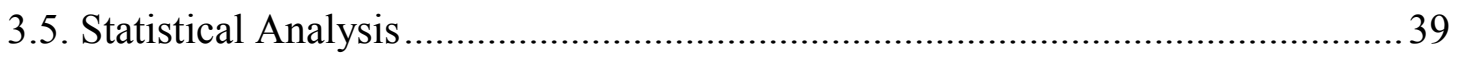

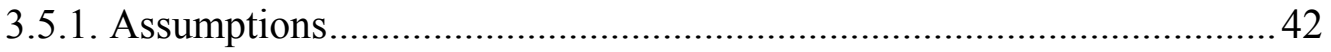

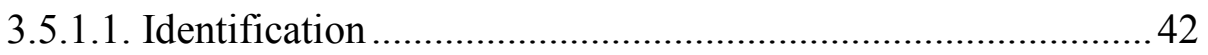

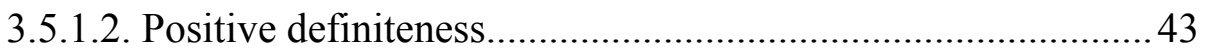

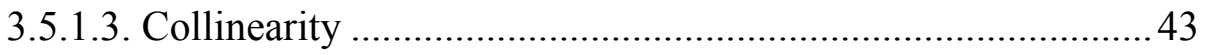

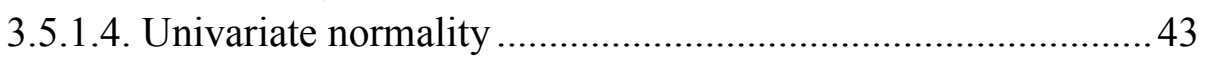

3.5.1.5. Multivariate normality .................................................... 46

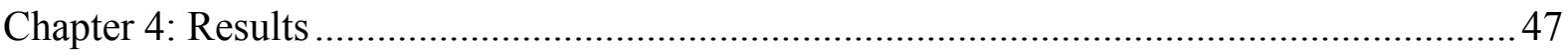

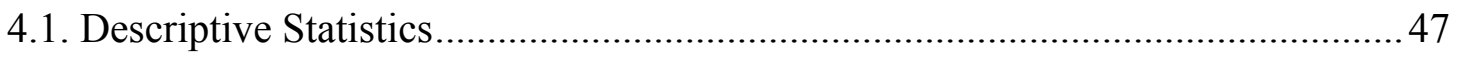

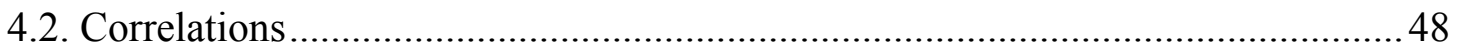

4.3. Structural Equation Model Predicting Self-Reported Prosocial Behaviour ......... 48

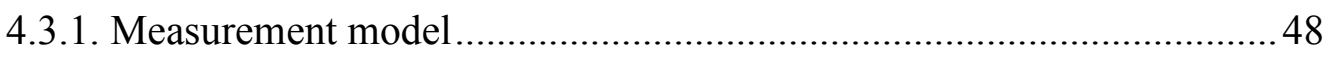

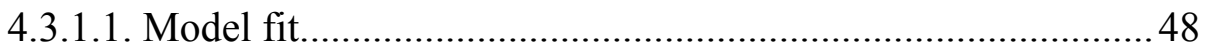

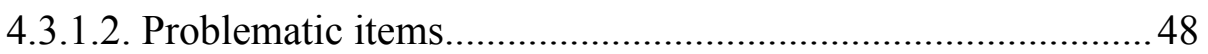

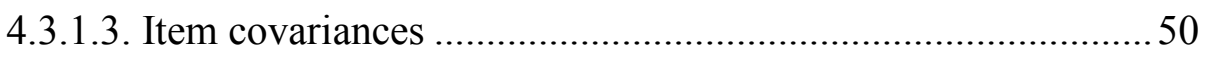

4.3.1.4. Modified model fit ................................................................ 50

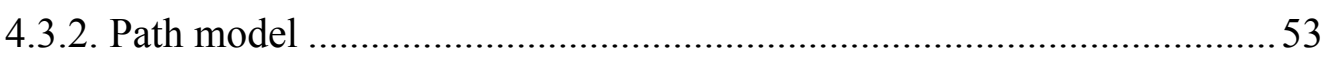

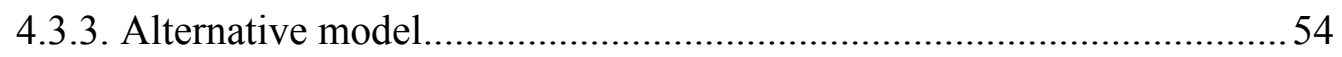

4.4. Structural Equation Model Predicting Teacher-Reported Prosocial Behaviour ... 54

4.4.1. Measurement model ......................................................................... 54

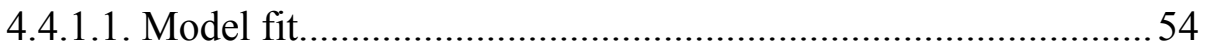

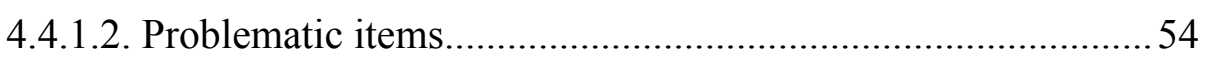

4.4.1.3. Item covariances ................................................................... 54

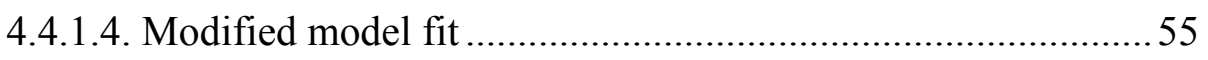

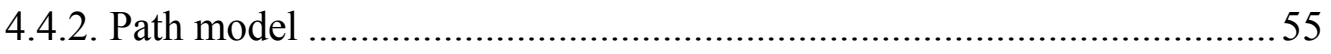

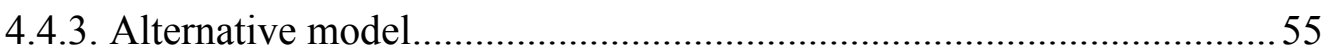

4.5. Testing the Model on Secure vs. Ambivalent and Secure vs. Avoidant

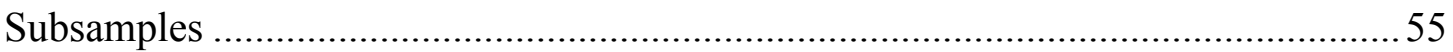

4.5.1. Model predicting self-reported prosocial behaviour..............................57

4.5.2. Model predicting teacher-reported prosocial behaviour ....................... 57

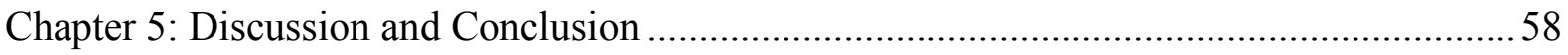

5.1. Predicting Self-Reported Prosocial Behaviour ...................................................... 58

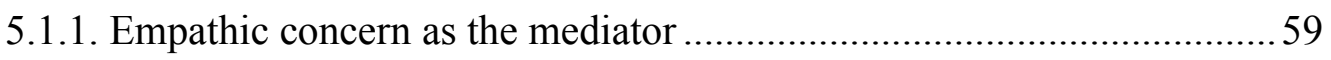

5.1.2. The influence of friend attachment ......................................................59 
5.1.3. Findings regarding mother and father attachment ............................6 60

5.1.4. Findings regarding closest grandparent attachment...............................62 62

5.2. Predicting Teacher-Reported Prosocial Behaviour............................................62

5.2.1. Differences between the teacher-report and self-report models ...........6 62

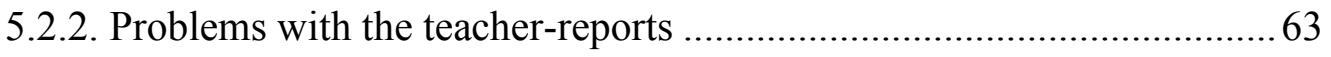

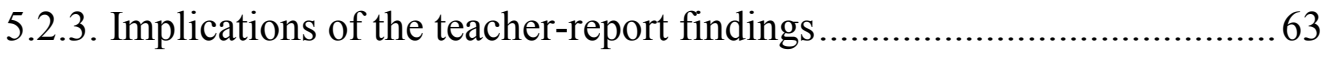

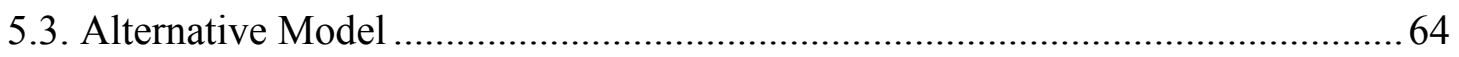

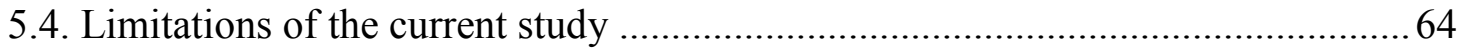

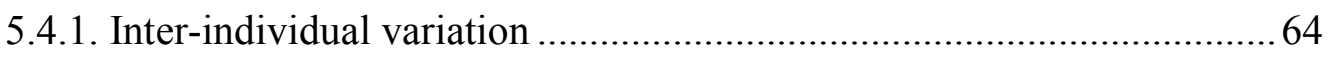

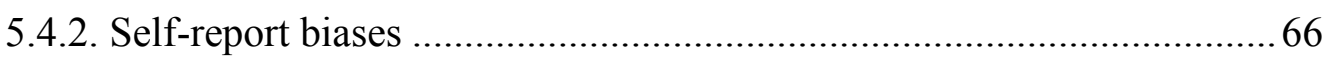

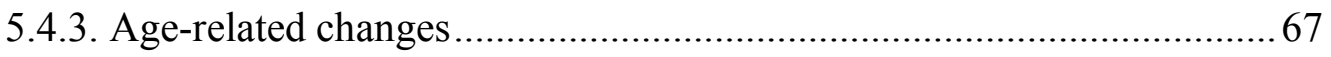

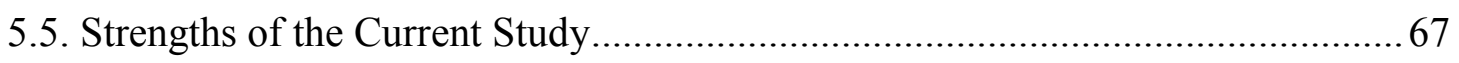

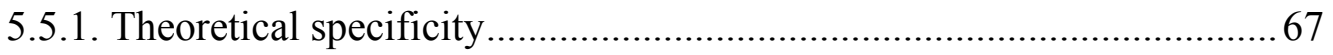

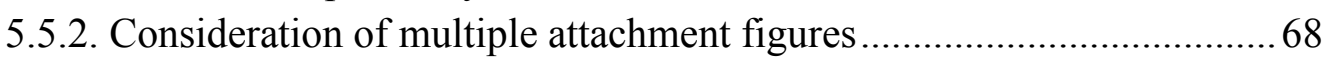

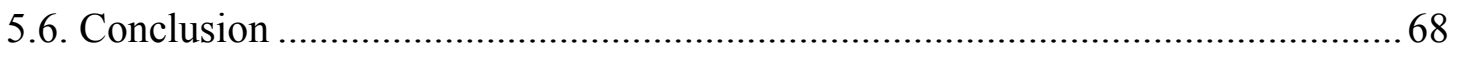

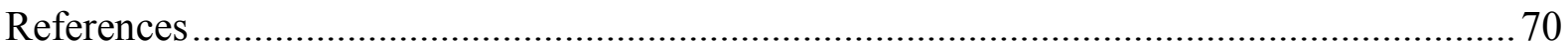

Appendix A: My Family, Friends and I Questionnaire ................................................ 88

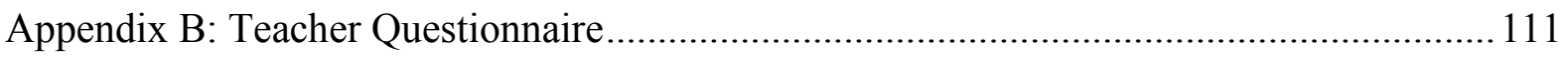

Appendix C: Permission from the Western Cape Education Department to Conduct the Study

Appendix D: Permission from the University of Cape Town Research Ethics Committee of

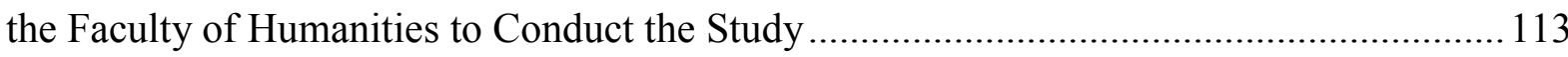

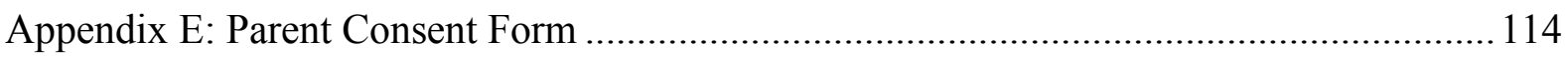

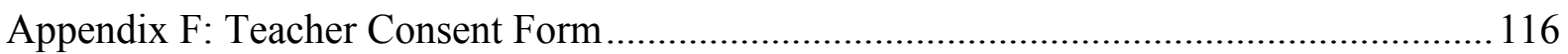

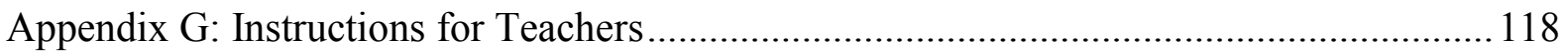




\section{LIST OF TABLES}

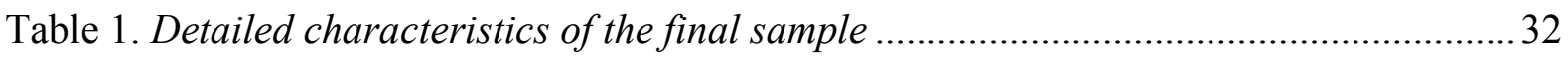

Table 2. Subscale rating combinations associated with each attachment style ...................... 36

Table 3. Mean bootstrapped skewness and kurtosis scores for study variables..................... 45

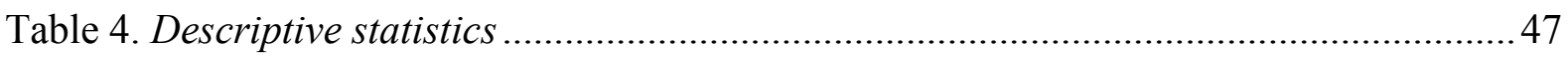

Table 5. Zero-order correlations between study variables ................................................... 49

Table 6. Standardized item-factor loadings for the measurement model used to predict self-

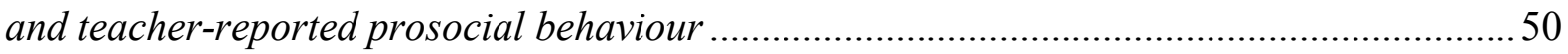




\section{LIST OF FIGURES}

Figure 1. Hypothesized theoretical model tested with Structural Equation Modelling 41

Figure 2. Histograms displaying the distributions of scores for each variable included in the analyses.

Figure 3. Results of the Structural Equation Models predicting self- and teacher-reported prosocial behaviour. 


\section{CHAPTER ONE: INTRODUCTION}

Adolescence is a time of rapid physical, mental and social change, and is often accompanied by an increase in risks to mental health and problem behaviours (Sigelman \& Rider, 2011). Consequently, research among adolescents has tended to focus on investigating the precedents and consequences of adverse social behaviours (Padilla-Walker, 2014). However, positive mental development is not only predicated on the absence of negative behaviours, but the presence of positive social attributes (Petersen, 2010). Just as the developments occurring during adolescence may be a risk for problem behaviours, they also facilitate and often result in an increase in prosocial behaviour (Eisenberg \& Spinrad, 2014). Although prosocial behaviour is a complex and multidimensional concept, it is broadly defined as voluntary actions performed for the benefit of others (Padilla-Walker \& Carlo, 2014), and has been linked with various positive outcomes. Consequently, researchers are increasingly acknowledging the need to address our limited understanding of prosocial development (Carlo, Crockett, Randall, \& Roesch, 2007).

Parents have long been recognized as important agents influencing the development of prosocial behaviour in their children (Hastings, Utendale, \& Sullivan, 2007). Grusec and Davidov (2010) argue that different parenting behaviours influence children in domainspecific ways, and the attachment dimension of parent-child relationships (Bowlby, 1969) provides a helpful framework for understanding at least one major way in which parents influence the prosocial development of their children. Despite this, however, attachment theory has been largely neglected by research seeking to understand prosocial behavioural development (Eisenberg, Fabes, \& Spinrad, 2006), and the research in this area is therefore limited. Furthermore, very few studies seek to understand the way in which the attachment quality of other, non-parental relationships influence prosocial outcomes (Thompson, 2006), despite the fact that adolescence marks a period in which attachment behaviours become more likely to be directed towards a variety of relationships (Markiewicz, Lawford, Doyle, \& Haggart, 2006). The current study seeks to further the theoretical understanding of how the quality of multiple differentiated attachment relationships influences prosocial outcomes in adolescents.

\subsection{Prosocial Behaviour}

1.1.1. The importance of prosocial development. Prosocial behaviour is understood by researchers, in its broadest sense, as "voluntary behaviour intended to benefit another" (Eisenberg \& Spinrad, 2014, p. 17). Whilst the research into the development of prosocial 
tendencies in young children is quite voluminous, research among adolescents is relatively under-developed (Padilla-Walker \& Carlo, 2014). This is due in part to the myopic focus of research on the development of negative behaviours during adolescence (Crick, 1996). However, positive youth development involves competence, confidence, connection, character, and most relevantly here, caring (Eisenberg et al., 2006), and the absence of negative traits does not necessarily entail the presence of positive traits (Carlo, Mestre, McGinley, \& Samper, 2014). In addition, this failure to consider adolescent prosocial development is strange given that adolescence presents a pertinent life stage during which the development of prosocial behaviour becomes especially important. Changes in adolescent brain development and cognition facilitate the use of more abstract and multidimensional approaches to human interaction (Steinberg, 2005) and greater emotional regulation capabilities (Eisenberg et al., 2006), as well as greater social mobility, all of which may enhance the likelihood that adolescents engage in prosocial behaviours toward others. Research suggests that more prosocial adolescents are likely to develop various other positive personal and social characteristics, and therefore understanding what differentiates those adolescents who are more prosocial than others is both theoretically meaningful and practically useful. Prosocial behaviour has been shown to positively predict, longitudinally, adolescents' acceptance in peer groups (Caprara, Barbaranelli, Pastorelli, Bandura, \& Zimbardo, 2000; Crick, 1996; Padilla-Walker, Carlo, \& Nielson, 2015; Zimmer-Gembeck, Geiger, \& Crick, 2005) and academic performance (Caprara et al., 2000), and is negatively associated with deviant peer affiliation (Carlo et al., 2014), delinquency, risky sexual behaviour, and drug use (Ludwig \& Pittman, 1999).

1.1.2. The multi-dimensionality of prosocial behaviour. A growing criticism of research into the precedents and consequences of prosocial behaviour is the tendency to define it as a global, unidimensional construct (Carlo, Knight, McGinley, Zamboanga, \& Jarvis, 2010). Padilla-walker and Carlo (2014) argue that this is inconsistent with the research evidence, and hinders progress toward a rich and nuanced understanding of prosocial development and the ability to create well-informed policies and interventions. Not all prosocial behaviours are equal, as they can be differentiated along several lines, such as whether they were spontaneous or compliant, public or private, and costly or not costly (Eisenberg \& Spinrad, 2014). Carlo and Randall (2002) have led the way in the attempt to develop a nuanced approach to measuring prosocial behaviour. Their Prosocial Tendencies Measure identifies six types of prosocial behaviour. These include (a) Altruism, which is behaviour intended solely for the benefit of another and often incurs a cost to the enactor; (b) 
Compliant prosocial behaviour, which is prosocial behaviour performed in response to a request or demand; (c) Emotional prosocial behaviour, which is behaviour intended to help another in an emotionally evocative situation; (d) Public prosocial behaviour, which is behaviour performed in front of an audience; (e) Anonymous prosocial behaviour, which is prosocial behaviour directed towards a recipient who does not know the identity of the enactor (e.g. an online donation); and (f) Dire prosocial behaviour, which is an extension of Emotional prosocial behaviour, but is performed in crisis or emergency situations. These prosocial behaviours are distinguishable among early adolescents (Carlo et al., 2010), and tend to have different precedents. For example, Emotional and Dire prosocial behaviours are most likely to be elicited by emotional precedents like sympathy (Carlo et al., 2010; Eisenberg \& Spinrad, 2014). There is therefore a need for ongoing research to be clear about the type of prosocial behaviour under investigation.

1.1.3. Socializing influences on prosocial development. In addition, research has not always prioritized theoretical clarity when considering the socialization antecedents of children's prosocial development. Frequently used concepts like parental "involvement" may contribute to highlighting the importance of the parenting role in the prosocial development of children, but they are theoretically vague. Grusec and Davidov (2010) conceptualize the parenting role as occurring within five domains, namely Control, Group Participation, Reciprocity, Guided Learning, and Protection. The protection domain, according to the authors, encapsulates the attachment concept of parent-child relationships (Bowlby, 1969), and is a useful domain for considering the development of prosocial behaviour, particularly those prosocial behaviours involving responding to others in distress. Nevertheless, attachment theory has been largely neglected by research into the development of prosocial behaviour. For example, a lengthy review of prosocial development by Eisenberg et al. (2006) considers multiple parenting antecedents of children's prosocial development, but none of these are attachment.

\subsection{Attachment Theory}

1.2.1. The attachment behavioural system. Bowlby (1969) used insights from ethology to understand the intense emotional bond that infants develop towards their caregivers (primarily mothers). According to his attachment theory, there exists within all humans an organized, innate behavioural system known as the attachment behavioural system. According to Mikulincer and Shaver (2003), any behavioural system can be understood according to six components: (a) a biological function which increases survival; 
(b) contextual triggers which activate the system; (c) a repertoire of behaviours that are utilized to obtain the goal of the system; (d) the particular goal pursued by these behaviours, the acquisition of which will deactivate the behavioural system; (e) the cognitive activities involved in the pursuit of the system's goals; and (f) the system's activating or deactivating links with other behavioural systems. As for the attachment system, its biological function is the protection of an individual from harm. Naturally then, its activating cues involve real, imagined or anticipated sources of threat. In such contexts, overt displays of distress are generated, such as crying, calling, or clinging, in order to obtain proximity to wiser and stronger caregivers. These wiser and stronger caregivers are generally identified by the fact that they provide some sort of physical and emotional care, appear consistently and continuously in the child's life, and have some sort of emotional investment in the child (Howes, 1999). The ultimate goal of these attachment behaviours is a return to a sense of security and safety, in which case the attachment system becomes deactivated, or at least attenuates (Bretherton, 1985). This is a significant achievement because, owing to the intensive nature of attachment system activation, it tends to have inhibitory links with other behavioural systems (e.g. caregiving, sexual, exploratory). Thus its attenuation allows the individual to attend to the demands of other systems. Overseeing this process are the cognitive operations which monitor the environment and the degree of success achieved by one's attempts to obtain proximity to caregivers and regain a sense of security.

1.2.2. Attachment throughout life. Attachment theory originally began with a focus on very young children and their mothers, but Bowlby (1969) always recognized that the attachment system is in life-long operation. Although adolescence seems to be marked by active attempts to avoid any sign of dependence on one's parents or other caregivers, most adolescents continue to direct attachment behaviours toward their parents and maintain emotionally close relationships with them (Allen \& Land, 1999). Furthermore, attachment is a well-researched topic among adults (Weiss, 1982) and has been especially useful in helping researchers understand certain romantic relationship processes (e.g. Kunce \& Shaver, 1994). However, attachment research among teenagers is lacking, despite the fact that the physical and social changes occurring during adolescence make it an interesting period in which to study attachment (Dykas \& Cassidy, 2011). Infants and young children, who have yet to develop the capacity for sophisticated abstract thinking, are relatively dependent on the real physical proximity of the attachment figure to regain a sense of security. Adolescents and adults, on the other hand, have the cognitive ability to derive a sense of attachment security from their own internalized experiences with various caregivers (Allen \& Land, 1999). Thus, 
although the physical and cognitive changes that come with age alter the manifestation and intensity of attachment system behaviour, the attachment system remains an important aspect of an individual's constitution.

1.2.3. Systematic differences in attachment-related behaviour. The problem which faces the goal of the attachment system is that there are two individuals involved, namely the individual who seeks protection and the caregiver who is expected to give it. In order for the attachment system's goal to be successful, caregivers to whom proximity is sought must be appropriately responsive (Mikulincer \& Shaver, 2003). If they are not, what becomes of the attachment system's organization and strategies? Ainsworth, Blehar, Waters, and Wall (1978), using a procedure known as the Strange Situation, were the first to show that the strategies of the attachment system become differentiated in systematic ways between individuals, depending on the care received from attachment figures.

The Strange Situation attempts to activate the attachment system of infants by placing them in an unfamiliar room and separating them from their mothers. After an initial session of free play, mothers are instructed to leave the room, while the child remains with an unfamiliar research associate. Mothers then return a few minutes later to reinstate contact with the child. By observing the infants' behaviour before, during, and after separation from the mother, Ainsworth et al. (1978) observed three primary attachment patterns, or styles. Most of the infants explored the room comfortably when their mothers were present, experienced attachment system activation and showed visible distress when their mothers left the room, and responded well to the mother's return, seeking proximity to her and quickly calming down (Ainsworth, 1982). These infants were regarded as Secure. Ainsworth et al. (1978) and decades of ensuing research have found that Secure infants tend to experience prompt responsiveness to their attachment cues and a warm, sensitive caregiving style (De Wolff \& van Ijzendoorn, 1997). Other infants appeared chronically anxious even before the mother left the room, and became extremely distressed by their mothers' departure. When their mothers returned, they showed a confusing combination of seeking proximity and angrily resisting their mothers' interactions (Ainsworth, 1982). As such, Ainsworth et al. (1978) named these infants Anxious-Ambivalent. Research suggests that these infants tend to experience care that is insensitive to their needs or unpredictable (Ainsworth, 1982). A third group of infants evidenced very little interest in their mothers, and were hardly distressed during the separation. Upon their mothers' return these infants showed little interest in reuniting or interacting with their mothers (Ainsworth, 1982). This group was named Avoidant. These infants' mothers tend to be averse to physical contact and are either wholly 
unresponsive to their attachment signals or punish them with anger and threats (Main \& Weston, 1982). Later a fourth attachment style was identified, which was named Disorganized-Disoriented (Sigelman \& Rider, 2011) and identified infants who displayed confusing and inconsistent approach and avoidance behaviours towards their parents in the Strange Situation. Bartholomew and Horowitz (1991) also devised a four-category attachment classification among adults which is parallel to Ainsworth et al.'s (1978) categories. However, the Disorganized-Disoriented category is generally only found in the most extreme cases and is seldom necessary in attachment research with normal populations (Mikulincer \& Shaver, 2003).

Thus, Ainsworth et al. (1978) were the first to demonstrate the systematic ways in which the attachment-related behaviour of infants varies according to the caregiving responses they have received. However, this interpretation of their findings has been challenged with an alternative hypothesis. According to the temperament hypothesis, the attachment styles observed are not the effects of the child's experiences with caregivers, but rather reflect differences in the child's temperament which subsequently influences the manner in which caregivers respond (Sroufe, 1985). Whilst there certainly is a bidirectional influence between parenting and child characteristics (Newton, Laible, Carlo, Steele, \& McGinley, 2014; Sameroff \& Chandler, 1975), there is also considerable evidence against the temperament hypothesis: (a) the consistency of attachment styles between different attachment figures (e.g. mother and father) is generally quite modest, which is not readily explainable if attachment styles are the result of stable infant characteristics; (b) variables that are related to parenting but have no relation to temperament have been shown to result in changes in attachment styles; and (c) prospective studies have controlled for temperament and found significant relations between caregiving and attachment styles (Sroufe, 1985). Thus, although it is proper to acknowledge the role of child characteristics on parenting practices, evidence nonetheless suggests that parenting is an important determinant of later attachment style.

1.2.4. Attachment working models. The finding that infants in the Strange Situation behave in differentiated ways based on their experiences with caregivers is consistent with Bowlby's (1969) contention that attachment strategies are adaptable to the caregiving context. Bowlby (1969) proposed that individuals form internal working models of their attachment experiences. These are generalized mental scripts formed on the basis of attachment-related memories that operate largely outside of conscious awareness (Cassidy, Kirsh, Scolton, \& Parke, 1996) and serve as the templates from which the individual 
interprets and approaches future attachment-related challenges (Kunce \& Shaver, 1994). They are therefore the links which facilitate the journey of attachment strategies employed on a case-by-case basis into enduring characteristics of the person (Mikulincer \& Shaver, 2003). Although these internal working models are quite resistant to change (Waters, Merrick, Treboux, Crowell, \& Albersheim, 2000), they can be revised in the face of compelling evidence or circumstances (Bretherton, 1985). Thus, although the construction of working models begins and, indeed, may be somewhat solidified in early life, these models are actively engaging with the contemporary landscape of an individual's life and as such have ongoing and contemporaneous effects (Thompson, 1999).

1.2.5. Attachment working models as emotion regulation strategies. The actual nature of the content of internal working models has often been defined inconsistently and vaguely. Most researchers would agree, following Bowlby (1969), that internal working models contain information about the self and others derived from attachment-related experiences. However, such a vague conceptualization breeds the tendency to divorce the concept of the working model from Bowlby's understanding of the role of the attachment system, and is often used to explain the influence of parents on virtually all social and personal developmental outcomes, thus making the concept too broad and ultimately vacuous. Undeniably, a secure working model is associated with a vast array of positive outcomes (Thompson, 1999), but simply expanding the working model concept to explain all of these correlates is uninformative. Sroufe, Egeland, Carlson, and Collins (2005) warn against this over-broadening of attachment theory, and encourage the placement of attachment in its proper context, in recognition of the myriad ways in which parents interact with and influence their children. As we have explored earlier, the context in which the attachment system becomes activated is the presence of real or perceived threats to personal wellbeing. Most directly then, the context in which internal working models of attachment are most relevant would be the same. This is already clearly implied by the fact that, via the Strange Situation, attachment styles are investigated through the creation of an environment that is distressing for the infants. Furthermore, since the goal of the attachment system is the transition from a negative emotional state to a positive sense of security, it is most relevant to regard the contents of internal working models as finding their meaning in this same pursuit. Consequently, many researchers have framed the attachment working model as, most fundamentally, a collection of strategies for the regulation of negative affect derived from repeated attachment-related experiences (Allen \& Miga, 2010; Mikulincer \& Shaver, 2009; Mikulincer, Shaver, \& Pereg, 2003; Thompson, 1999; Zimmermann, 1999). These 
encompass all of the components of emotion regulation highlighted by Gross (2008), including the selection, modification, and appraisal of threatening situations, methods of attentional deployment utilized in such situations, and the intensity and valence of the emotional reaction to the situation (Thompson, 1994). Thus by conceptualizing attachment working models in this way, progress is made towards better understanding at least one major way in which individuals develop their ability (or lack of ability) to regulate their emotions and behaviours in threatening contexts, an ability argued by Eisenberg, Champion, and Ma (2004) to be one of the most important in human development.

1.2.5.1. Strategies of secure working models. Kobak, Cole, Ferenz-Gillies, Fleming, and Gamble (1993) first outlined how the attachment-related experiences of individuals would lead to the emotional regulation strategies employed by those with different attachment styles. To begin with, an actual or perceived threat causes activation of the attachment system and ensuing feelings of distress. If there is a discrepancy between the attachment system's demand for attachment figure availability and the attachment figure's actual availability, proximity-maintaining attachment behaviours are employed to reduce this discrepancy. The question then regards whether or not the attachment figure is responsive to these proximity maintenance cues. Through repeated experiences like this in which the attachment figure is responsive to the individual's proximity maintenance attempts, a secure working model of attachment is likely to be developed. By incorporating the caregiver's strengths into one's own self-conceptualization, and internalizing the emotion regulation strategies initially performed by the caregiver (Mikulincer \& Shaver, 2003), the secure person is expected to have a high tolerance for confronting distressing information (Van Emmichoven, Van Ijzendoorn, De Ruiter, \& Brosschot, 2003), develop a sense of selfefficacy with regards to handling negative emotions, and to come to view distressing situations as less threatening and more manageable (Cassidy, 1994; Mikulincer et al., 2003).

1.2.5.2. Strategies of anxious-ambivalent working models. On the other hand, if the individual's proximity maintenance attempts are initially unsuccessful in eliciting caregiver responsiveness, the individual must decide whether seeking proximity to the caregiver is a viable option or not. If the caregiver has evidenced a history of inconsistent availability (Cassidy, 1994) and the individual becomes fixated on the danger and vulnerability that might accompany their facing the distressing situation alone (Mikulincer \& Shaver, 2003), the attachment system is hyper-activated and bids for proximity are intensified. This hyperactivation of the attachment system is thought to characterize the Anxious-Ambivalent attachment style, and is expected to be accompanied by various strategies of emotional under- 
regulation (Cole, Michel \& Teti, 1994). These include a hypervigilance to signs of distress even in relatively benign contexts, a tendency to ruminate on negative experiences (Mikulincer \& Orbach, 1995), an intensifying of personal distress (Mikulincer et al., 2003), and negative beliefs about one's own ability to handle distressing situations (Mikulincer, Shaver, Cassidy, \& Berant, 2009). Thus, hyperactivating strategies "produce a selfamplifying cycle of distress in which chronic attachment system activation interferes with engagement in nonattachment-related activities" (Mikulincer et al., 2003, p. 85). Research evidence seems to bear out these theoretical expectations. Those with anxious ambivalent attachment styles have less confidence in their abilities to regulate their mood (Creasey, Kershaw, \& Boston, 1999), respond to threatening situations with more distress (Collins, 1996; Westmaas \& Silver, 2001), are more likely to perceive threats in the actions of others (Collins, Ford, Guichard, \& Allard, 2006), and have heightened access to negative memories (Mikulincer \& Orbach, 1995), death-related thoughts (Fraley \& Shaver, 1997), and fears of relational separation (Mikulincer, Dolev, \& Shaver, 2004). These expectations are also supported at the unconscious level, as those with anxious-ambivalent attachment receive Rorschach scores associated with heightened distress and emotion regulation difficulties (Berant, Mikulincer, Shaver, \& Segal, 2005), and exhibit a brain activation profile reflective of these difficulties (Gillath, Bunge, Shaver, Wendelken, \& Mikulincer, 2005).

1.2.5.3. Strategies of avoidant working models. Alternatively, if seeking caregiver proximity is considered an unviable option due to consistent caregiver rejection and/or punishment for attachment behaviours (Cassidy, 1994), the attachment system is deactivated and bids for proximity cease. This deactivation strategy is thought to characterize individuals with an Avoidant attachment style and, in contrast to the hyper-activating strategy, is accompanied by various strategies of emotional over-regulation (Cole et al., 1994). These include the suppression of any thoughts or emotions that may threaten to elicit attachment system activation, an exaggerated sense of self-reliance (Mikulincer et al., 2009), minimization of the expression of negative emotions such as sadness and distress (Cassidy, 1994), a general denial of attachment needs (Mikulincer et al., 2003) and a refusal to acknowledge or direct attention towards stimuli which may evoke attachment needs (Shaver, Mikulincer, \& Chun, 2008). The available research evidence also confirms these theoretical expectations. Deactivating individuals' Rorschach scores indicate a lack of acknowledgement of their personal needs and a disengagement from the world (Berant et al., 2005). They are prone to inflexible emotion regulation strategies and have limited access to their personal feelings (Zimmermann, 1999). Finally, avoidant individuals suppress negative memories 
(Mikulincer \& Orbach, 1995) and thoughts of loss (Fraley \& Shaver, 1997) or separation (Mikulincer et al., 2004) and evidence low emotional arousal (Fraley \& Shaver, 1997; Mikulincer \& Orbach, 1995). That avoidant individuals actually do repress negative or distressing thoughts and feelings, rather than simply lacking these traits altogether, is supported by the fact that when cognitively taxed these individuals' repressive strategies begin to break down and allow these unwanted thoughts and feelings to exert their influence (Mikulincer et al., 2004).

\subsection{Emotion Regulation and Empathic Concern}

1.3.1. The expected prosocial outcome of attachment security. With attachment styles properly conceptualized it is possible to consider how an individual's attachment outcomes are likely to affect prosocial behaviour. In the interest of clarity, as previously discussed, it is necessary to be specific as to what type of prosocial behaviour individual attachment styles are likely to influence. Given that attachment occurs and has its implications in contexts of emotional distress, it is reasonable to assume that prosocial behaviour in the same context is the likely object of interest here, as indeed is supposed by Grusec and Davidov (2010). It might thus be expected that those with favourable attachment outcomes will display heightened prosocial behaviour in emotional or dire contexts, to use the language of Carlo and Randall (2002).

1.3.2. Empathic concern and personal distress. When confronted with the distress of another, many assume that the tendency to experience empathy is likely to result in prosocial outcomes, with empathy here defined as the experience of an emotion that is the same or very similar to that of another (Eisenberg, 2009). However, Eisenberg (2009) warns that empathy itself is not enough, as it must first translate into sympathy, which is a feeling of otheroriented concern. From here on the term "empathic concern" will be used as a substitute for sympathy, to properly distinguish it from other processes, such as perspective taking, which in itself is considered to be only a component of empathy and empathic concern, but not sufficient to translate empathy into actual prosocial behaviour (Eisenberg et al., 2006; Eisenberg, Wentzel, \& Harris, 1998). Those experiencing the vicarious induction of emotional arousal via empathy who cannot maintain this arousal within a tolerable range are expected to experience personal distress, rather than empathic concern (Eisenberg et al., 1994). Personal distress is an aversive, self-focused reaction to the distress of another that is primarily concerned with reducing one's own distress and is thus unlikely to lead to prosocial behaviour (Eisenberg, 2009). By contrast, individuals with good emotion regulation 
capabilities are expected to be able to shift attention away from their own feelings of vicariously induced distress and experience other-oriented empathic concern, making them more likely to perform actual other-focused prosocial behaviours (Eisenberg et al., 1997).

Research has borne out the expected link between emotion regulation abilities and the tendency to experience empathic concern for others in distress. Empathic concern and personal distress have unique and different covert physiological markers (Eisenberg et al., 1988). Amongst both children and adults, those with more favourable emotion regulation abilities are more likely to display situational and dispositional empathic concern toward the distress of others, rather than personal distress, both contemporaneously (Eisenberg et al., 1991; Eisenberg et al., 1994; Eisenberg et al.,1996; Eisenberg, Fabes, Murphey, Maszk, Smith, \& Karbon, 1995; Eisenberg, Fabes, Schaller, Carlo, \& Miller, 1991; Fabes, Eisenberg, \& Eisenbud, 1993; Fabes, Eisenberg, Karbon, Troyer, \& Switzer, 1994; Guthrie et al., 1997) and longitudinally (Eisenberg et al., 1997; Eisenberg, Fabes, Shepard, Murphey, Jones, \& Guthrie, 1998). Furthermore, the experience of empathic concern over personal distress does indeed increase the likelihood of engaging in prosocial behaviours toward others (Eisenberg et al., 1989; Eisenberg et al., 1990; Michalik et al., 2007; Miller, Eisenberg, Fabes, \& Shell, 1996).

1.3.3. Attachment and empathic concern. Translating these expectations into attachment terms, it would be expected that those with secure attachment, who are favourably equipped to handle negative emotions, to be prone to experiencing empathic concern, whereas those with anxious-ambivalent attachment styles, who are prone to exaggerated and aversive self-focused reactions to negative emotions, would be more likely to experience personal distress. Given that those who are avoidantly attached are not prone to the same emotional under-regulation evidenced by anxious-ambivalent individuals, one may wonder whether they are immune to the deficits in empathic concern resultant from sub-optimal emotion regulation strategies described thus far. Nevertheless, evidence suggests that avoidant forms of emotional over-regulation are also associated with personal distress in response to the distress of others (Eisenberg et al., 1988), perhaps because these individuals have such a great aversion to the experience of emotional vulnerability, whether it is induced vicariously or internally. Moreover, a tendency to evade empathic concern for others is innate in the avoidant emotion regulation strategy, since entangling themselves with the neediness of others runs counter to their desire for emotional independence (Shaver et al., 2008). "For them, besides being a 'hassle' and a drain to personal resources, a distressed person threatens to become a mirror of the self's own weaknesses and supressed weaknesses and 
vulnerabilities" (Shaver et al., 2008, p. 136). Nevertheless, it may be worthwhile for research to test these theoretical expectations for all three of the attachment styles. Therefore, by applying the considerations thus far, there is reason to hypothesize that attachment security (or lack thereof) is likely to influence one's tendency to experience empathic concern for others, which in turn is likely to influence their tendency to respond with prosocial behaviour to the distress of others.

\subsection{Structure of this Dissertation}

The dissertation is comprised of five chapters. In Chapter 1, the topics under investigation were expounded, as were the expectations borne by this study's theoretical framework. Chapter 2 provides an overview of what prior relevant research has found regarding the relationship between attachment relationships and prosocial behaviour, before describing the aims and hypotheses of the current study. In Chapter 3, the design, research methods, statistical analyses and sample used to test the hypotheses are described. Chapter 4 outlines the findings yielded by the analyses. Finally, Chapter 5 summarizes and critically discusses these findings, drawing implications for future research and proposing real-world applications of the results of this study. 


\section{CHAPTER 2: LITERATURE REVIEW}

Chapter 1 highlighted the theoretical considerations of the current study, and described how attachment theory may provide an important framework by which to understand the development of prosocial behaviour. In this chapter, previous research bearing on the association between attachment relationships and prosocial development among early adolescents is outlined. The importance of considering the simultaneous influence of multiple attachment relationships is highlighted as an issue not adequately clarified by previous research. After considering the findings and limitations of previous research, the aims and hypotheses of the current study are enunciated.

2.1. Attachment to Parents. Empirical research relevant to these theoretical expectations has generally found that very young children with warm, responsive parents and secure attachments evidence more empathic responding and prosocial behaviour (Eisenberg et al., 2006). However research with older children and adolescents is far more limited. Among early adolescents, a warm parent-child relationship and secure attachment predicted global measures of prosocial behaviour (Keskin \& Çam, 2010; Thompson \& Gullone, 2008), as well as humane treatment towards animals (Thompson \& Gullone, 2008), emotional intelligence (the accurate perception of and response to the emotions of others) (Delhaye, Kempenaers, Stroobants, Goossens, \& Linkowski, 2013), self-reported parent-directed prosocial behaviour (Eberly \& Montemayor, 1999), and prosocial problem-solving strategies with close friends (Shomaker \& Furman, 2009). Thompson and Gullone (2008) also tested a mediation model and found that empathy mediated the relation between parent attachment and adolescents' prosocial behaviour and humane treatment of animals. Research with older $11^{\text {th }}$ grade adolescents also found parent attachment to be positively associated with peer-nominated prosocial behaviour (Dykas, Ziv, \& Cassidy, 2008). Among a sample of late adolescents, parent attachment was positively associated with prosocial behaviour via the mediation of emotional competence, and negatively associated with aggression via the mediation of sympathy (Laible, 2007). Experimental research has even confirmed a link between attachment security and prosocial behaviour among college undergraduates: anxiously attached individuals were more hesitant and cooperated less with others, but an experimental secure attachment prime increased cooperative behaviour among these participants (McClure, Bartz, \& Lydon, 2013).

2.1.1. Differentiating between mother and father attachment. One concern with the above research is that the object of participants' secure attachment was vague or referred to 
both mothers and fathers, rather than differentiating between mothers and fathers. Some studies explore the relation between attachment to a single, undefined "closest parent" and prosocial behaviour. For example, a study among high school students found a relation between closest parent attachment and sympathy (Laible, Carlo, \& Raffaelli, 2000). Research has also found a positive relation between closest parent attachment and all six of Carlo and Randall's (2002) prosocial behaviours via the mediation of sympathy (Carlo, McGinley, Hayes, \& Martinez, 2011) among college students. The problem with such research is that it does not aid in differentiating the influence of mother and father attachment on adolescent prosocial behaviour. Fathers and mothers tend to engage in different contexts and activities with their adolescent children (Newland et al., 2013). However, few studies have differentiated between mother and father attachment in the existing literature. Studies using indices of parent-child relationship quality related to attachment have generally tended to find that mothering is more strongly related to adolescent prosocial development, whereas fathering tends to be associated with adolescent problem behaviours (Profe \& Wild, 2015). For example, a warm mother-child relationship, but not a warm father-adolescent relationship, has been linked to increased prosocial behaviour among pre- and young adolescents via the mediation of sympathy both concurrently and longitudinally (Carlo, Mestre, Samper, Tur, \& Armenta, 2010). Another study differentiated between targets of prosocial behaviour and found a positive mother- and father-adolescent relationship to be related to increased prosocial behaviour towards strangers and friends via the mediation of empathic concern (for mothers only) and emotion regulation (for mothers and fathers), although a positive mother-adolescent relationship was a stronger predictor of prosocial behaviour (Padilla-Walker \& Christensen, 2010).

Other studies using specific measures of attachment security have found a positive relationship between mother attachment and global measures of prosocial behaviour (Markiewicz, Doyle, \& Brendgen, 2001), although Padilla-Walker and Nelson (2010) found this relationship only for boys who were low in dispositional fearfulness. Mother attachment has also been found to predict teacher-reported positive social behaviour specifically towards peers via the mediation of emotional regulation (Contreras, Kerns, Weimer, Gentzler, \& Tomich, 2000), and roles as defenders for bullied peers (Nickerson, Mele, \& Princiotta, 2008). On the contrary, Simons, Paternite, and Shore (2001) found no relation between mother attachment and young adolescent prosocial behaviour, although evidence of the psychometric integrity of their prosocial measure is lacking, and it appears to have included various items regarding general sociability rather than prosocial behaviour. The few studies 
that have assessed father attachment among adolescents have failed to find a relation with prosocial outcomes (Davidov \& Grusec, 2006; Markiewicz et al., 2001; Nickerson et al., 2008). Thus, current evidence suggests that mother and father attachment quality are not equally influential on adolescent prosocial outcomes, although the current dearth of research indicates the need for more studies to confirm or disconfirm these findings.

2.1.2. Limitations of previous research. Apart from the general lack of research investigating links between parent attachment and adolescent prosocial behaviour, the existing research is subject to various limitations. The majority of research relies on adolescent self-reports of prosocial behaviour (Padilla-Walker \& Carlo, 2014). Evidence suggests relatively poor and insignificant concurrence between self-reports of prosocial behaviour and teacher- or parent-reports (Goodman, Meltzer \& Bailey, 1998), raising the issue of the vulnerability of self-reports to social desirability biases. It is therefore prudent to seek to confirm findings based on adolescent self-report with reports from less subjective informants. Some have used parent-reports of child prosocial behaviour, but unfortunately these measures have been found to be significantly biased when compared to teacher reports (Scourfield, John, Martin, \& McGuffin, 2004). Teachers may thus be a useful source of information regarding the prosocial behaviour of children, particularly towards their peers at school. Some studies have in fact used school peers as informants, but these studies usually ask children to simply nominate peers who are generally prosocial. Such nominations may lack the depth of dedicated prosocial behaviour reports, which teachers could provide. In addition, teacher-reports and peer-reports of prosocial behaviour have been shown to be highly convergent (Greener, 2000).

Moreover, the majority of research has been conducted among predominantly white adolescents from America and Europe, thus limiting the generalizability of current findings. In a multicultural and multiracial society such as South Africa, inequalities in the access to resources resultant from past apartheid policies and cultural differences influence the role of parents and family structures (Amoateng \& Richter, 2007). For example, research suggests that black and coloured youth in Cape Town experience less communication with their parents than their white peers (Harper \& Seekings, 2010). Data suggests that family disruption in South Africa as a whole is common, with only $34 \%$ of young children living with both parents (Statistics South Africa, 2013a). Among black African children this proportion is even lower, at slightly more than $20 \%$ (Amoateng \& Heaton, 2015). Therefore, research in South Africa may provide an important test of the generalizability of current evidence regarding parent attachment and adolescent prosocial behaviour. 
2.2. Moving Beyond Parent Attachment. The current paper has so far emphasised the role of parental attachment as an influence on child prosocial behaviour, because parents have been the most frequent objects of theoretical and empirical study in the attachment literature. However, although parents are usually the first attachment figures in a child's life they are not necessarily the only attachment figures (Thompson, 2006). Especially as adolescents begin to gain greater autonomy and expand their social networks, it is likely that multiple relationships serve attachment needs and inform internal working models. Thus, Thompson (2006) notes that studies considering multiple attachment relationships are likely to provide a clearer picture of socialization influences and have greater predictive power. Despite this, attachment research has produced relatively little information on the influence of nonparental attachment figures.

According to Van Ijzendoorn et al. (1992, as cited in Sagi-Schwartz \& Aviezer, 2005), there are four possible ways to understand the way in which attachments to multiple figures influence any particular child outcome: (a) The monotropy model proposes that only one most salient attachment figure would be influential in any given outcome domain; (b) The hierarchy model allows that multiple figures may influence outcomes in any particular domain, albeit in a hierarchical fashion, such that one figure would be most influential, followed by other less influential figures; (c) The independence model emphasises that attachment to any given figure occurs in a particular context, which is likely to determine the scope of their influence; finally, (d) the integration model assumes that all attachment figures would be influential in an equal and cumulative sense.

2.2.1. Attachment to friends. In a cohort study spanning children between grades 1 and 9, Levitt, Guacci-Franco, and Levitt (1993) found that the social networks of children expanded from early childhood to early adolescence and that early adolescents were increasingly likely to include same-age friends in their network of closest relationships (see also Nickerson \& Nagle, 2005). In fact, Markiewicz et al. (2006), in a cohort study spanning from early adolescence to young adulthood, found that young adolescents were the most likely age group to turn to same-age friends for attachment needs. Whereas parents are invested in their child's future and are thus more likely to assume a disciplinary approach and focus on children's negative behaviours, friends may be perceived as more accepting and focused on what is important to the child's present (Giordano, 2003). Given the increasing self-identification of adolescents, this opportunity for acceptance and self-disclosure may facilitate strong emotional bonds among friends. Although romantic relationships are often viewed as the apex of friendship relationships in adolescence and a source of attachment, 
these are relatively rare and of short duration in early adolescence (Doyle, Lawford, \& Markiewicz, 2009).

Laible (2007) found that both parent and friend attachment had indirect associations of equal strength with adolescent prosocial behaviour, but, in line with Laible et al.'s (2000) findings, friend attachment was more strongly related with sympathy. In contrast, Carlo et al. (2011) found that both closest parent and friend attachment influenced prosocial behaviour via the mediation of sympathy among young adult college students, but the relationship was generally stronger for the closest parent. Other studies, however, provide strong indications of the importance of friend attachment. Rubin et al. (2004) found that when friendship quality was at least moderate, mother attachment did not influence the social competence of preadolescents. Similarly, Laible, Carlo and Roesch (2004) found that whereas friend attachment influenced late adolescent prosocial behaviour via sympathy, closest parent attachment did not. The limited research considering both parent and peer attachment among adolescents seems to suggest that something like the monotropy or hierarchy models applies in favour of friend attachment. However, findings are mixed and studies which properly differentiate between mothers and fathers, whilst also accounting for friends, is lacking, suggesting the need for more studies taking these various relationships into account.

2.2.2. Attachment to grandparents. Extended family members, particularly grandparents (Levitt, 2005), often increase in importance beginning in middle childhood (Levitt et al., 1993). Relatively recent data suggests that grandparents may make a significant contribution to the prosocial development of children, although the means by which this occurs are poorly understood. Yorgason and Gustafson (2014) tested the relation between multiple aspects of grandparent-adolescent relationships (including frequency of contact, material assistance, relationship with parents, and emotional closeness) and adolescent prosocial behaviour. Results indicated that among these different relationship factors, emotional closeness to grandparents was an important predictor of concurrent prosocial behaviour towards family, friends and strangers alike. The authors suggested that attachment security may be an important relational variable by which grandparents influence the prosocial behaviour of their grandchildren.

Several lines of available evidence suggest that grandparents may be important, emotionally salient members of children's social networks. To begin with, the reduced fertility and mortality rates existent in modern society have resulted in more children having living grandparents for a significant proportion of their lives (Griggs, Tan, Buchanan, AttarSchwartz, \& Flouri, 2010), through adolescence and even into adulthood. Furthermore, the 
increase in dual-worker households and single-parent households (as a result of migrant labour) often results in grandparents becoming frequent caregivers of their grandchildren (Attar-Schwartz, Tan, \& Buchanan, 2009). In South Africa, around 38\% of children live in multi-generational households, and grandparents are the most popular alternative caregivers for children (Statistics South Africa, 2013b). Research in Cape Town indicates that black and coloured youth report high reliance on and responsibility toward their grandparents (Harper \& Seekings, 2010), further suggesting that grandparents are a prominent feature in South African families. Research in the United States shows that a significant number of young adolescents consider their grandparents as attachment figures (Levitt, 2005).

Some studies have focused on families in which a grandparent has assumed sole legal custody of an adolescent grandchild, and findings suggest that these relationships are characterized by close emotional bonds and deep respect (Dolbin-MacNab \& Keiley, 2006), with grandparents affectionately referred to in parental terms (Sands, Goldberg-Glen, \& Shin, 2009). However, even in nuclear family structures, the grandparent-grandchild relationship may be a significant source of attachment security. Early research found that grandparents were often perceived as providing a secure and loving relationship with significant emotional power (Kornhaber \& Woodward, 1981), able to provide a form of unconditional love and acceptance without the burden of responsibilities existent in parent-child relationships (Barranti, 1985). Although the frequency of contact and importance of the grandparentgrandchild relationship may attenuate somewhat between middle childhood and late adolescence (Creasey \& Kaliher, 1994), adolescents (Attar-Schwartz et al., 2009) and even adults (Poehlmann, 2003) often continue to regard grandparents as important people in their lives. A large, national study in the United Kingdom among adolescents, predominantly from intact families, found that most adolescents regarded their closest grandparents as important and had frequent contact with them. The average score for adolescent-reported grandparentadolescent closeness was 3.28/4 (Attar-Schwartz et al., 2009). A representative subsample of these adolescents described their grandparents as emotional and practical "safety-nets" who were perceived as sensitive and caring listeners in times of need and were able to dedicate their time wholly to their grandchildren (Griggs et al., 2010). Similarly, a large sample of adolescents from the United States indicated high emotional closeness to their closest grandparents (average 8/10), frequent contact, and high likelihood of confiding in their grandparents (Dunifon \& Bajracharya, 2012). In sum, then, available evidence suggests that grandparents are important figures in the lives of many adolescents today, and because of 
their unique roles in families, may offer important sources of attachment security (Barranti, 1985).

However, research examining links between grandparent-grandchild relationships and grandchild outcomes is quite limited. Grandparents have often been conceptualized as resources to mitigate the adverse effects of negative family events or practices, like divorce, rather than as independent contributors to adolescent development (Barnett, Scaramella, Neppl, Ontai, \& Conger, 2010; Botcheva \& Feldman, 2004; Flouri, Buchanan, Tan, Griggs, \& Attar-Schwartz, 2010). This is questionable, since research actually suggests that children from intact families have closer relationships with their grandparents (Lussier, DeaterDeckard, Dunn, \& Davies, 2002). Some studies have researched grandparents in relation to adolescent problem outcomes more generally. Whilst some studies have found that increased grandparent-grandchild closeness was associated with fewer internalizing and externalizing problems (Attar-Schwartz, Tan, Buchanan, Flouri, \& Griggs, 2009; Henderson, Hayslip, Sanders, \& Louden, 2009; Khalid, Ahmed, \& Imdad, 2012; Lussier et al., 2002; Ruiz \& Silverstein, 2007), these often do not control for the parent-child relationship. Two studies conducted in Cape Town, controlling for parent-child relationship and other variables, have found no relation between grandparent involvement and adolescent problem behaviours (Profe \& Wild, 2015; Wild \& Gaibie, 2014).

Research on the relation between the grandparent-grandchild relationship and more positive developmental outcomes, such as prosocial behaviour, has offered a more consistent picture, particularly among adolescents. Despite some conflicting results (Barnett et al., 2010; Khalid et al., 2012), various studies have found a positive relationship between grandparentadolescent closeness and positive social development in adolescents. In a large, nationally representative sample of young adolescents in England and Wales, grandparent-grandchild closeness was associated with a global measure of prosocial behaviour (Attar-Schwartz et al., 2009), although parent-child relationship was not accounted for. However, other research has confirmed this link whilst controlling for parent-child relationship both concurrently (Ellis, Quist, Robinson, \& Peterson, 2010; Profe \& Wild, 2015; Wild \& Gaibie, 2014) and longitudinally (Gustafson, 2013; Yorgason, Padilla-Walker, \& Jackson, 2011). Although various authors have suggested the possibility of attachment being an important dimension of the grandparent-adolescent grandchild relationship (Lussier et al., 2002; Ruiz \& Silverstein, 2007; Yorgason \& Gustafson, 2014), at present few studies have assessed this dynamic directly. The strongest evidence currently comes from Levitt et al. (2002) who, among a middle-childhood sample, found that the presence of a close grandparent attachment figure 
was associated with a significant improvement in adjustment regardless of gender and ethnicity and when considering various other attachment figures. Among an older sample, Henderson et al. (2009) measured the security of attachment to maternal grandmothers among late-adolescents/young adults and found attachment quality positively predicted social competence.

At present, evidence exists for an independent influence of grandparent-grandchild relationship quality on adolescent prosocial outcomes. However, little understanding of this link is at hand. The most significant progress towards this understanding so far has been offered by Gustafson (2013), who found that sympathy and perspective-taking partially mediated the link between grandparent emotional closeness and adolescent prosocial behaviour towards friends, family and strangers alike. Although grandparents may influence the outcomes of their grandchildren in various ways (both direct and indirect), available evidence appears to single out the importance of the direct emotional aspect of grandparentgrandchild relationships as especially important (Ellis et al., 2010; Yorgason \& Gustafson, 2014). Therefore it seems appropriate to move beyond global measures of grandparent involvement to assessments of more specific conceptualizations of this dyadic relationship, such as that provided by attachment theory.

The relative dearth of research in this area also warrants further research to bolster confidence in existing findings. In addition, some methodological shortcomings of the extant literature need to be further addressed. Although the majority of research linking grandparent relationship quality and adolescent prosocial behaviour control for the parent-child relationship, there is often an inconsistency between the measures of the parent-child relationship and the grandparent-child relationship. This throws into question whether the measures are assessing the same variables. The use of a well-established measure of attachment security applied to both parents and grandparents will provide a needed consistency of measurement. There is also a need to include measures of friend attachment, as this has not been controlled for in the grandparent literature. Finally, although two studies have been conducted in South Africa (Profe \& Wild, 2015; Wild \& Gaibie, 2014), the majority of existing research has been conducted in Europe and North America. For the same reasons mentioned for parent-child research, conducting research in South Africa will provide a needed test of the generalizability of existing findings.

2.3. Summary of Previous Research. Although research is limited, there seems to be evidence suggesting the role of attachment security to mother, friends and closest 
grandparents in predicting adolescent prosocial behaviour. A major limitation of current research, however, is a failure to consider these multiple attachment relationships concurrently to better understand their relative contributions. Furthermore, although some work has been done to confirm the theoretical expectation that attachment security leads to better prosocial behaviour via the mediation of empathic concern, few studies have specifically sought to confirm this link or understand the generalizability of this link across insecure attachment styles.

\subsection{Aims and Hypotheses of the Current Study}

The objective of this study was to test a theoretical model whereby mother, father, friend and closest grandparent attachment influences prosocial behaviour via the mediation of empathic concern. The sample comprised learners from Cape Town in grade 7, the final year of primary school education in South Africa. From a methodological point of view, grade 7 learners, as opposed to high school learners, spend more time with a specific teacher, which will increase the robustness of a teacher-report of adolescent prosocial behaviour. Theoretically, this early adolescent stage is marked by rapid change in prefrontal brain development (Levin et al., 1991), allowing for an increase in moral reasoning and empathic response abilities (Carlo et al., 2007). Thus, prosocial behaviour development is an important factor at an age where such behaviours are likely to increase much-desired social acceptability (Wentzel, 2014). A secondary aim of this research was to test whether the proposed model generalizes to both types of insecure attachment. The following hypotheses were formulated:

1) Mother, father, friend and closest grandparent attachment will be positively associated with empathic concern, as well as with teacher-reported and self-reported prosocial behaviour.

2) Empathic concern will completely mediate the relation between attachment to mothers, fathers, grandparents and friends, and prosocial behaviour.

3) Although research is mixed as to the independent contributions of multiple attachment figures when considered simultaneously, previous evidence supports a tentative suggestion that attachment to friends will either: (a) emerge as the sole significant contributor to prosocial outcomes, in line with the monotropy model, or (b) emerge as the strongest significant predictor of prosocial outcomes, followed by a significant contribution of mother attachment, followed possibly by grandparent attachment, in line with the hierarchy model. Furthermore, on the basis of previous research, it was 
hypothesized that, when taking all four of the attachment relationships into account, father attachment would not have a significant relationship with the outcome variables.

4) Empathic concern will completely mediate the relation between attachment to all four figures and prosocial behaviour for both secure vs. anxious-ambivalent, and secure vs. avoidant, individuals. 


\section{CHAPTER 3: METHOD}

This chapter outlines the research design, sample, and statistical technique utilized for the current study. The process of accessing a sufficient number of participants is described, as well as the instruments completed by these participants in order to acquire relevant data. The procedure followed for the collection of the study's data is also summarized, before explaining the Structural Equation Modelling (SEM) statistical technique used to analyse the data. The statistical assumptions required by SEM are detailed and investigated.

\subsection{Research Design}

The study took place as an extension of ongoing research at the University of Cape Town into the influences of parental and grandparental involvement on the adjustment of young adolescents (Profe \& Wild, 2015: Wild \& Gaibie, 2014). As the primary variables of interest were not subject to manipulation, the study design involved quantitative, correlational analyses. The data was cross-sectional, as a survey (see Appendix A and Appendix B) including various psychometrically established measures was administered to study participants at a single point in time. The selected statistical analyses (described on pages 3946) demand large sample sizes, and therefore surveys provide a simple and inexpensive method for collecting a large amount of data within the time constraints of a masters degree. Furthermore, given that research is relatively scant in this area, the use of established surveys allows for data to be more comparable for previous and future studies employing the same measures (Cozby, 2009).

\subsection{Participants}

The final sample consisted of 520 grade 7 learners (58\% male) from 9 schools in Cape Town. The age of the participants ranged from 11 to 14 years, with a mean age of 12.33 years $(S D=0.52)$. Most of the sample identified as coloured or mixed-race $(n=241 ; 46 \%)$ and white $(n=190 ; 37 \%)$. Slightly more than half of the sample came from nuclear families $(n=$ $293 ; 56 \%)$. Overall, $78 \%(n=408)$ of the participants lived with at least one sibling, and $21 \%$ $(n=110)$ lived with at least one grandparent. Detailed characteristics of the sample are presented in Table 1. 
Table 1

Detailed characteristics of the final sample.

\begin{tabular}{|c|c|c|}
\hline Variable & & $n$ (\% of final sample) \\
\hline \multicolumn{3}{|l|}{$\operatorname{Age}^{a}$} \\
\hline & 11 & $5(1)$ \\
\hline & 12 & $330(63)$ \\
\hline & 13 & $154(30)$ \\
\hline & 14 & $8(2)$ \\
\hline
\end{tabular}

$\operatorname{Sex}^{\mathrm{b}}$

Race $^{\mathrm{c}}$

Male

$304(58)$

Female $209(40)$

Family structure $^{\mathrm{d}}$

$\begin{array}{ll}\text { Black African } & 25(5) \\ \text { Coloured (mixed-race) } & 241(46) \\ \text { White } & 190(37) \\ \text { Indian } & 17(3) \\ \text { Did not want to answer } & 19(4) \\ \text { Other } & 16(3)\end{array}$

$\begin{array}{ll}\text { Nuclear } & 293(56) \\ \text { Single-parent } & 61(12) \\ \text { Step-family } & 33(6) \\ \text { Single-parent multigenerational }^{\mathrm{e}} & 10(2) \\ \text { Two-parent multigenerational }^{\mathrm{f}} & 52(10) \\ \text { Skipped-generation }^{\mathrm{g}} & 7(1) \\ \text { Other }^{\mathrm{h}} & 56(11)\end{array}$

Lives with a sibling
No
$103(20)$
Yes
$409(78)$

Lives with a grandparent

$\begin{array}{ll}\text { No } & 402(77) \\ \text { Yes } & 110(21) \\ & \\ \text { Mother's mother } & 206(40) \\ \text { Mother's father } & 61(12) \\ \text { Father's mother } & 122(23) \\ \text { Father's father } & 41(8)\end{array}$

\footnotetext{
a 23 participants did not indicate their age

${ }^{\mathrm{b}} 7$ participants did not indicate their sex

${ }^{c} 12$ participants did not indicate their race

d 8 participants did not provide information on their family structure

${ }^{\mathrm{e}}$ Living with only one biological parent and at least one grandparent

${ }^{\mathrm{f}}$ Living with both biological parents and at least one grandparent

${ }^{\mathrm{g}}$ Living with at least one grandparent and none of their biological parents.

${ }^{\mathrm{h}}$ This category typically describes those living in homes with other extended family members, or anything not fitting one of the categories above.

i 90 participants did not provide data on who their closest grandparent is. Many indicated that they were unable to choose a single grandparent with whom they have the closest relationship.
} 
3.2.1. Sample size calculation. Calculating the required sample size for Structural Equation Modelling is an area of much debate and uncertainty. Generally, sample sizes of 200 or more are considered large (Iacobucci, 2009; Kline, 2011). Kline (2011) also recommends using the required sample size for linear multiple regression analyses as a standard by which to judge the adequacy of a sample for structural equation modelling. According to a post-hoc Cohen's $f^{2}$ measure of effect size using G*Power (version 3.1.9.2), a sample size of 520 would allow for the detection of a small effect of 0.03 with 0.88 power in a linear regression with 5 predictors. Furthermore, Marsh, Hau, Balla and Grayson (1998) suggest that a high indicator-to-variable ratio improves the power and reliability of a sample used in Confirmatory Factor Analysis, such that samples with $n$ as low as 50 always converged if there were a ratio of 12 indicators per factor. Given that the current measures have a particularly high indicator to variable ratio (i.e. the latent variables in the path models are measured by numerous manifest variables), there is good reason to think that the current sample size is adequate.

3.2.2. Sampling procedure. The sample for the current study was obtained using both a convenience and purposive procedure. A database of all the primary schools within the southern suburbs area of Cape Town was obtained, because schools within that geographical area were most accessible to the researcher. Thirty-seven schools for which contact information could be found were then contacted via email. Those schools which did not respond to the email timeously were contacted telephonically. Nine of the contacted schools responded positively. Two of the schools were co-educational (mixed sex), situated in middle- to lower-income areas and had school fees below R8000 per year. Four of the schools were co-educational, situated in middle- to upper-income areas with school fees between R8000 and R20000 per year. Finally, three of the schools were situated in middle- to upper-income areas with school fees between R20 000 and R40 000 per annum, one of which was a girls-only school, whereas the other two were boys-only schools. All of the schools were English-medium.

These 9 schools consisted of 23 classrooms and a total of 684 Grade 7 learners. The first school surveyed did not provide detailed information regarding the reason for why 24 learners did not participate. However, for the remaining 8 schools, 42 learners were absent on the day of data collection, 16 learners' parents did not wish for them to participate, and 1 learner was present but did not hand in his survey. Consequently, a total of 601 learners completed the research survey. Two additional inclusion criteria were applied to this remaining sample: Learners were required to have two living parents, since the loss of a 
parent introduces a myriad of potential confounding variables (e.g. Brent, Melhem, Donohoe, $\&$ Walker, 2009), and because this study included an investigation of grandparent-adolescent relationships, participants were required to have at least one living grandparent. On the basis of these criteria, 69 participants were excluded because they did not have at least one living grandparent, 1 was removed because of a deceased mother, and a further 11 were removed because of deceased fathers. This resulted in the final sample of 520 participants described above.

\subsection{Measures}

The measures used for collecting data from participating learners were contained in a survey (including some measures that were not used in the current study) consisting of 23 pages and entitled My Family, Friends and I (Appendix A). The measure completed by participants' teachers was presented on a single page to the teacher (Appendix B). All of the surveys were printed in English, as the participating schools were all English-medium, and previous research (Profe \& Wild, 2015) among adolescents in Cape Town found that the vast majority of participants preferred to answer questionnaires in English (even when Afrikaans was a prominent language in the school). The measures used are outlined below.

3.3.1. Demographic information. Participants were requested to indicate their age, sex, race, and with whom they live for descriptive purposes.

3.3.2. Mother, father, friend and closest grandparent attachment. The mother, father and peer version of the Inventory of Parent and Peer Attachment (IPPA; Armsden, 1986) was used to measure attachment security. The original IPPA was designed to measure parent (28 items) and friend (25 items) attachment with a 5-point Likert-type scale, and was validated among late-adolescent college students (Armsden \& Greenberg, 1987). For both the parent and friend subscales, internal reliability was satisfactory (ranging from .73 to .91), and criterion validity was evidenced through the scale's association with psychological wellbeing. Armsden (1986) divided the original questionnaire into a measure of mother, father and friend attachment (each 25 items). The measure's items are arranged into three subscales (Pace, Martini, \& Zavattini, 2011), namely the Trust (10 items), Communication (9 items for parents; 8 items for friends) and Alienation ( 6 items for parents; 7 items for friends) subscales, and a total measure of attachment security is scored by adding the subscales together. The Alienation subscale scores are coded so that a higher score indicates lower alienation, and therefore a higher total score for this measure indicates more secure attachment. The IPPA has been used extensively among younger adolescents also. Gullone 
and Robinson (2005) measured attachment among 9-15 year-old children and found good internal reliability (.69-.87). These same authors found that IPPA attachment scores were associated with self-esteem and the Care Dimension of the Parental Bonding Instrument (Parker, Tupling, \& Brown, 1979). Numerous other studies have confirmed that the IPPA is a valid measure of attachment among young adolescents, with theoretically expected links to parental separation (Woodward, Fergusson, \& Belsky, 2000), social skills (Coleman, 2003; Engels, Finkenauer, Meeus, \& Deković, 2001), depression (Milne \& Lancaster, 2001), parent and friend communication (Meeus, Oosterwegel, \& Vollebergh, 2002) and self-esteem (Simons et al., 2001). The IPPA has previously also been used to measure grandparent attachment (Henderson et al., 2009). In order to do this, the same scale used for parents was used, with the word "grandparent" substituted for the word "mother"/"father". The reliability for the subscales and overall attachment scales in the current sample were satisfactory. For the mother Trust, Communication, Alienation and total Attachment scores, Cronbach's Alphas were 0.90, 0.87, 0.79 and 0.94 respectively. In the same order, the Cronbach's Alphas for the father scales were $0.92,0.91,0.80$ and 0.95 . For the grandparent scales, they were 0.88, 0.88, 0.68 and 0.92. Finally, for the friend scales, they were 0.92, 0.90, 0.64 and 0.93 .

Although primarily a continuous measure of attachment security, the IPPA can also be used to categorize respondents into attachment styles. Armsden and Greenberg (1987) first conceptualized this approach using Ainsworth et al.'s (1978) framework, and Vivona (2000) further tested its validity. Participants are first classified as to whether they fall into the lowest, middle or highest third of scores on each of the Trust, Communication and Alienation subscales. Participants are then assigned an attachment style based on the combination of their classifications across the three subscales. Table 2 outlines the various possible combinations and the attachment styles associated with them. Attachment styles devised with this method were discriminated in theoretically predicted ways along participant characteristics such as parental provision of a secure base and autonomy support, worry, depression and anxiety (Vivona, 2000). This method was used to classify participants into attachment styles, in order to test the generalizability of the theoretical model across all three attachment styles. 
Table 2

Attachment subscale rating combinations associated with each attachment style

\begin{tabular}{llll}
\hline Attachment style & Trust & Communication & Alienation \\
\hline Secure & Middle & Middle & Low \\
& Middle & High & Middle \\
High & Middle & Middle \\
& High & High & Middle \\
High & Middle & Low \\
& Middle & High & Low \\
& High & High & Low \\
Avoidant & Low & Low & High \\
& Low & Low & Middle \\
& Middle & Low & High \\
& Low & Middle & High \\
& & & \\
Ambivalent & Middle & Middle & High \\
& Middle & Middle & Middle \\
& Middle & Low & Middle \\
& Low & Middle & Middle \\
\hline
\end{tabular}

Note. Each line of three conditions, from left to right, represents a single combination resulting in the attachment style indicated.

3.3.3. Empathic concern. The Empathic Concern (EC; 7 items) subscale of the Interpersonal Reactivity Index (IRI; Davis, 1980), a 5-point Likert scale, was used to measure empathic concern. The IRI consists of four subscales (empathic concern, as well as Fantasy, Personal Distress and Perspective-Taking [PT] subscales). However, the majority of studies employing the IRI use only the PT and EC subscales (Davis, 1983; Hawk et al., 2013; Laible et al., 2000). The PT subscale, however, measures the tendency to cognitively consider the perspectives of others in a variety of circumstances, rather than the tendency to feel concern for others in need that is theoretically relevant here. Studies using the empathic concern subscale among young adolescents indicate satisfactory internal reliability (all $>.70$ ) (Davis, 1980; Gustafson, 2013; Hawk et al., 2013; Laible et al., 2000) and validity through its association with helping, openness, agreeableness (Hawk et al., 2013), and prosocial behaviour (Gustafson, 2013). Internal reliability for the Empathic Concern Subscale in the current study was 0.61 .

3.3.4. Prosocial behaviour. The Emotional ( 5 items) and Dire ( 3 items) subscales of the Prosocial Tendencies Measure - Revised (PTM-R; Carlo, Hausmann, Christiansen, \& Randall, 2003), both 5-point Likert measures, were combined and used as the self-report 
measure of prosocial behaviour. The original PTM was developed by Carlo and Randall (2002) and tested among undergraduate college students. The Emotional and Dire subscales evidenced satisfactory internal consistency (.75 and .63 , respectively) and were positively associated with measures of perspective-taking and prosocial moral reasoning. Carlo et al. (2003) revised the original PTM for use among younger adolescents. Cronbach's alphas for the Emotional and Dire subscales among early adolescents was high (.86 and .71, respectively), and evidenced good test-retest reliability (both .72). The Emotional and Dire subscales were positively related with internalized prosocial moral reasoning, perspectivetaking, and empathic accuracy, and negatively associated with hedonistic and approvalorientated moral reasoning. Other studies have also used the PTM-R among early adolescents (Carlo et al., 2010; Carlo, Knight, McGinley, \& Hayes, 2011; Carlo, McGinley, Hayes, Batenhorst, \& Wilkinson, 2007) and found good internal consistency for both subscales ( $\alpha=$ .62-.90). The scales have also been shown to associate with sympathy scores (Carlo et al., 2007) and evidenced cross-gender and cross-cultural utility (Carlo et al., 2010). The two subscales were combined because they are highly correlated (Carlo et al., 2003; Carlo \& Randall, 2002), are conceptually similar, and the combination of these two factors in Confirmatory Factor Analysis (CFA) yields a similar fit to a CFA in which they are separated (Carlo et al., 2010). Internal reliability scores for the Emotional and Dire subscales, as well as the total prosocial behaviour scale, were satisfactory in the current sample, with Cronbach's Alphas of 0.82, 0.76 and 0.87 , respectively.

The Prosocial Behaviour subscale of the Strengths and Difficulties Questionnaire (SDQ; Goodman, 1997) was used as the teacher-report of prosocial behaviour. This is a 5item, 3-point Likert scale. Although commonly used as a self-report measure, Goodman (1997) originally created this scale as a teacher- and parent-report for children aged 4-16. The scale has been used extensively around the world, as well as in South Africa (Cluver \& Gardner, 2006; Profe \& Wild, 2015). The psychometric properties of the teacher-reported scale are satisfactory, according to a review by Stone, Otten, Engels, Vermulst, and Janssens (2010). Internal consistency is generally high (on average $\alpha=.82$ ), high item-factor loadings are found (average .70-.80), good test-retest reliability is evident (>.70), and concurrent (Becker et al., 2006) and predictive (Hawes \& Dadds, 2004) validity have been supported. Internal reliability for the current sample was satisfactory, with a Cronbach's alpha of 0.89 . Although this subscale of the SDQ is considered to be a global measure of prosocial behaviour, as opposed to the specificity of the PTM-R subscales described above, it 
nevertheless contains items intuitively similar to the PTM-R subscales and provided a healthy benchmark test for the vulnerability of self-reports to social desirability bias.

Teacher-reports for 97 participants were not returned, and for a further 22 participants a research assistant made an error in the distribution of surveys, and therefore it was not possible to correctly match the teacher reports with their corresponding participant surveys. After applying the inclusion criteria, this resulted in 103 participants of the final sample lacking teacher reports. The subsample without teacher reports did not differ significantly from the subsample with teacher reports $(n=417)$ on any of the variables of interest, with the exception that those without teacher reports scored lower on empathic concern $(M=26.14$, $S D=4.77)$ than those with teacher reports $(M=27.62, S D=4.22), t(133.78)=-2.80, p<$ .01. Furthermore, the subsample with teacher reports did not differ from the total sample in any of the other variables of interest (all $t$ test comparisons yielded $p$ values higher than 0.3 ).

\subsection{Procedure}

Permission to conduct the present study was obtained from the Western Cape Education Department (Appendix C) as well as the University of Cape Town Research Ethics Committee of the Faculty of Humanities (Appendix D). For each of the 9 schools which indicated a willingness to participate in the study, the researcher arranged a face-to-face meeting with the primary correspondent (usually a Grade 7 teacher or the principal). During this face-to-face meeting the details of the study were discussed, a data collection date was set, and the class lists for each grade 7 class were obtained. These class lists were then used to assign a random participant number to each child in the class, to avoid the use of the child's name in all further analyses and thus ensure anonymity.

About one week before each school's data collection date, the researcher brought various documents to the school. One of these was the parent consent form (Appendix E), which Grade 7 teachers then sent home with learners. Since the study involved minimal risk to participants, a passive form of consent was obtained from parents; that is, parents were only required to send back the consent form if they did not wish for their child to participate. No response was regarded as consent. Along with the parent consent forms, the researcher provided teachers with a class list including all of their learners' names and participant numbers, a pile of questionnaires to fill out for each child in their class using their unique participant numbers (Appendix B), a consent form for their own participation (Appendix F), and a letter providing clear instructions about the study procedure and what was expected of them (Appendix G). Teachers were ensured that their participation was completely voluntary, 
that their responses would remain anonymous, and that no negative outcomes would be incurred for non-participation. To encourage the teachers to participate, they were offered a chance to be included in a draw for a shopping voucher if they completed their surveys. Completed teacher surveys were then collected from the teachers after administering the surveys to their class.

On the day arranged for data collection, the researcher and a certain number of research assistants (number of Grade 7 classes minus 1) arrived at the school, and were then assigned to different Grade 7 classes (except in the case of one school, where the researcher administered the survey, with the help of the Grade 7 teachers, to all Grade 7 learners in a single venue). The researchers then introduced themselves and explained the study to the learners, including their rights to not participate in the study without negative consequences or to withdraw at any time. Participants were then each handed a survey marked with their unique participant numbers, read through the enclosed assent form, signed, and continued with the survey. Researchers monitored the room at all times, answering any questions and ensuring that learners were at ease and having their privacy respected. The survey process generally took between 30 to 45 minutes. Once all the learners had handed in their surveys, the researchers thanked the children and teachers and collected the completed teachers' questionnaires. The surveys were immediately collected by the researcher and stored securely at his home. All of the data was then encoded into a Microsoft Excel spreadsheet by the researcher.

\subsection{Statistical Analysis}

The overall aim of this study was to determine the relative influence of mother, father, closest grandparent and friend attachment on self- and teacher-reported prosocial behaviour via the mediation of empathic concern. Structural Equation Modelling (SEM) with maximum likelihood estimation was used in order to test these relationships. Data was imported from a Microsoft Excel spreadsheet into RStudio (version 0.99.467), and the package lavaan (version 0.5-19; Rosseel, 2012) was used to perform the SEM analyses. Alpha was 0.05 for all analyses. Computations were performed using facilities provided by the University of Cape Town's ICTS High Performance Computing team (http://hpc.uct.ac.za).

Descriptive statistics for the variables included in the analyses, such as means, standard deviations, ranges, skewness and kurtosis values were calculated. To test hypothesis 1 , the zero-order correlations between the variables of interest were computed. 
The SEM that was investigated is presented in Figure 1. A separate model was run for each outcome variable, namely self-reported and teacher-reported prosocial behaviour. Therefore, each model began with a total of 6 latent variables. Mother, father, closest grandparent and friend attachment were the exogenous latent variables, whereas empathic concern was the endogenous latent variable. Finally, prosocial behaviour (first self-reported, then teacher) were the outcome latent variables. Covariances between the exogenous variables were assumed and controlled for.

Before testing each hypothesized structural model, the measurement models for the latent variables were determined by performing a Confirmatory Factor Analysis (CFA). Each latent variable and all of its standard items were included as the a priori measurement model. The metric of each latent variable was determined by fixing its variance to 1 . For simplicity and because only the total scores were of primary interest, the subscales for each measure were collapsed and their constituent items were amalgamated as indicators of the single, overall factor. This approach was further justified by the high internal consistencies of most of the overall measures presented earlier. Then, the a priori model was evaluated via a succession of methods. First, the fit indices for the measurement model were used to determine whether the measurement model fit the data satisfactorily. Four fit indices were consulted. First, the Model $\chi^{2}$ tests the degree of fit between each observed covariance and that implied by the model. A nonsignificant $\chi^{2}{ }_{\mathrm{M}}$ indicates good fit. However, it was expected that attaining a non-significant $\chi^{2}{ }_{\mathrm{M}}$ would be difficult given that the $\chi^{2}{ }_{\mathrm{M}}$ statistic tends to be inflated by large sample sizes (Kenny, 2015), models with many variables (Iacobucci, 2009), when used on non-multivariate-normal distributions, and in the presence of high item-item covariance (Kline, 2011). Therefore, three other descriptive measures of fit, namely the Comparative Fit Index (CFI), the Standardized Root Mean Square Residual (SRMR) and the Root Mean Square Error of Approximation (RMSEA), were consulted. Ideally, these measures should have values of $>0.90,<.08$, and $<.05$, respectively, to indicate good fit (Kline, 2011). However, given that the RMSEA and SRMR are absolute fit indexes, and thus proximal to the rigour of $\chi_{\mathrm{M}}^{2}$, and CFI is an inferior measurement in confirmatory contexts (Rigdon, 1996), more weight was given to the RMSEA and SRMR in evaluating model fit. The standardized loadings of each item on their respective factors were also consulted. Finally, the modification indices for the model were consulted, to see whether any unaccounted covariances between items existed. Proposed item-item covariances with high modification indices (20 or above) were tested via bootstrapping, and those which were robust to extensive resampling were retained. 


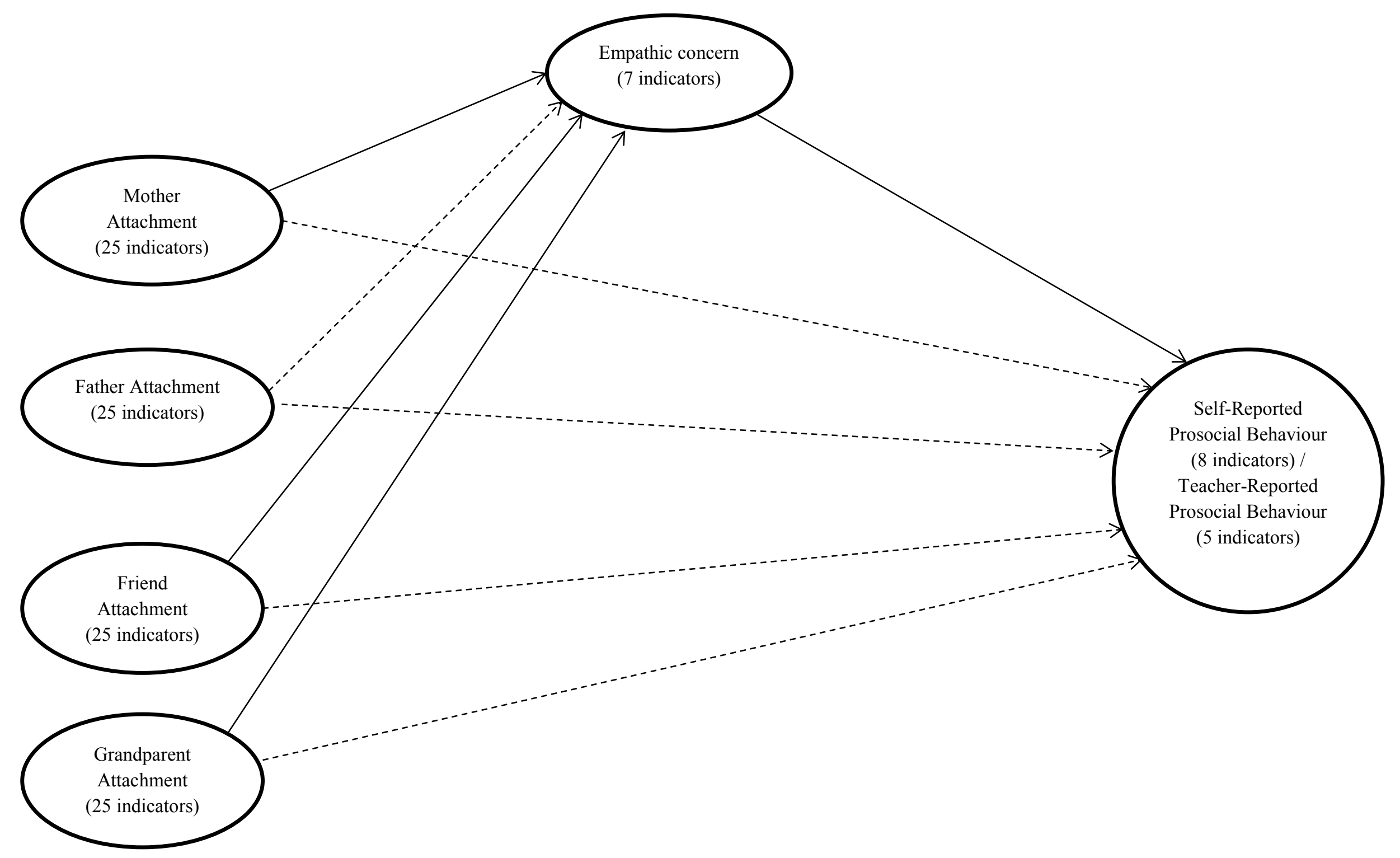

Figure 1. Hypothesized theoretical model tested with Structural Equation Modelling. Owing to the high number of indicators and space limitations, the measurement model has not been included here. The dashed line represents a hypothesized null relationship. 
Once the measurement model had been established, the structural model including the hypothesized paths between the latent variables was tested. To determine the acceptability of the hypothesized model, the same fit indices as previously described were consulted, and path coefficients between latent variables were interpreted. To confirm whether the relationship between attachment scores and prosocial behaviour was totally mediated by empathic concern, a model with direct paths between the attachment scores and prosocial behaviour was compared, using a chi-square difference test, with a model in which these direct paths were constrained to zero.

There did not appear to be any dependency of missing data on observed data for any of the variables, and therefore data was missing at random (Kline, 2011). Therefore, for both the CFA and SEM analyses case-wise maximum likelihood estimation was used to deal with missing data. Enders and Bandalos (2001) found that case-wise maximum likelihood estimation was a superior method for dealing with missing data compared to other methods, such as listwise deletion

As a secondary aim of this study, the hypothesized theoretical model was tested on two subsamples; namely, one subsample containing those classified as secure and avoidant, and another subsample containing those classified as secure and ambivalent. These classifications were calculated with respect to the attachment figure having the strongest relationship with outcome variables in the whole-sample analyses, using the methods outlined earlier. Unfortunately, dividing attachment subscale scores into lower, middle and upper quantiles required complete data, and thus listwise deletion was applied. Owing to a high amount of missing data, listwise deletion reduced the sample size considerably. Therefore, a complete dataset was created by imputing missing values using expectation-maximization with bootstrapping via the Amelia II package (version 1.7.4; Honaker, King, \& Blackwell, 2011) before deriving the two subsamples. Although the two subsamples naturally contained fewer cases ( $n=341$ for the secure vs. avoidant subsample; $n=326$ for the secure vs. ambivalent sample), they were still sufficiently large by some of the criteria mentioned earlier to warrant further analysis.

3.5.1. Assumptions. The various statistical assumptions made for SEM analyses were investigated, and the results are outlined below.

3.5.1.1. Identification. An SEM must be identified, meaning that it is theoretically possible to compute a unique set of parameter estimates (Kline, 2011). Given that the hypothesized model features unidirectional causal effects, it is recursive, and therefore identified (Kline, 2011). 
3.5.1.2. Positive definiteness. The data matrix submitted for SEM analysis should be positive definite, meaning that it is invertible, all of its eigenvalues are greater than 0 , its determinant is greater than 0 , and none of its covariances are out of bounds (Kline, 2011). This was determined using the psych package (version 1.5.6; Revelle, 2015). By examining all of the minor matrices of the correlation matrix by removing one variable at a time and finding the corresponding eigen values, it was determined that the correlation matrix was positive definite.

3.5.1.3. Collinearity. To determine whether there was any serious collinearity between separate variables, the squared multiple correlation between each variable of interest and the rest was calculated. Kline (2011) notes that an $R_{\text {smc }}^{2}$ value over 0.90 is indicative of serious multicollinearity. $R_{\text {smc }}^{2}$ for the variables of interest in this study ranged from 0.06 to 0.35 , indicating no serious collinearity.

3.5.1.4. Univariate normality. SEM assumes that each individual variable's scores are normally distributed about their mean. The distributions of scores for the variables of interest, overlaid with a normal distribution curve, are presented in figure 2 below. Analysis of these distributions shows that the variables generally deviate from normality. All of the attachment variables are negatively skewed, indicating a tendency for high attachment scores. This is not altogether surprising, since studies typically find that most people are securely attached (e.g. Mickelson, Kessler, \& Shaver, 1997). Furthermore, mother attachment and grandparent attachment appear to have positive kurtoses, whereas father and friend attachment indicate negative kurtoses. Self-reported and teacher-reported prosocial behaviour, as well as empathic concern, indicate negative skew. Again, this is not surprising, since both selfreports (Carlo et al., 2003; Profe \& Wild, 2015; Van Roy, Grøholt, Heyerdahl, \& ClenchAas, 2006) and teacher-reports (Van Widenfelt, Goedhart, Treffers, \& Goodman, 2003) of young adolescents' prosocial behaviour tend to yield high average scores. In addition, both self-reported prosocial behaviour and empathic concern scores suggest negative kurtoses, whereas teacher-reported prosocial behaviour scores seem to be distributed with a positive kurtosis. 

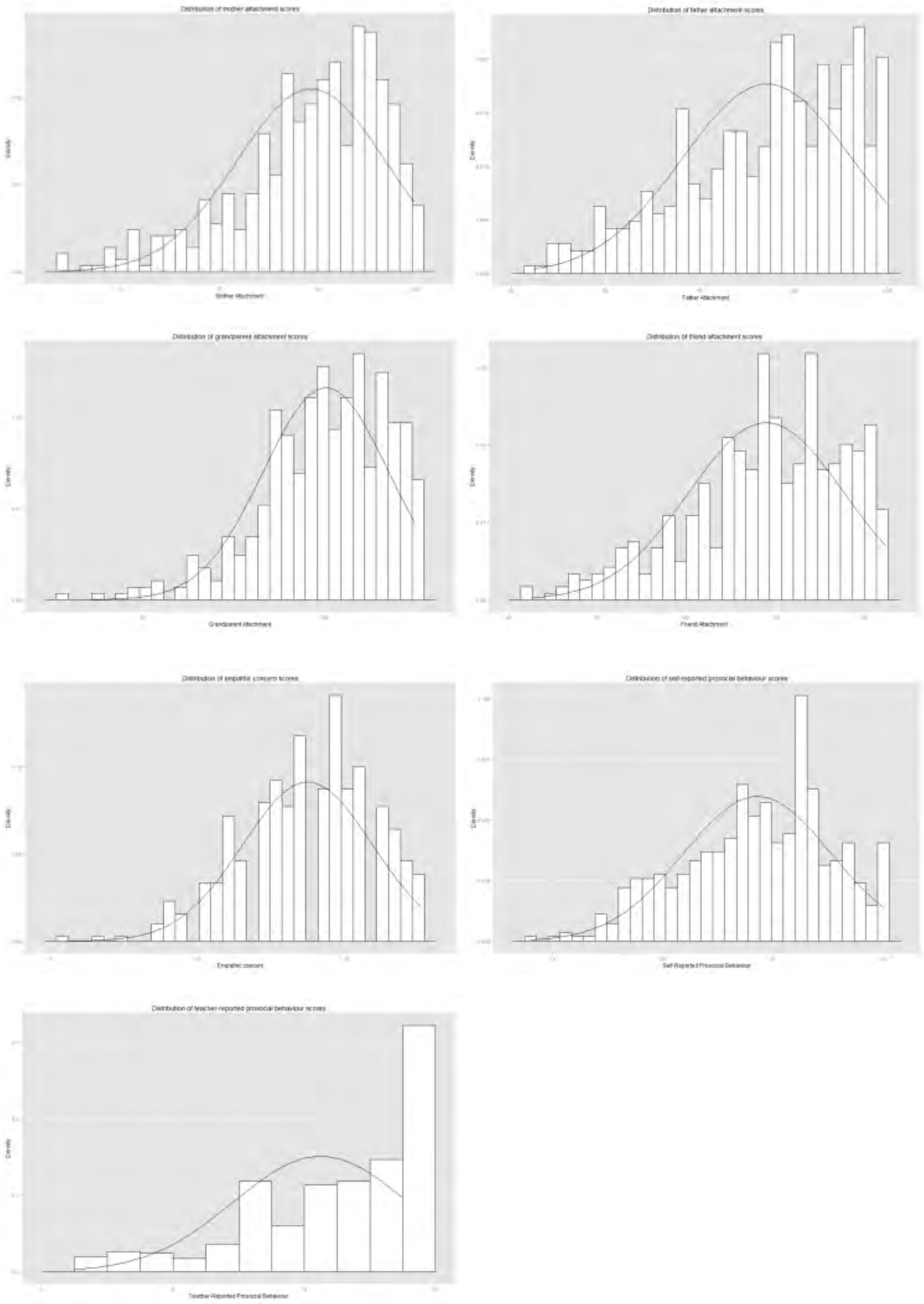

Figure 2. Histograms displaying the distributions of scores for each variable included in the analyses. 
Mean skewness and kurtosis scores for the variables calculated using bootstrapping with 10000 iterations suggest that the sample distributions reflect the population distributions, and are presented in Table 3. These values are all well below the skewness value of 3 and kurtosis value of 10 cautioned by Kline (2011) as indicating serious skewness. However, given that the skewness and kurtoses scores were based on bootstrapped empirical distributions, it was considered inappropriate to proceed with analyses which assume a normally distributed population. Bootstrapped analyses, which do not assume the population scores are normally distributed but rather derive the model statistics from empirical sampling distributions, were used to determine the item-factor loadings, and the Satorra-Bentler correction (Satorra \& Bentler, 1994) was applied to model fit statistics. Given that the sample size is relatively large, bootstrapping procedures are a robust strategy against biased coefficient estimates, according to research by Nevitt and Hancock (2001). These authors found that bootstrapping with 250 iterations was sufficient for unbiased computations; therefore, item-factor loadings from the measurement models reported in the current study were based on bootstrapping with 250 iterations. Furthermore, the Satorra-Bentler statistic generally yields favourable results as a corrective for non-normal distributions (Chou \& Bentler, 1995).

Table 3

Mean bootstrapped skewness and kurtosis scores for study variables

\begin{tabular}{lcccc}
\hline & Skewness $(S D)$ & $95 \% C I$ & Kurtosis $(S D)$ & $95 \% C I$ \\
\hline Mother attachment & $-0.93(0.09)$ & $-1.11,-0.76$ & $0.46(0.28)$ & $-0.04,1.05$ \\
Father attachment & $-0.62(0.07)$ & $-0.77,-0.48$ & $-0.40(0.16)$ & $-0.69,-0.07$ \\
$\begin{array}{l}\text { Closest grandparent } \\
\text { attachment }\end{array}$ & $-0.87(0.13)$ & $-1.13,-0.61$ & $0.92(0.49)$ & $0.05,1.95$ \\
Friend attachment & $-0.65(0.08)$ & $-0.81,-0.50$ & $-0.12(0.19)$ & $-0.47,0.30$ \\
$\begin{array}{l}\text { Empathic concern } \\
\begin{array}{l}\text { Self-reported prosocial } \\
\text { behaviour }\end{array}\end{array}$ & $-0.43(0.10)$ & $-0.64,-0.23$ & $-0.14(0.29)$ & $-0.63,0.49$ \\
$\begin{array}{l}\text { Teacher-reported prosocial } \\
\text { behaviour }\end{array}$ & $-1.02(0.09)$ & $-1.20 .-0.85$ & $0.28(0.25)$ & $-0.16,0.83$ \\
\hline
\end{tabular}


3.5.1.5. Multivariate normality. SEM analyses assume not only that each individual variable is normally distributed, but also that all variables are normally distributed at each level of the other variables, that all bivariate relationships are linear and that residuals are distributed homoscedastically. Two statistical measures of multivariate normality were applied to the data: Mardia's Test (Mardia, 1970) and the Generalized Shapiro-Wilk test (Villasenor-Alva \& Gonzalez-Estrada, 2009). Results for the Mardia Test $\left(\hat{y} 1_{, p}=6425.51\right.$, $\left.p<.05 ; \hat{y} 2_{, p}=13549.23, p<.05\right)$ and Shapiro-Wilk test $\left(W^{*}=0.96, p<.05\right)$ indicated that the data were not multivariately normal. This finding was unsurprising, given that one of the preconditions for multivariate normality is univariate normality (Kline, 2011). Furthermore, given that the sample size is relatively large, even slight variations in normality are likely to be significant (Kline, 2011). As noted above, however, the large sample size allowed for robust measures to be taken to ensure unbiased statistics. 


\section{CHAPTER 4: RESULTS}

This chapter presents the results of the study's statistical analyses. As outlined in chapter 2 , recall that the primary hypotheses predicted that, first, attachment quality to mothers, fathers, friends and grandparents would be positively associated with empathic concern and prosocial behaviour. Second, it was expected that empathic concern would completely mediate the relation between attachment to all four figures and prosocial behaviour. Third, friends should emerge as the most influential indirect influence on prosocial behaviour. Fourth, these expectations should generalize when comparing secure vs. anxious-ambivalent, and secure vs. avoidant, individuals

\subsection{Descriptive Statistics}

The means, standard deviations and ranges for the variables included in this study are presented in Table 4. Although no South African norms exist for any of these measures, the means are comparable to those found in previous studies for attachment (Coleman, 2003; Henderson et al., 2009; Simons et al., 2001), empathic concern (Hawk et al., 2013; Laible et al., 2000), and self-reported prosocial behaviour (Carlo et al., 2003; Carlo et al., 2011), although the mean for teacher-reported prosocial behaviour was unusually high (Van Widenfelt et al., 2003).

Table 4

Descriptive statistics

\begin{tabular}{|c|c|c|c|c|c|}
\hline & $n$ & $M$ & $S D$ & Min. & Max. \\
\hline Mother attachment & 478 & 98.54 & 19.00 & 34 & 125 \\
\hline Father attachment & 458 & 93.06 & 22.59 & 31 & 125 \\
\hline $\begin{array}{l}\text { Closest grandparent } \\
\text { attachment }\end{array}$ & 444 & 100.41 & 17.24 & 27 & 125 \\
\hline Friend attachment & 448 & 97.92 & 17.45 & 45 & 125 \\
\hline Empathic concern & 487 & 27.33 & 4.37 & 11 & 35 \\
\hline $\begin{array}{l}\text { Self-reported prosocial } \\
\text { behaviour }\end{array}$ & 508 & 28.56 & 6.68 & 8 & 40 \\
\hline $\begin{array}{l}\text { Teacher-reported prosocial } \\
\text { behaviour }\end{array}$ & 416 & 12.49 & 2.65 & 5 & 15 \\
\hline
\end{tabular}

Note. All scales are scored such that a higher score represents more of the construct measured. 


\subsection{Correlations}

The zero-order correlations between all the variables of interest are presented in Table 5. All of the attachment scores were significantly correlated with one another, indicating that secure attachment relationships tended to occur in tandem, albeit the strengths of these correlations were moderate. As the hypotheses would predict, all attachment scores were positively related to empathic concern, which in turn was positively related with self- and teacher-reported prosocial behaviour. Furthermore, all of the attachment variables were significantly positively related to self-reported prosocial behaviour, but not with teacherreported prosocial behaviour. Lastly, it is noteworthy that self- and teacher-reported prosocial behaviour were significantly, but moderately, positively correlated.

\subsection{Structural Equation Model Predicting Self-reported Prosocial Behaviour}

4.3.1. Measurement model. The initial CFA tested the a priori measurement model, i.e. the proposed measurement model of the latent variables including all of their respective observed variables (survey items).

4.3.1.1. Model fit. The fit results for the initial a priori measurement model were mixed, but promising. As expected, Model $\chi^{2}$ was significant, $\chi_{M}^{2}(6425)=10585.54, p<.05$. CFI was also unsatisfactorily low, at 0.77 . Results for the RMSEA and SRMR, however, indicated satisfactory fit. RMSEA was 0.044, 95\% CI [0.043, 0.045], and SRMR was 0.07.

4.3.1.2. Problematic items. All of the items loaded significantly onto their latent variables. However, one item was problematic. Item 9 of the friend attachment scale's loading $(\beta=-0.13, p<.05)$ was not in the expected direction. The item reads: "I feel the need to be in touch with my friends more often", and is intended to measure alienation from one's friends. However, it appears that respondents interpreted this item as a longing to be with one's friends, which indicates a positive relational attribute, and answered accordingly. This item was therefore removed. 
Table 5

Zero-order correlations between study variables

\begin{tabular}{|c|c|c|c|c|c|c|c|}
\hline & 1 & 2 & 3 & 4 & 5 & 6 & 7 \\
\hline 3. Grandparent attachment & $0.49 * *$ & $0.34 * *$ & & & & & \\
\hline 5. Empathic concern & $0.32 * *$ & $0.18^{*}$ & $0.28 * *$ & $0.33 * *$ & & & \\
\hline $\begin{array}{l}\text { 6. Self-reported prosocial } \\
\text { behaviour }\end{array}$ & $0.24 * *$ & $0.21 * *$ & $0.28 * *$ & $0.30 * *$ & $0.77 * *$ & & \\
\hline $\begin{array}{l}\text { 7. Teacher-reported prosocial } \\
\text { behaviour }\end{array}$ & 0.07 & 0.01 & -0.04 & 0.13 & $0.21 * *$ & $0.21 * *$ & \\
\hline
\end{tabular}

$* p<.05$

$* * p<.01$ 
4.3.1.3. Item covariances. The modification indices indicated a large number of itemitem covariances, which are too numerous to present here. For the full measurement model including all of these covariances, please download the $R$ script from https://www.dropbox.com/s/x4ptb64tmxue5cl/Final\%20measurement\%20models.rar?dl=0. Most of the item-item covariances were between a) items from the same scales and subscales, or b) items from different subscales but the same scales, measuring similar constructs and/or similarly worded. Therefore, these covariances were to be expected from the fact of their existence on scales measuring the same latent traits. Some covariances, however, were between items from different scales. Most of these seemed to reflect a consistency in the quality of communication between respondents and their various attachment figures, or a similarity in the perception of the quality of care received between attachment figures. For example, a covariance between item 18 of the mother and father attachment scales, which reads, "I don't get much attention from my mother/father", reflects a consistency in the parenting experienced by the respondent from both parents.

4.3.1.4. Modified model fit. The modified CFA, excluding the poorly performing items and including the item-item covariances suggested by the modification indices, resulted in adequate fit. Although, as expected, Model $\chi^{2}$ was significant, $\chi_{\mathrm{M}}^{2}(6218)=8544.38, p<.05$, the rest of the fit indices showed improvement: $\mathrm{CFI}=0.87$, which is not far from the desired value of 0.9 ; $\mathrm{RMSEA}=0.033,95 \% C I[0.032,0.035]$; $\mathrm{SRMR}=0.065$. The final measurement model is presented in Table 6 .

Table 6

Standardized item-factor loadings for the measurement model used to predict self-and teacher-reported prosocial behaviour

\begin{tabular}{cccc}
\hline & \multicolumn{2}{c}{ Standardized $(S E)$} \\
\hline Scale $^{\text {Mother Attachment }}{ }^{\mathrm{a}}$ & Item & Self-reported model & Teacher-reported mo \\
& 1 & $0.76(0.07)$ & $0.76(0.08)$ \\
2 & $0.63(0.09)$ & $0.62(0.11)$ \\
3 & $0.63(0.08)$ & $0.64(0.09)$ \\
4 & $0.66(0.08)$ & $0.65(0.09)$ \\
5 & $0.62(0.06)$ & $0.61(0.07)$ \\
6 & $0.48(0.06)$ & $0.48(0.06)$ \\
7 & $0.61(0.06)$ & $0.62(0.08)$ \\
8 & $0.41(0.06)$ & $0.41(0.06)$ \\
9 & $0.50(0.05)$ & $0.52(0.06)$ \\
10 & $0.57(0.05)$ & $0.57(0.06)$
\end{tabular}


Table 6

Standardized item-factor loadings for the measurement model used to predict self-and teacher-reported prosocial behaviour

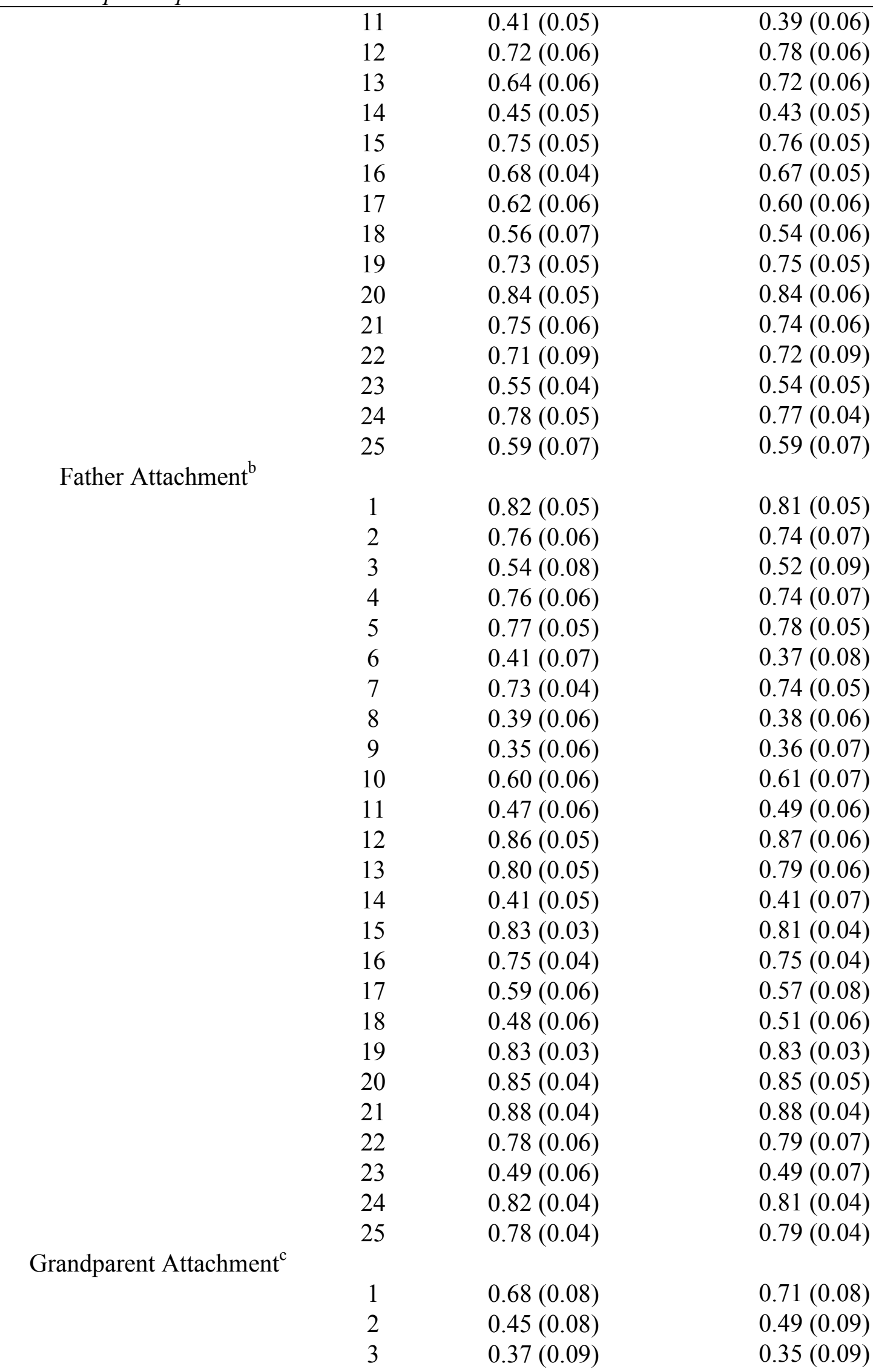


Table 6

Standardized item-factor loadings for the measurement model used to predict self-and teacher-reported prosocial behaviour

\begin{tabular}{|c|c|c|c|}
\hline & 4 & $0.51(0.08)$ & $0.53(0.10)$ \\
\hline & 5 & $0.68(0.05)$ & $0.70(0.05)$ \\
\hline & 6 & $0.35(0.06)$ & $0.32(0.07)$ \\
\hline & 7 & $0.66(0.06)$ & $0.67(0.05)$ \\
\hline & 8 & $0.35(0.06)$ & $0.33(0.07)$ \\
\hline & 9 & $0.20(0.07)$ & $0.21(0.07)$ \\
\hline & 10 & $0.19(0.07)$ & $0.18(0.08)$ \\
\hline & 11 & $0.35(0.05)$ & $0.34(0.05)$ \\
\hline & 12 & $0.73(0.07)$ & $0.75(0.08)$ \\
\hline & 13 & $0.70(0.06)$ & $0.72(0.07)$ \\
\hline & 14 & $0.39(0.05)$ & $0.38(0.06)$ \\
\hline & 15 & $0.76(0.04)$ & $0.77(0.04)$ \\
\hline & 16 & $0.66(0.04)$ & $0.68(0.04)$ \\
\hline & 17 & $0.45(0.08)$ & $0.44(0.09)$ \\
\hline & 18 & $0.42(0.06)$ & $0.44(0.07)$ \\
\hline & 19 & $0.71(0.04)$ & $0.69(0.04)$ \\
\hline & 20 & $0.80(0.05)$ & $0.80(0.06)$ \\
\hline & 21 & $0.76(0.05)$ & $0.75(0.06)$ \\
\hline & 22 & $0.67(0.08)$ & $0.67(0.09)$ \\
\hline & 23 & $0.55(0.06)$ & $0.54(0.06)$ \\
\hline & 24 & $0.72(0.04)$ & $0.71(0.05)$ \\
\hline & 25 & $0.72(0.05)$ & $0.71(0.05)$ \\
\hline \multicolumn{4}{|l|}{ Friend Attachment $^{\mathrm{d}}$} \\
\hline & 1 & $0.60(0.06)$ & $0.60(0.07)$ \\
\hline & 2 & $0.60(0.06)$ & $0.63(0.07)$ \\
\hline & 3 & $0.74(0.06)$ & $0.77(0.06)$ \\
\hline & 4 & $0.37(0.05)$ & $0.38(0.06)$ \\
\hline & 5 & $0.54(0.07)$ & $0.58(0.07)$ \\
\hline & 6 & $0.74(0.05)$ & $0.74(0.06)$ \\
\hline & 7 & $0.63(0.04)$ & $0.66(0.05)$ \\
\hline & 8 & $0.71(0.07)$ & $0.69(0.07)$ \\
\hline & 10 & $0.39(0.06)$ & $0.43(0.06)$ \\
\hline & 11 & $0.39(0.06)$ & $0.42(0.06)$ \\
\hline & 12 & $0.74(0.06)$ & $0.72(0.07)$ \\
\hline & 13 & $0.73(0.06)$ & $0.72(0.07)$ \\
\hline & 14 & $0.69(0.06)$ & $0.66(0.07)$ \\
\hline & 15 & $0.79(0.05)$ & $0.77(0.05)$ \\
\hline & 16 & $0.78(0.04)$ & $0.78(0.04)$ \\
\hline & 17 & $0.82(0.05)$ & $0.83(0.05)$ \\
\hline & 18 & $0.47(0.07)$ & $0.45(0.07)$ \\
\hline & 19 & $0.76(0.05)$ & $0.75(0.05)$ \\
\hline & 20 & $0.71(0.06)$ & $0.69(0.06)$ \\
\hline & 21 & $0.83(0.05)$ & $0.82(0.06)$ \\
\hline & 22 & $0.27(0.06)$ & $0.31(0.06)$ \\
\hline & 23 & $0.42(0.06)$ & $0.51(0.07)$ \\
\hline
\end{tabular}


Table 6

Standardized item-factor loadings for the measurement model used to predict self-and teacher-reported prosocial behaviour

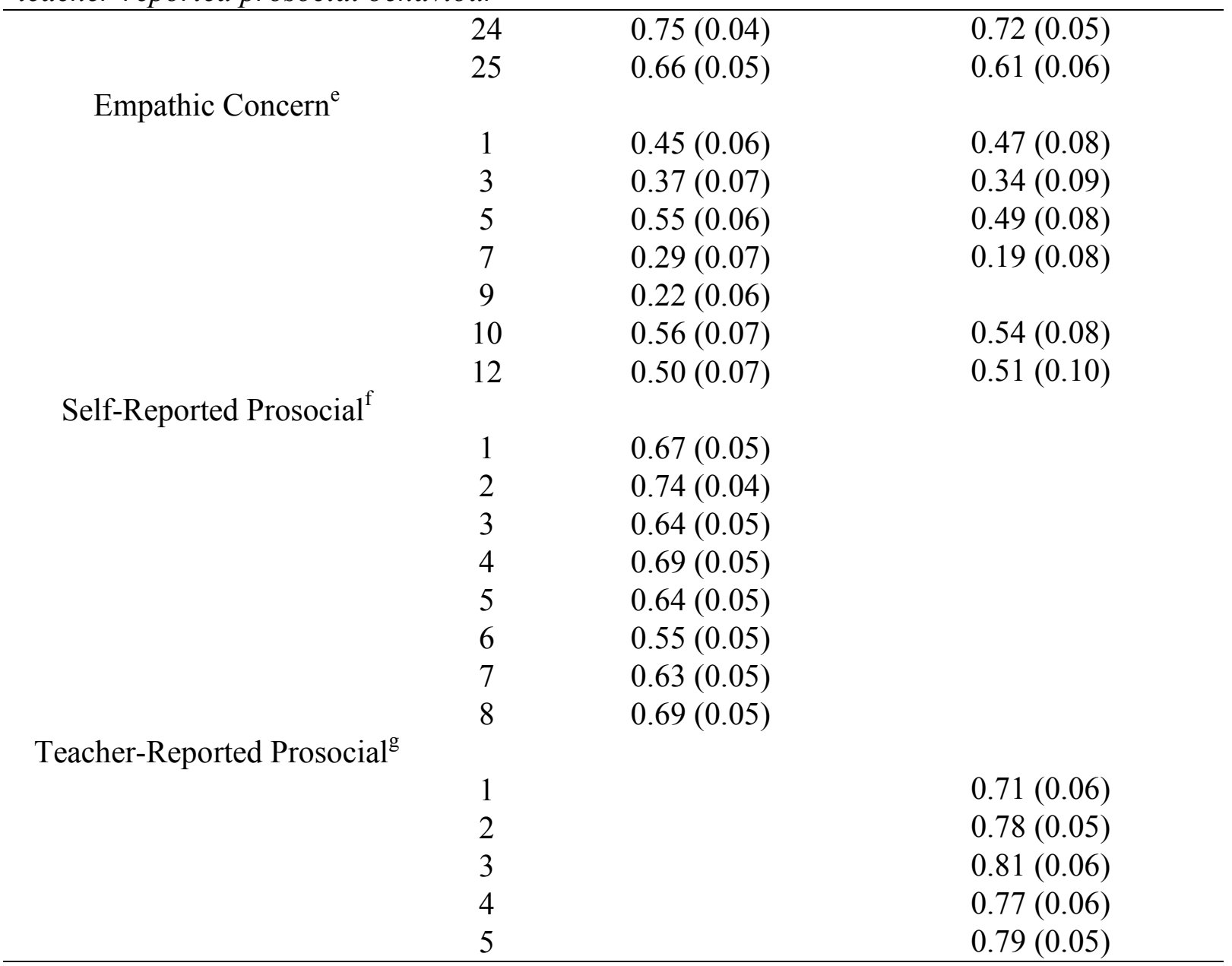

Note. All loadings are significant, $p<.05$.

a Pages 97-99

${ }^{b}$ Pages 100-102

${ }^{c}$ Pages 103-105

${ }^{\mathrm{d}}$ Pages 106-108

ePages 109-110

fPages 95-96

${ }^{\mathrm{g}}$ Appendix B

4.3.2. Path model. The hypothesized path model showed satisfactory fit to the data: $\chi_{\mathrm{M}}^{2}(6218)=8544.37, p<.05 ; \mathrm{CFI}=0.87 ; \mathrm{RMSEA}=0.033, C I[0.032,0.035] ; \mathrm{SRMR}=$ 0.065. The model, including the path coefficients, is presented in Figure 3. None of the direct paths between attachment and self-reported prosocial behaviour were significant, and therefore they were constrained to zero. This did not result in any difference to the fit of the model, $\Delta \chi^{2}(4)=2.73, p>.05$. With all of the attachment variables considered together, only friend attachment emerged as a unique, indirect influence on prosocial behaviour. As the 
security of attachment to friends increased, so self-reported prosocial behaviour increased via the mediation of empathic concern (indirect effect $\beta=0.38, p<0.01$ ).

4.3.3. Alternative model. When performing SEM analyses it is important to test equivalent models, since SEM can only tell whether or not the hypothesized model is a good fit to the data, and not whether alternative models are bad fits for the data (Kline, 2011). Therefore, an alternative model was specified in which empathic concern influences prosocial behaviour, which in turn influences the quality of attachment to mother, father, grandparent and friends. This was essentially a test of the temperament hypothesis, where it is the traits of the child that influences the quality of attachment, and not vice versa. The alternative model acquired similar fit to the hypothesized model: $\chi^{2}{ }_{\mathrm{M}}(6222)=8551.84, p<.05 ; \mathrm{CFI}=0.87$; RMSEA $=0.033,95 \% C I[0.032,0.035] ;$ SRMR $=0.065$. All of the paths from self-reported prosocial behaviour to attachment scores were significant.

\subsection{Structural Equation Model Predicting Teacher-reported Prosocial Behaviour}

4.4.1. Measurement model. As before, the initial CFA tested the a priori measurement model.

4.4.1.1. Model fit. The apriori measurement model evidenced promising fit according to the RMSEA and SRMR, but as before, $\chi^{2}{ }_{\mathrm{M}}$ was significant, $\chi^{2}{ }_{\mathrm{M}}(6089)=9748.38, p<.05$, and CFI was unsatisfactory at 0.75 . RMSEA was $0.047, C I[0.046,0.049]$ and SRMR was 0.071 .

4.4.1.2. Problematic items. As before, item 9 of the friend attachment scale loaded in an unexpected direction $(\beta=-0.08, p>.05)$, and this time did not load significantly onto the latent variable. In addition, item 9 from the empathic concern scale failed to load significantly onto its latent factor $(\beta=0.18, p>.05)$. The item reads, "When I see someone being treated unfairly, I sometimes don't feel very much pity for them", and its poor performance is likely due to its negative wording (Barnette, 2000) and verbosity. Both of these problematic items were removed from further analyses.

4.4.1.3. Item covariances. As before, most of the item-item covariances were between items of the same subscale or scale, and covariances between items from different scales seemed to reflect consistency in the perceptions of parenting and communication among attachment figures. The $R$ script containing all of the covariances can be downloaded from https://www.dropbox.com/s/x4ptb64tmxue5cl/Final\%20measurement\%20models.rar?dl=0. 
4.4.1.4. Modified model fit. The modified model showed improved fit: $\chi^{2}{ }_{M}(5804)=$ 8088.56, $p<.05 ; \mathrm{CFI}=0.84$; $\mathrm{RMSEA}=0.038, C I[0.036,0.040]$; $\mathrm{SRMR}=0.067$. The final measurement model is presented in Table 6.

4.4.2. Path model. The hypothesized path model showed satisfactory fit to the data: $\chi_{\mathrm{M}}^{2}(5804)=8088.56, p<.05 ; \mathrm{CFI}=0.84 ; \mathrm{RMSEA}=0.038, C I[0.036,0.040] ; \mathrm{SRMR}=0.067$. The model, including the path coefficients, is presented in Figure 3. None of the direct paths between attachment and self-reported prosocial behaviour were significant, and therefore they were constrained to zero. This did not result in any difference to the fit of the model, $\Delta \chi^{2}(4)=3.64, p>.05$. As before, only friend attachment emerged as an independent, significant influence on empathic concern. However, in this instance the total indirect effect for friend attachment on prosocial behaviour failed to reach significance $(\beta=0.07, p>.05)$.

4.4.3. Alternative model. As before, a model representing the temperament hypothesis was tested. This model also acquired satisfactory fit: $\chi^{2}{ }_{M}(5808)=8125.95, p<.05$; CFI $=0.84$; $\mathrm{RMSEA}=0.038, C I[0.036,0.040]$; SRMR $=0.072$. However, in this case only the path from teacher-reported prosocial behaviour to friend attachment was significant.

\subsection{Testing the Model on Secure vs. Ambivalent and Secure vs. Avoidant Subsamples}

As described earlier, the models obtained using the whole sample were tested on two subsamples, to determine whether attachment security predicts prosocial behaviour similarly when comparing secure and avoidant adolescents, and secure and ambivalent adolescents. Because friend attachment proved to be the strongest predictor in the whole-sample analyses, subsamples were created based on attachment style to friends. Eighty-nine percent of the sample could be classified using the criteria, which is a higher proportion of the sample than that classified by Armsden and Greenberg (1987). According to the criteria, $44 \%$ of the sample was securely attached to their friends, $30 \%$ was avoidantly attached, and $26 \%$ was ambivalently attached. Although these rates feature a lower proportion of secure individuals and a higher proportion of ambivalent individuals than is typically observed in population studies (Mickelson et al., 1997), they are somewhat more in line with population studies than were Armsden and Greenberg's (1987), where only 33\% of respondents were securely attached to their friends, $37 \%$ were avoidant, and 30\% were ambivalent. 


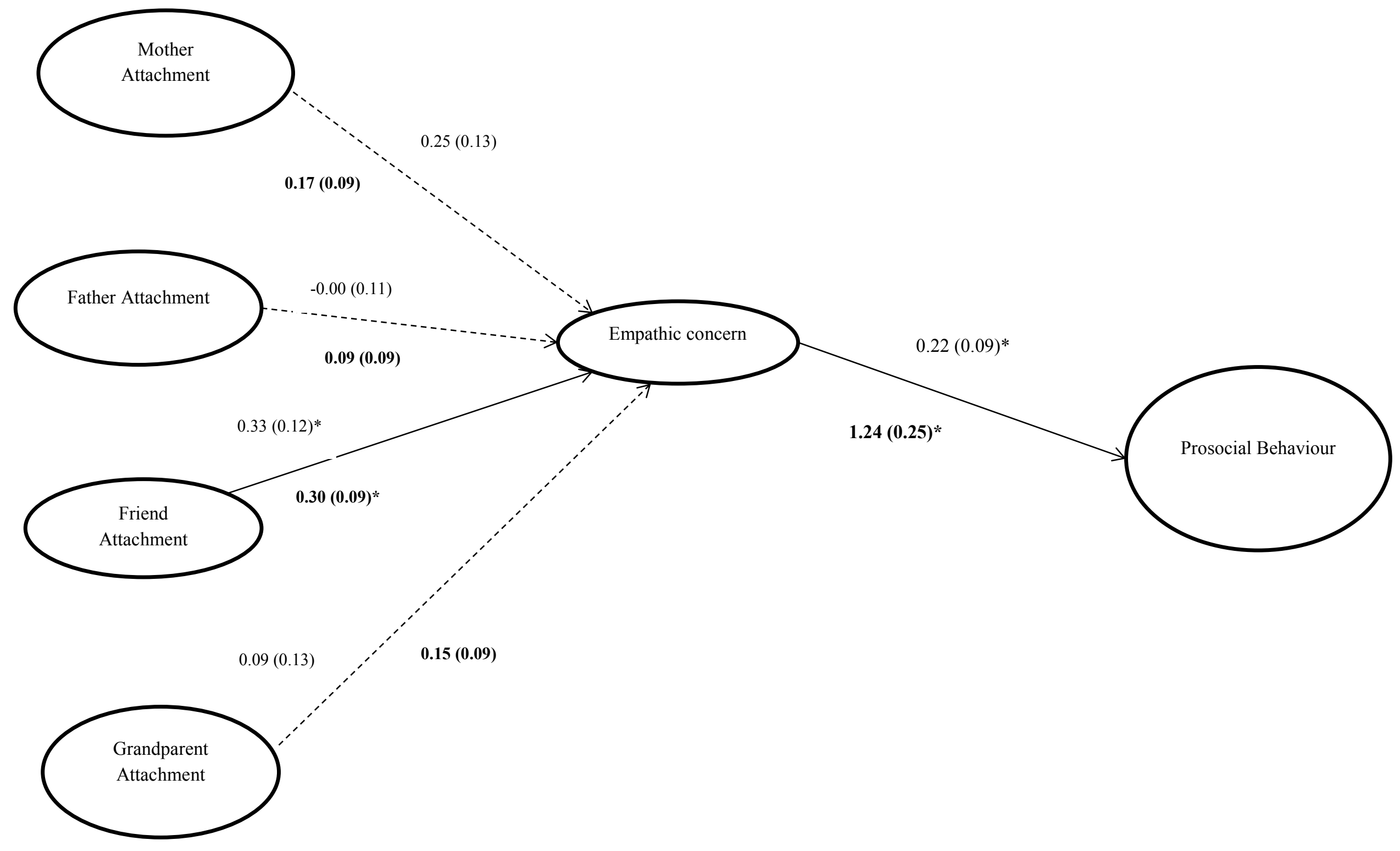

Figure 3. Results of the Structural Equation Models predicting self- and teacher-reported prosocial behaviour. Figures in bold represent the standardized betas for the model predicting self-reported prosocial behaviour. ${ }^{*} p<.05$. 
4.5.1. Model predicting self-reported prosocial behaviour. With self-reported prosocial behaviour as the outcome variable, the model obtained for the whole sample achieved satisfactory fit for both the secure vs. ambivalent and secure vs. avoidant subsamples. Fit indices for the secure vs. ambivalent subsample were as follows: $\chi^{2}{ }_{\mathrm{M}}(6245)$ $=9202.58, p<.05 ; \mathrm{CFI}=0.82 ; \mathrm{RMSEA}=0.038, C I[0.037,0.040]$; $\mathrm{SRMR}=0.066$. For the secure vs. avoidant subsample, fit indices were as follows: $\chi^{2}{ }_{\mathrm{M}}(6250)=8930.28, p<.05$; CFI $=0.88 ; \mathrm{RMSEA}=0.035, C I[0.034,0.037] ; \mathrm{SRMR}=0.063$. The model did not fit significantly differently between the two subsamples: $\Delta \chi^{2}(5)=1.42, p>.05$.

4.5.2. Model predicting teacher-reported prosocial behaviour. With teacherreported prosocial behaviour as the outcome variable, similar results were obtained. Fit indices for the secure vs. ambivalent subsample were as follows: $\chi^{2}{ }_{\mathrm{M}}(5912)=8889.06, p<.05$; $\mathrm{CFI}=0.82 ; \mathrm{RMSEA}=0.039, C I[0.038,0.041]$; SRMR $=0.066$. For the secure vs. avoidant subsample, fit indices were as follows: $\chi^{2}{ }_{\mathrm{M}}(5917)=8688.71, p<.05 ; \mathrm{CFI}=0.87$; RMSEA $=$ $0.037, C I[0.036,0.039]$; SRMR $=0.063$. Model fit did not differ significantly between the two subsamples: $\Delta \chi^{2}(5)=3.13, p>.05$. 


\section{CHAPTER 5: DISCUSSION AND CONCLUSION}

The results of this study generally supported the hypotheses. In line with hypothesis 1 , the zero-order correlations indicated that mother, father, closest grandparent and friend attachment were all significantly positively associated with empathic concern and selfreported prosocial behaviour. However, none of the attachment scores were significantly correlated with teacher-reported prosocial behaviour. Hypothesis 2 predicted on the basis of previous theoretical contentions that empathic concern would completely mediate the relationship between attachment scores and prosocial behaviour. This was supported in the Structural Equation Models, with both self-reported and teacher-reported prosocial behaviour as the outcome variables, by the fact that constraining the direct paths between attachment scores and prosocial behaviour to zero did not result in any significant difference to the models' fit. According to hypothesis 3, it was expected that either the monotropy or hierarchy models of multiple attachment figures would be supported regarding prosocial outcomes, in favour of friend attachment. Indeed, for both self-reported and teacher-reported prosocial behaviour friend attachment emerged as the sole significant predictor of empathic concern, in line with the monotropy model. Furthermore, for self-reported prosocial behaviour, but not teacher-reported prosocial behaviour, the indirect effect of friend attachment on prosocial behaviour was significant. Finally, in confirmation of hypothesis 4 , there was no significant difference between the fit of the theoretical model when comparing a subsample of secure and anxious-ambivalent adolescents and a subsample of secure and avoidant adolescents. In this chapter, these results are critically discussed and their implications are highlighted.

\subsection{Predicting Self-Reported Prosocial Behaviour}

Initial support for the hypotheses came from the zero-order correlations, which in line with hypothesis 1 indicated that all attachment scores were significantly positively associated with both empathic concern and self-reported prosocial behaviour. This further supports the findings of previous studies regarding the relationship between prosocial behaviour and mother attachment (Contreras et al., 2000; Markiewicz et al., 2001; Nickerson et al., 2008), as well as friend attachment (Laible, 2007; Laible et al., 2004). Furthermore, the significant zero-order correlation between grandparent attachment and prosocial behaviour is in line with the expectations borne out by studies on the relation between grandparent involvement and prosocial behaviour (Attar-Schwartz et al., 2009; Ellis et al., 2010; Profe \& Wild, 2015; Wild $\&$ Gaibie, 2014). That father attachment attained a significant positive correlation with 
prosocial behaviour is in fact contrary to previous findings (Markiewicz et al., 2001), though this may be a residual effect of the strong correlation between father and mother attachment.

5.1.1. Empathic concern as the mediator. Structural Equation Modelling allowed a further examination of the theoretical link between attachment and self-reported prosocial behaviour. In line with hypothesis 2 , empathic concern completely mediated the path from mother, father, closest grandparent and friend attachments to prosocial behaviour, confirming the expectations borne out by Bowlby's (1969) attachment theory. It also vindicates the expectations of theorists like Grusec and Davidov (2010) who considered the attachment domain of the parent-child relationship to influence children's response to the distress of others via its emotion regulatory influence on empathic concern tendencies. Such findings provide data consistent with the conviction of many attachment theorists to conceptualize attachment working models as emotion regulation strategies, and also support the utility of Eisenberg's (2009) insights into how emotion regulation strategies are likely to influence the development of empathic concern and prosocial behaviour. They also provide further support to previous studies indicating the mediating role of sympathy between attachment and prosocial behaviour (Carlo et al., 2010; Carlo et al., 2011; Laible, 2007; Laible et al., 2000; Thompson \& Gullone, 2008). Additionally, in line with hypothesis 4 empathic concern was a total mediator between attachment and prosocial behaviour when comparing secure and anxious-ambivalent adolescents, as well as when comparing secure and avoidant adolescents. Thus, although the two types of insecure attachment working models are theoretically expected to result in the opposite emotion regulation strategies, they have in common their deleterious effect on empathic concern tendencies.

5.1.2. The influence of friend attachment. Structural Equation Modelling also allowed a consideration of the combined influence of multiple attachment figures, thus providing evidence of the relative importance of the respective attachment figures to prosocial behaviour. In line with the expectations of the monotropy model, when all attachment figures were considered simultaneously, only one attachment relationship emerged as a significant independent influence on empathic concern. This finding is in line with and further supports the previous findings of Sagi-Schwartz and Aviezer (2005). Interestingly, this sole significant influence was friend attachment. This is consistent with the idea that during adolescence parents begin to decrease in their emotional and protective importance, whilst friends increase in importance (Creasey \& Kaliher, 1994; Markiewicz et al., 2006). It is also consistent with previous research which found that friend attachment emerges as the sole predictor of prosocial behaviour over parent attachment (Laible et al., 
2004; Rubin et al., 2004). In South Africa, the seventh grade is the final year of primary school, and in many schools learners remain in the same classes with one another throughout the duration of primary school. As such many of the young adolescents in this grade have spent a considerable amount of time with one another. Since attachment relationships are often formed in the context of frequent proximity (Nickerson \& Nagle, 2005), adolescents in the seventh grade have had a number of years to form strong, influential attachment bonds with one another. Thus it may be suggested that, at least in South Africa, the seventh grade is a particularly important time for considering the influence and prevalence of close friendship bonds. Future research might consider the question raised by some theorists (Weiss, 1982) as to whether friend attachment bonds are directed toward the friendship group as a whole, or towards particular individuals. The measure used in the current study certainly refers to friends in a general sense, but there is no way to determine whether adolescents answered with respect to the group or particularly salient individual friends. It must be noted that, in accordance with expectations regarding the hierarchy model, mother attachment consistently emerged as the predictor variable with the second-highest beta value, followed by closest grandparent attachment. However, these beta values failed to reach statistical significance. Given that previous studies indicating a significant relation between mother attachment and prosocial behaviour seldom account for friend attachment, this may encourage some caution when interpreting their findings.

\subsubsection{Findings regarding mother and father attachment. These results must} encourage a more nuanced investigation of the influence of parent attachment during early adolescence, rather than disregarding its importance altogether. Other research (Carlo et al., 2011) has found, contrary to the current results, that it is in fact parent attachment and not friend attachment that is the most important predictor of prosocial outcomes among adolescents. Thus it may be worth considering whether moderating factors influence the relative importance of attachment figures' influence on prosocial behaviour. For example, Freeman and Brown (2001) found that the relative importance of parent and friend attachments to adolescents was dependent on the individual combination of attachment (in)security experienced with each figure. Thus without taking these factors into consideration the results obtained from any given sample may be a function of the predominant pattern of relative attachment security to parents and friends. The issue of interindividual differences in attachment hierarchies is considered later under the study's limitations. Furthermore, the cross-sectional nature of the current study precludes a consideration of the influence of earlier parent attachment on the outcomes. Parent 
attachment, and especially mother attachment, is usually the first and most formative attachment relationship in early life, and has a profound influence on the ability of individuals to form secure attachments with other figures (Grossmann, Grossman, \& Kindler, 2005). Thus it may have been reasonable, with appropriate longitudinal data, to posit that the influence of parents in the journey to empathic concern and prosocial behaviour occurs temporally prior, in its influence on friend attachment, which then in turn influences prosocial behaviour contemporaneously. Thus at most it can be concluded that friend attachment is most important as a contemporaneous influence, but that other attachments are by no means inconsequential in the longitudinal development of prosocial tendencies.

However, this defence of the importance of parents may have more relevance for mothers, as the finding that father attachment had virtually no relation to the outcome variables when controlling for the other attachment figures was in line with expectations and previous research (Davidov \& Grusec, 2006; Markiewicz et al., 2001; Nickerson et al., 2008). There is no indication from previous research, or from the current data, that the concept of attachment is inappropriately applied to fathers. Indeed, father attachment scores had a similar distribution and mean to the other figures in this study. Moreover, father attachment was related in theoretically expected ways to outcome variables in the zero-order correlations. What can be concluded, however, is that contemporaneously and when taking mother, closest grandparent, and friend attachment into account, father attachment had little independent influence on prosocial outcomes. Research has generally suggested that paternal figures engage in different activities with children than maternal figures. Whereas mothers tend to participate in nurturing, affectionate and social activities with children, fathers are more likely to participate in physical, outdoor and challenging or risky activities with children (Newland et al., 2013). These differing activities may indeed lead to multiple disparate influential pathways to child outcomes, but in either case the concept of attachment is unchanged. After all, despite these differing activities children continue to see both their fathers and mothers as protectors and sources of safety (Newland et al., 2013). Thus, highlighting these differing activities and parenting styles serves to reiterate Thompson's (1999) contention, as well as the emphases of the independence model, that attachment to different figures forms in different contexts. Future research might consider how, whilst the attachment construct itself remains the same cross-contextually, the context in which it is formed influences the outcomes which it will produce. Fathers then, given their greater activity in outdoor and risk activity, might influence via attachment the emotion regulatory capacities of children in contexts of exploration (Sroufe et al., 2005). 
5.1.4. Findings regarding closest grandparent attachment. Although closest grandparent involvement emerged as the predictor variable with the third-highest beta value, this association failed to reach statistical significance. It is unfortunately difficult to compare these results with previous studies or to make a decisive ruling on the utility of considering the influence of the grandparent-grandchildren relationship from an attachment point of view, since previous studies into the influence of grandparents on prosocial behaviour did not control for friend relationships. The distribution and mean of grandparent attachment scores was similar to all of the other figures' scores, and related in expected ways to outcome variables in the zero-order correlations. Thus, all that could be said currently is that the influence of grandparent attachment on prosocial outcomes, as with mother and father attachment, fails to reach significance when concurrently considering friend attachment. This does not rule out the potential importance of grandparent attachment for prosocial outcomes in individual cases, nor does it rule out the possibility that grandparent attachment is influential in other outcome domains. For example, Levitt et al. (2002) found that grandparent attachment relationships were significantly associated with fewer adjustment problems among a middle-childhood sample, even when considering multiple other attachment figures. Thus it may be worth future research pursuing the influence of grandparent attachment in contexts where grandparents are likely to be more salient, such as grandparent-headed households (Poehlmann, 2003), or with regard to other child outcomes.

\subsection{Predicting Teacher-Reported Prosocial Behaviour}

5.2.1. Differences between the teacher-report and self-report models. The results for the model predicting teacher-reported prosocial behaviour did not differ in any substantial way from those for the model predicting self-reported prosocial behaviour. In both models, friend attachment emerged as the only significant predictor of empathic concern. However, one major difference is notable: whereas in the model predicting self-reported prosocial behaviour the indirect relationship between friend attachment and prosocial behaviour was significant, in the model predicting teacher-reported prosocial behaviour it was not. Even the zero-order correlations indicated that none of the attachment variables were significantly related to teacher-reported prosocial behaviour, partially contradicting hypothesis 1 . This raises the question as to which of the results is more accurate. Is this evidence that the selfreport of prosocial behaviour was subject to social desirability bias, whereas the teacherreport of prosocial behaviour was more accurate and challenged the theoretical expectations of the study? This contention is difficult to maintain, because bootstrapped skewness scores 
indicated that it was in fact the teacher-report scores that were most negatively skewed. In fact, the modal total score for teacher-reported prosocial behaviour was 15 (the highest possible score), and the median total score was 13/15. In other words, there was a greater tendency for teacher-reports to yield high prosocial behaviour scores than was the case for self-reports. This is inconsistent with the idea that teacher-reports were a more accurate buffer against self-report scores biased to be unrealistically high.

5.2.2. Problems with the teacher-reports. These results should not reflect poorly on teacher-reports in general, as teachers have often been relied upon as accurate sources of information with empirical support (Scourfield et al., 2004). Rather, it is likely that two primary factors influenced the unsatisfactory results of the teacher reports. First, the response format of the teacher-report may have been sub-optimal. Each item has only three response alternatives, in contrast to the five response alternatives afforded by all of the self-report measures. Some research suggests that having less than 5 response alternatives on a likert scale is both undesirable to respondents and deleterious to the reliability and validity of results (Preston \& Coleman, 2000). Indeed, during the data collection process some teachers did express difficulty choosing between the alternatives. A higher number of alternatives thus may have resulted in greater variability of the scores. Second, owing to time constraints data collection took place near the end of the first term of the South African school year, meaning in most cases that teachers had only known the participants for 2-3 months. Many teachers expressed difficulty in answering the questions because they did not consider themselves adequately familiar with the participants. All of the participating classes consisted of between 25 and 40 learners, and therefore it is understandable that teachers would have had insufficient time to get to know the behaviour of all of the participants comprehensively. These results should inspire due caution with studies involving teacher reports or observational data, as these measures could be just as vulnerable to biases based on insufficient knowledge as self-reports are to social desirability bias.

5.2.3. Implications of the teacher-report findings. Nevertheless, if these caveats are to be overlooked and anything is to be taken from the results for teacher-reported behaviour, it can only be that the need for theoretical specificity when studying prosocial behaviour is supported. Whereas the self-report measure was developed specifically to measure prosocial behaviours in the context of emotional distress, which was theoretically expected to be an outcome of attachment security (Grusec \& Davidov, 2010), the teacher-report was a global measure of prosocial behaviour. Therefore, these facts are noteworthy: (a) in contrast to selfreported prosocial behaviour, none of the attachment scores were correlated with teacher- 
reported prosocial behaviour; and (b) in contrast to the model predicting self-reported prosocial behaviour, none of the attachment scores yielded a significant indirect relationship with teacher-reported prosocial behaviour. These findings support some of the theoretical contentions noted in the introduction, namely that: (a) research should be specific as to the type of prosocial behaviour under investigation (Padilla-walker and Carlo, 2014); and (b) attachment theory should not be considered an explanation for the development of all types of prosocial behaviour (Sroufe et al., 2005). This contention is, however, in direct contrast to the findings of Carlo et al. (2011), who found that parental attachment was related to a variety of types of prosocial behaviour. More research is needed to clarify the extent of the influence that attachment has on different prosocial outcomes.

\subsection{Alternative Model}

An alternative model for both the self-reported and teacher-reported prosocial behaviour models which, in line with the temperament hypothesis earlier, posited that child characteristics were the precedents of attachment scores, obtained satisfactory fit scores. Given that the data used in this study is cross-sectional it need not be concluded that the hypothesized models are thrown into doubt by this finding, but merely that the data is consistent with what has always been proposed by the transactional model of development (Sameroff \& Chandler, 1975). According to this perspective, both parent and child characteristics mutually influence one another over the course of the child's development. Research has confirmed that child characteristics do indeed exert an influence over parental (Brody \& Ge, 2001), grandparental (Dolbin-Macnab \& Keiley, 2006), and friend behaviour (Rubin, Bowker, McDonald \& Menzer, 2013). However, without appropriate longitudinal data the current study cannot contribute anything substantial to the transactional hypothesis besides a cautionary reminder of its central tenets. Future studies may be advised to take a longitudinal approach in further understanding the role of attachment quality on adolescent outcomes.

\subsection{Limitations of the Current Study}

The results of the current study must be considered within the context of several inevitable limitations.

5.4.1. Inter-individual variation. In order to investigate the relative importance of different attachment relationships, the current study pre-determined the attachment figures to include and measured attachment security as a continuous construct. Unfortunately, this method limits the study's ability to interrogate inter-individual differences in the influence of 
attachment relationships in three primary ways. First, in line with Bretherton's (1990, as cited in Zimmermann, 1999) contention that attachment working models are often relationspecific, the manner in which the occurrence of different combinations of relationshipspecific working models influence outcomes cannot be considered. For example, does an anxious-ambivalent relationship with one's friends moderate the influence that a secure attachment to mothers would have on prosocial outcomes? As far as could be ascertained, no study has fully sought to investigate this particularly complex question except to say that the presence of many relationship-specific secure working models are better than few (Levitt, 2005).

Second, as has been noted earlier, the context in which attachment relationships are formed is important (Thompson, 1999). Might the relative influence of attachment figures on prosocial outcomes differ according to family, social, or economic context? The current sample had a clear majority (56\%) of adolescents from nuclear families, and thus the results may be predominantly reflective of adolescents from this family context. Similarly, the racial distribution of the sample was not representative of the broader population of the Western Cape or South Africa. Although 33\% of the Western Cape population identify as black African (Statistics South Africa, 2012), only 5\% of the current participants were black African. Over $36 \%$ of the current sample identified as white, which is more than double the proportion of white people in the Western Cape population (Statistics South Africa, 2012). There is no conceivable theoretical reason to suppose that the attachment behavioural system should differ in its influences or effects across racial lines. After all, many of Ainsworth's (1967) insights into attachment, which she later applied to North American infants, were derived from her observations of Ugandan infants. Research seems to confirm that the influence of attachment is not moderated by racial characteristics (Levitt, 2005; Rice, Cunningham, \& Young, 1997). However, in South Africa race is confounded with various other social, familial and economic variables. It has already been noted that in South Africa, there are notable differences between the family compositions of white children and their black African and coloured counterparts (Amoateng \& Heaton, 2015; Harper \& Seekings, 2010). Thus, the low proportion of black African participants may limit the generalizability of the findings because of the different family contexts prominent among different races. It cannot be stated with confidence whether adolescents from households in which grandparents are either primary or secondary caregivers (collectively comprising $13 \%$ of the sample) evidence different patterns of influence from grandparental attachment. Nor can it be said how attachment influences might change for adolescents from households lacking one parent 
(12\% of the sample), or adolescents from step-families ( $6 \%$ of the sample). Again, as far as the current researcher knows previous research has been largely silent on this matter. Qualitative research interrogating the relationship structures of adolescents from different family structures might provide clues about differing attachment hierarchies.

Third and finally, the pre-selection of attachment figures for the sake of comparability may: (a) inappropriately apply the attachment concept to figures that for some respondents do not fit the role of attachment figures; and (b) leave out certain figures that are important attachment figures to some respondents. For example, some research (Seibert \& Kerns, 2009) suggests that siblings are important attachment figures for many adolescents, and thus future research should also consider their influence on adolescent outcomes. Furthermore, although previous research suggests that in many cases grandparents can be considered attachment figures (Kornhaber \& Woodward, 1981), other research with North American samples indicates that grandparents may only be close enough to grandchildren to be considered attachment figures in about 50\% of cases (Levitt, 2005). This was borne out in the current research by the fact that some respondents indicated on their questionnaires that they did not know their grandparents well enough to answer some of the grandparent attachment questions. However, it should also be said that the prominence of grandparents in South African households (Harper \& Seekings, 2010), in comparison to North American households (Jacobsen, Mather, \& Dupuis, 2012), may increase the proportion of participants with grandparent attachment figures in South African samples.

5.4.2. Self-report biases. Although self-reports of prosocial behaviour appeared to be less biased towards high scores than teacher-reports in this study, this is no proof that selfreports were not nevertheless corrupted by social-desirability bias. Similarly, all of the other measures used in the current study were self-reports, and were thus also susceptible to bias. With something as subjective as empathic concern, the use of self-reports is perhaps unavoidable. It could also be argued that the perceptions of children regarding their caregivers, rather than some objective measure of attachment, would be most reflective of children's relationships with caregivers and most influential on their developmental outcomes (Fletcher, Steinberg, \& Williams-Wheeler, 2004). However, this argument may be countered with the fact that child self-reports of attachment such as the IPPA are subject to parental idealisation (Maier, Bernier, Pekrun, Zimmermann, \& Grossmann, 2004). This risk is even more real when considering attachment-related strategies, since parental idealisation is one of the strategies considered common amongst avoidant individuals as a means to suppress painful attachment-related memories (Creasey \& Ladd, 2004). More indirect measures of 
attachment working models such as the Adult Attachment Interview (George, Kaplan, \& Main, 1985) may be less susceptible to this bias, but this measure is considerably more timeconsuming than the IPPA and requires expert training, and therefore was not feasible for the current study.

5.4.3. Age-related changes. Finally, although the present study provides a much needed extension of attachment research among young adolescents, the constraints of the sample's age entails that the results should not be generalized to other ages. It is generally accepted that the hierarchy of attachment figures changes during the course of the lifespan, beginning most often with parents at the place of prominence during early childhood, followed by friends during adolescence, and then by romantic partners during late adolescence/early adulthood (Markiewicz et al., 2006). Thus it is sensible that in the current findings friends emerged as the primary influencers of prosocial behaviour, but it is impossible to infer that this would be the case in every life stage. As discussed earlier, parents may exert a lasting influence beginning in early life, even though their contemporaneous influence may attenuate in later life stages, and as such may be most influential on contemporaneous prosocial outcomes in the pre-adolescent period. In young adulthood, research has considered the influence of romantic partner attachment on prosocial/supportive behaviour within the dyad (Carnelley, Pietromonaco, \& Jaffe, 1996; Kunce \& Shaver, 1994; Simpson, Rholes, \& Nelligan, 1992), but not how this may influence prosocial behaviour more generally. Hopefully in future more extensive research will clarify the shifting importance of various attachment figures for prosocial development across the lifespan.

\subsection{Strengths of the Current Study.}

Despite these limitations, the current study provides an informative contribution to the existing attachment literature using a large, South African sample and a robust statistical technique. It is one of very few studies to separately consider the influence of multiple attachment figures, and as such is an important departure from the failure of previous research to do so (Levitt, 2005). Thus the methods, results, strengths and limitations of the current study provide important insights for future studies.

5.5.1. Theoretical specificity. Although attachment theory has very seldom been used to understand prosocial development (Eisenberg et al., 2006), the current study used contemporary theoretical and empirical insights from attachment theory to conceptualize one manner in which important figures in the lives of children may influence the development of prosocial behaviour. That the results were consistent with these theoretical expectations 
provides an empirical justification for future studies to address the many unanswered questions that remain. Following Padilla-Walker and Carlo (2014), the current study also departed from theoretically uninformative global measures of prosocial behaviour, choosing instead to be specific about the type of prosocial behaviour under investigation. The global measure of teacher-reported prosocial behaviour used, which was not related to any of the attachment scores, provided tentative support for the importance of defining prosocial outcomes carefully. By continuing this trend, future research may aid in the development of a much more nuanced and comprehensive understanding of how varying socialization experiences influence varying prosocial outcomes.

5.5.2. Consideration of multiple attachment figures. By considering multiple attachment figures, the findings of this study have supported the importance of close friendship bonds in the young adolescent life stage for the development of prosocial responses to the distress of others. Thus, on the basis of these findings schools, child-care workers and parents might be recommended to implement interventions that encourage the development of close, secure attachment bonds to same-age peers or close friends. Experimental research provides evidence for the potential beneficial effects of such interventions. Mikulincer et al. $(2001,2005)$ have found that the contextual activation of attachment security facilitates empathic concern for others as well as actual prosocial behaviour toward others. Furthermore, interventions have already been applied successfully to improve the attachment security of young children (Bakersmans-Kranenburg, Van Ijzendoorn, \& Juffer, 2003) and adolescents (Keiley, 2002) to their parents. Thus practitioners would do well to consider how such interventions could be applied to the friendship context among young adolescents. It may be tempting to wonder why those invested in the development of adolescents should be particularly concerned with encouraging prosocial responsiveness to the distress of others. However, considering that $57 \%$ of South African school children experience school-based bullying (" $57 \%$ of SA children claim to have been bullied at school," 2013), encouraging this sort of prosocial behaviour may be of great relevance.

\subsection{Conclusion}

Attachment theory has for a long time provided an important insight into how individuals' close relationships might influence their development. However, as contemporary research attempts to shift its emphasis from problematic development to understanding positive development, attachment theory has seldom been utilized to aid this 
understanding. Furthermore, almost 50 years after Bowlby (1969) first explicated attachment theory, there is still very little understanding of how multiple attachment relationships concurrently influence outcomes. Using a sample of South African adolescents between the ages of 11 and 14, the results of this study have yielded several important insights. The conceptualization of attachment working models as emotion regulation strategies aided in the process of understanding how attachment security may increase the likelihood that early adolescents would respond prosocially to others in distress via its facilitation of greater empathic concern. The results were consistent with these insights. Furthermore, by considering the influence of multiple attachment figures, the results highlight the importance of early adolescents having secure attachment relationships with their friends. Although the study's novel consideration of the influence of grandparent attachment was unable to provide any definitive answers regarding their contribution to adolescent prosocial development, the results emphasise the importance of controlling for the influences of friendships, and considering the family context when exploring the influences of grandparent attachment. Cumulatively, the results support the idea that as children reach the beginning of the adolescent phase, a due emphasis on facilitating their participation in healthy, close and secure friendships is advisable. By doing so, the findings of this study suggest that early adolescents will be more likely to develop an other-oriented concern for others that results in helping those in need. 


\section{REFERENCES}

$57 \%$ of SA children claim to have been bullied at school. (2013, January 24). Times Live.

Retrieved from http://www.timeslive.co.za/local/2013/01/24/57-of-sa-children-claimto-have-been-bullied-at-school

Ainsworth, M.D.S. (1967). Infancy in Uganda: Infant care and the growth of love. Oxford, England: John Hopkins Press.

Ainsworth, M.D.S. (1982). Attachment: Retrospect and prospect. In C.M. Parks \& J. Stevenson-Hinde (Eds.), The place of attachment in human behaviour (pp. 3-30). London, England: Tavistock Publications.

Ainsworth, M.D.S., Blehar, M.C., Waters, E., \& Wall, S. (1978). Patterns of attachment: Assessed in the strange situation and at home. New York, NY: Erlbaum.

Allen, J.P., \& Land, D. (1999). Attachment in adolescence. In J. Cassidy \& P.R. Shaver (Eds.), Handbook of attachment: Theory, research, and clinical applications (pp. 319335). New York, NY: Guilford Press.

Allen, J.P., \& Miga, E.M. (2010). Attachment in adolescence: A move to the level of emotion regulation. Journal of Social and Personal Relationships, 27, 181-190.

Amoateng, A.Y., \& Heaton, T.B. (2015). Changing race differences in family structure and household composition in South Africa. South African Review of Sociology, 46, 59-79.

Amoateng, A. Y., \& Richter, L. M. (2007). Social and economic context of families and households in South Africa. In A. Y. Amoateng, \& T. B. Heaton (Eds.), Families and households in post-apartheid South Africa: Socio-demographic perspectives (pp. 1-25). Cape Town, South Africa: HSRC Press.

Armsden, G., \& Greenberg, M.T. (1987). The Inventory of Parent and Peer Attachment: Individual differences and their relationship to psychological wellbeing in adolescence. Journal of Youth and Adolescence, 16, 427-454.

Armsden, G. (1986). Attachment to parents and peers in late adolescence: Relationships to affective status, self-esteem, and coping with loss, threat and challenges (Unpublished doctoral dissertation). University of Washington, Seattle, WA.

Attar-Schwartz, S., Tan, J-P. \& Buchanan, A. (2009). Adolescents' perspectives on relationships with grandparents: The contribution of adolescent, grandparent, and parent-grandparent relationship variables. Children and Youth Services Review, 31, 1057-1066. 
Attar-Schwartz, S., Tan, J-P., Buchanan, A., Flouri, E., \& Griggs, J. (2009). Grandparenting and adolescent adjustment in two-parent biological, lone-parent, and step-families. Journal of Family Psychology, 23, 67-75.

Bakermans-Kranenburg, M.J., Van Ijzendoorn, M.H., \& Juffer, F. (2003). Less is more: Meta-analyses of sensitivity and attachment interventions in early childhood. Psychological Bulletin, 129, 195-215.

Barnett, M.A., Neppl, T.K., Scaramella, L.V., Ontai, L.L., \& Conger, R.D. (2010). Grandmother involvement as a protective factor for early childhood social adjustment. Journal of Family Psychology, 24, 635-645.

Barranti, C.C.R. (1985). The grandparent/grandchild relationship: Family resource in an era of voluntary bonds. Family Relations, 34, 343-352.

Bartholomew, K., \& Horowitz, L.M. (1991). Attachment styles among young adults: A test of a four-category model. Journal of Personality and Social Psychology, 61, 226-244.

Becker, A., Steinhausen, H.C., Baldursson, G., Dalsgaard, S., Lorenzo, M.J., Ralston, S.J., Döpfner, M., Rothenberger, A., \& ADORE Study Group (2006). Psychopathological screening of children with ADHD: Strengths and Difficulties Questionnaire in a panEuropean study. European Child and Adolescent Psychiatry, 15, 56-62.

Berant, E., Mikulincer, M., Shaver, P.R., \& Segal, Y. (2005). Rorschach correlates of selfreported attachment dimensions: Dynamic manifestations of hyperactivating and deactivating strategies. Journal of Personality Assessment, 84, 70-81.

Botcheva, L.B., \& Feldman, S.S. (2004). Grandparents as family stabilizers during economic hardship in Bulgaria. International Journal of Psychology, 39, 157-168.

Bowlby, J. (1969). Attachment and loss: Vol. 1. Attachment. New York, NY: Basic Books.

Brent, D., Melhem, N., Donohoe, M.B., \& Walker, M. (2009). The incidence and course of depression in bereaved youth 21 months after the loss of a parent to suicide, accident, or sudden natural death. American Journal of Psychiatry, 166, 786-794.

Bretherton, I. (1985). Attachment theory: Retrospect and prospect. Monographs of the Society for Research in Child Development, 50, 3-35.

Brody, G.H., \& Ge, X. (2001). Linking parenting processes and self-regulation to psychological functioning and alcohol use during early adolescence. Journal of Family Psychology, 15, 82-94.

Caprara, G.V., Barbaranelli, C., Pastorelli, C., Bandura, A., \& Zimbardo, P.G. (2000). Prosocial foundations of children's academic achievement. Psychological Science, 11, 302-306. 
Carlo, G., \& Randall, B.A. (2002). The development of a measure of prosocial behaviours for late adolescents. Journal of Youth and Adolescence, 31, 31-44.

Carlo, G., Crockett, L.J., Randall, B.A., \& Roesch, S.C. (2007). A latent growth curve analysis of prosocial behaviour among rural adolescents. Journal of Research on Adolescence, 17, 301-324.

Carlo, G., Hausmann, A., Christiansen, S., \& Randall, B.A. (2003). Sociocognitive and behavioural correlates of a measure of prosocial tendencies for adolescents. Journal of Early Adolescence, 23, 107-134.

Carlo, G., Knight, G.P., McGinley, M., \& Hayes, R. (2011). The roles of parental inductions, moral emotions, and moral cognitions in prosocial tendencies among Mexican American and European American early adolescents. Journal of Early Adolescence, 31, 757-781.

Carlo, G., Knight, G.P., McGinley, M., Zamboanga, B.L., \& Jarvis, L.H. (2010). The multidimensionality of prosocial behaviours and evidence of measurement equivalence in Mexican American and European American early adolescents. Journal of Research on Adolescence, 20, 334-358.

Carlo, G., McGinley, M., Hayes, R.C., \& Martinez, M.M. (2011). Empathy as a mediator of the relations between parent and peer attachment and prosocial and physically aggressive behaviours in Mexican American college students. Journal of Social and Personal Relationships, 29, 337-357.

Carlo, G., McGinley, M., Hayes, R., Batenhorst, C., \& Wilkinson, J. (2007). Parenting styles or practices? Parenting, sympathy, and prosocial behaviours among adolescents. The Journal of Genetic Psychology, 168, 147-176.

Carlo, G., Mestre, V., Mcginley, M., \& Samper, P. (2014). The protective role of prosocial behaviours on antisocial behaviours: The mediating effects of deviant peer affiliation. Journal of Adolescence, 37, 359-366.

Carlo, G., Mestre, M.V., Samper, P., Tur, A., \& Armenta, B.E. (2010). Feelings or cognitions? Moral cognitions and emotions as longitudinal predictors of prosocial and aggressive behaviours. Personality and Individual Differences, 48, 872-877.

Carnelley, K.B., Pietromonaco, P.R., \& Jaffe, K. (1996). Attachment, caregiving, and relationship functioning in couples: Effects of self and partner. Personal Relationships, $3,257-278$.

Cassidy, J. (1994). Emotion regulation: Influences of attachment relationships. Monographs of the Society for Research in Child Development, 59, 228-249. 
Cassidy, J., Kirsh, S.J., Scolton, K.L., \& Parke, R.D. (1996). Attachment and representations of peer relationships. Developmental Psychology, 32, 892-904.

Chou, C-P., \& Bentler, P.M. (1995). Estimates and tests in Structural Equation Modelling. In R.H. Hoyle (Ed.), Structural Equation Modelling (pp. 37-55). Thousand Oaks, CA: Sage.

Cluver, L., \& Gardner, F. (2006). The psychological well-being of children orphaned by AIDS in Cape Town, South Africa. Annals of General Psychiatry, 5. 8. doi: $10.1186 / 1744-859 X-5-8$.

Cole, P.M., Michel, M.K., \& Teti, L.O. (1994). The development of emotion regulation and dysregulation: A clinical perspective. Monographs of the Society for Research in Child Development, 59, 73-100.

Coleman, P.K. (2003). Perceptions of parent-child attachment, social self-efficacy, and peer relationships in middle childhood. Infant and Child Development, 12, 351-368.

Collins, N.L. (1996). Working models of attachment: Implications for explanation, emotion and behaviour. Journal of Personality and Social Psychology, 71, 810-832.

Collins, N.L., Ford, M.B., Guichard, A.C., \& Allard, L.M. (2006). Working models of attachment and attribution processes in intimate relationships. Personality and Social Psychology Bulletin, 32, 201-219.

Contreras, J.M., Kerns, K.A., Weimer, B.L., Gentzler, A.L., \& Tomich, P.L. (2000). Emotion regulation as a mediator of associations between mother-child attachment and peer relationships in middle childhood. Journal of Family Psychology, 14, 111-124.

Cozby, P. C. (2009). Methods in Behavioral Research (10th ed.). New York, NY: McGrawHill.

Creasey, G.L., \& Kaliher, G. (1994). Age differences in grandchildren's perceptions of relations with grandparents. Journal of Adolescence, 17, 411-426.

Creasey, G., \& Ladd, A. (2004). Negative mood regulation expectancies and conflict behaviours in late adolescent college student romantic relationships: The moderating role of generalized attachment representations. Journal of Research and Adolescence, $14,235-255$.

Creasey, G., Kershaw, K., \& Boston, A. (1999). Conflict management with friends and romantic partners: The role of attachment and negative mood regulation expectancies. Journal of Youth and Adolescence, 28, 523-543. 
Crick, N.R. (1996). The role of overt aggression, relational aggression, and prosocial behaviour in the prediction of children's future social adjustment. Child Development, 67, 2317-2327.

Davidov, M., \& Grusec, J.E. (2006). Untangling the links of parental responsiveness to distress and warmth to child outcomes. Child Development, 77, 44-58.

Davis, M.H. (1980). A multidimensional approach to individual differences in empathy. JSAS Catalogue of Selected Documents in Psychology, 10, 85-104.

Davis, M.H. (1983). Measuring individual differences in empathy: Evidence for a multidimensional approach. Journal of Personality and Social Psychology, 44, 113126.

De Wolff, M.S., \& Van Ijzendoorn, M.H. (1997). Sensitivity and attachment: A metaanalysis on parental antecedents of infant attachment. Child Development, 68, 571-591.

Delhaye, M., Kempenaers, C., Stroobants, R., Goossens, L., \& Linkowski, P. (2013). Attachment and socio-emotional skills: A comparison of depressed inpatients, institutionalized delinquents and control adolescents. Clinical Psychology and Psychotherapy, 20, 424-433.

Dolbin-MacNab, M.L., \& Keiley, M.K. (2006). A systemic examination of grandparents' emotional closeness with their custodial grandchildren. Research in Human Development, 3, 59-71.

Doyle, A.B., Lawford, H., \& Markiewicz, D. (2009). Attachment style with mother, father, best friend, and romantic partner during adolescence. Journal of Research on Adolescence, 19, 690-714.

Dunifon, R., \& Bajracharya, A. (2012). The role of grandparents in the lives of youth. Journal of Family Issues, 33, 1168-1194.

Dykas, M.J., \& Cassidy, J. (2011). Attachment and the processing of social information across the lifespan: Theory and evidence. Psychological Bulletin, 137, 19-46.

Dykas, M.J., Ziv, Y., \& Cassidy, J. (2008). Attachment and peer relations in adolescence. Attachment \& Human Development, 10, 123-141.

Eberly, M.B., \& Montemayor, R. (1999). Adolescent affection and helpfulness toward parents: A 2-year follow-up. Journal of Early Adolescence, 19, 226-248.

Eisenberg, N., \& Spinrad, T.L. (2014). Multidimensionality of prosocial behaviour: Rethinking the conceptualization and development of prosocial behaviour. In L.M. Padilla-Walker, \& G. Carlo (Eds.), Prosocial development: A multidimensional approach (pp. 17-39). New York, NY: Oxford University Press. 
Eisenberg, N. (2009). Empathy-related responding: Links with self-regulation, moral judgment, and moral behaviour. In M. Mikulincer, \& P.R. Shaver (Eds.), Prosocial motives, emotions, and behaviour: The better angels of our nature (129-148). Washington, DC: American Psychological Association.

Eisenberg, N., Champion, C., \& Ma, Y. (2004). Emotion-related regulation: An emerging construct. Merrill-Palmer Quarterly, 50, 236-259.

Eisenberg, N., Fabes, R.A., \& Spinrad, T.L. (2006). Prosocial development. In N. Eisenberg (Ed.), Handbook of child psychology, volume 3: Social, emotional, and personality development (6th ed.) (pp. 646-718). Hoboken, NJ: John Wiley \& Sons, Inc.

Eisenberg, N., Fabes, R.A., Miller, P.A., Fultz, J., Shell, R., Mathy, R.M., \& Reno, R.R. (1989). Relation of sympathy and personal distress to prosocial behaviour: A multimethod study. Journal of Personality and Social Psychology, 57, 55-66.

Eisenberg, N., Fabes, R., Miller, P.A., Shell, R., Shea, C., \& May-Plumlee, T. (1990).

Preschoolers' vicarious emotional responding and their situational and dispositional prosocial behaviour. Merrill-Palmer Quarterly, 36, 507-529.

Eisenberg, N., Fabes, R.A., Murphey, B., Maszk, P., Smith, M., \& Karbon, M. (1995). The role of emotionality and regulation in children's social functioning: A longitudinal study. Child Development, 66, 1360-1384.

Eisenberg, N., Fabes, R.A., Murphy, B., Karbon, M., Maszk, P., Smith, M., O’Boyle, C., \& Suh, K. (1994). The relations of emotionality and regulation to dispositional and situational empathy-related responding. Journal of Personality and Social Psychology, 66, 776-797.

Eisenberg, N., Fabes, R.A., Murphy, B., Karbon, M., Smith, M., \& Maszk, P. (1996). The relations of children's dispositional empathy-related responding to their emotionality, regulation, and social functioning. Developmental Psychology, 32, 195-209.

Eisenberg, N., Fabes, R.A., Schaller, M., Carlo, G., \& Miller, P.A. (1991). The relations of parental characteristics and practices to children's vicarious emotional responding. Child Development, 62, 1393-1408.

Eisenberg, N., Fabes, R.A., Schaller, M., Miller, P., Carlo, G., Poulin, R., Shea, C., \& Shell, R. (1991). Personality and socialization correlates of vicarious emotional responding. Journal of Personality and Social Psychology, 61, 459-470.

Eisenberg, N., Fabes, R.A., Shepard, S.A., Murphy, B.C., Jones, S., \& Guthrie, I.K. (1998). Contemporaneous and longitudinal prediction of children's sympathy from dispositional regulation and emotionality. Developmental Psychology, 34, 910-924. 
Eisenberg, N., Fabes, R.A., Shepard, S.A., Murphy, B.C., Guthrie, I.K., Jones, S., Friedman, J., Poulin, R., \& Maszk, P. (1997). Contemporaneous and longitudinal prediction of children's social functioning from regulation and emotionality. Child Development, 68, 642-664.

Eisenberg, N., Schaller, M., Fabes, R.A., Bustamante, D., Mathy, R.M., Shell, R., \& Rhodes, K. (1988). Differentiation of personal distress and sympathy in children and adults. Developmental Psychology, 24, 766-775.

Eisenberg, N., Wentzel, M., \& Harris, J.D. (1998). The role of emotionality and regulation in empathy-related responding. School Psychology Review, 27, 506-521.

Ellis, C., Quist, M., Robinson, R., \& Peterson, D. (2010). Grandparent/grandchild relationship: Linking grandparent involvement to adolescent prosocial behaviours. FHSS Mentored Research Conference. Book 58. Retrieved from http://scholarsarchive.byu.edu/fhssconference_studentpub/58

Enders, C.K., \& Bandalos, D.L. (2001). The relative performance of full information maximum likelihood estimation for missing data in Structural Equation Models. Structural Equation Modelling, 8, 430-457.

Engels, R.C.M.E., Finkenauer, C., Meeus, W., \& Deković, M. (2001). Parental attachment and adolescents' emotional adjustment: The associations with social skills and relational competence. Journal of Counselling Psychology, 48, 428-439.

Fabes, R.A., Eisenberg, N., \& Eisenbud, L. (1993). Behavioural and physiological correlates of children's reactions to others in distress. Developmental Psychology, 29, 655-663.

Fabes, R.A., Eisenberg, N., Karbon, M., Troyer, D., \& Switzer, G. (1994). The relations of children's emotion regulation to their vicarious emotional responses and comforting behaviours. Child Development, 65, 1678-1693.

Fletcher, A.C., Steinberg, L., \& Williams-Wheeler, M. (2004). Parental influences on adolescent problem behaviour: Revisiting Stattin and Kerr. Child Development, 75 , 781-796.

Flouri, E., Buchanan, A., Tan, J-P., Griggs, J., \& Attar-Schwartz, S. (2010). Adverse life events, area socio-economic disadvantage, and adolescent psychopathology: The role of closeness to grandparents in moderating the effect of contextual stress. Stress, 13, 402412.

Fraley, R.S., \& Shaver, P.R. (1997). Adult attachment and the suppression of unwanted thoughts. Journal of Personality and Social Psychology, 73, 1080-1091. 
Freeman, H., \& Brown, B.B. (2001). Primary attachment to parents and peers during adolescence: Differences by attachment style. Journal of Youth and Adolescence, 30, 653-674.

George, C., Kaplan, N., \& Main, M. (1985). Adult Attachment Interview protocol (2 ${ }^{\text {nd }}$ ed.). Unpublished manuscript, University of California, Berkeley, CA.

Gillath, O., Bunge, S.A., Shaver, P.R., Wendelken, C., \& Mikulincer, M. (2005).

Attachment-style differences in the ability to suppress negative thoughts: Exploring the neural correlates. NeuroImage, 28, 835-847.

Giordano, P.C. (2003). Relationships in adolescence. Annual Review of Sociology, 29, 257281.

Goodman, R. (1997). The Strengths and Difficulties Questionnaire: A research note. Journal of Child Psychology and Psychiatry, 38, 581-586.

Goodman, R., Meltzer, H., \& Bailey, V. (1998). The strengths and difficulties questionnaire: A pilot study of the validity of the self-report version. European Child and Adolescent Psychiatry, 7, 125-130.

Greener, S.H. (2000). Peer assessment of children's prosocial behaviour. Journal of Moral Education, 29, 47-60.

Griggs, J., Tan, J-P., Buchanan, A., Attar-Schwartz, S., \& Flouri, E. (2010). 'They’ve always been there for me': Grandparental involvement and child well-being. Children \& Society, 24, 200-214.

Gross, J.J. (2008). Emotion regulation. In M. Lewis, J.M. Haviland-Jones, \& Barrett L.F. (Eds.), Handbook of emotions (3rd ed.). New York, NY: Guilford Press.

Grossmann, K., Grossmann, K.E., \& Kindler, H. (2005). Early care and the roots of attachment and partnership representations: The Bielefeld and Regensburg studies. In K.E. Grossmann, K. Grossmann, \& E. Waters (Eds.), Attachment from infancy to adulthood: The major longitudinal studies (pp. 98-136). New York, NY: Guilford Press.

Grusec, J.E., \& Davidov, M. (2010). Integrating different perspectives on socialization theory and research: A domain-specific approach. Child Development, 81, 687-709.

Gullone, E., \& Robinson, K. (2005). The Inventory of Parent and Peer Attachment-Revised (IPPA-R) for children: A psychometric investigation. Clinical Psychology and Psychotherapy, 12, 67-79. 
Gustafson, K.L.B. (2013). Emotional involvement with grandparents as a key component of prosocial development: Testing empathic concern as a mediator (Unpublished master's dissertation). Brigham Young University, Provo, UT.

Guthrie, I.K., Eisenberg, N., Fabes, R.A., Murphy, B.C., Holmgren, R., Mazsk, P., \& Suh, K. (1997). The relations of regulation and emotionality to children's situational empathyrelated responding. Motivation and Emotion, 21, 87-108.

Harper, S., \& Seekings, J. (2010). Claims on and obligations to kin in Cape Town, South Africa (CSSR Working Paper No. 272). Retrieved from http://www.cssr.uct.ac.za/publications/working-paper/2010/claims-and-obligations-kincapetown-south

Hastings, P.D., Utendale, W.T., \& Sullivan, C. (2007). The socialization of prosocial development. In J.E. Grusec, \& P.D. Hastings (Eds.). Handbook of socialization: Theory and research (pp. 638-664). New York, NY: Guilford Publications.

Hawes, D.J., \& Dadds, M.R. (2004). Australian data and psychometric properties of the Strengths and Difficulties Questionnaire. Australian and New Zealand Journal of Psychiatry, 38, 644-651.

Hawk, S.T., Keijsers, L., Branje, S.J.T., Van der Graaff, J., De Wied, M., \& Meeus, W. (2013). Examining the Interpersonal Reactivity Index (IRI) among early and late adolescents and their mothers. Journal of Personality Assessment, 95, 96-106.

Henderson, C.E., Hayslip, B., Sanders, L.M., \& Louden, L. (2009). Grandmother-grandchild relationship quality predicts psychological adjustment among youth from divorced families. Journal of Family Issues, 30, 1245-1264.

Honaker, J., King, G., \& Blackwell, M. (2011). Amelia II: A program for missing data. Journal of Statistical Software, 45. Retrieved from https://www.jstatsoft.org/article/view/v045i07

Howes, C. (1999). Attachment relationships in the context of multiple caregivers. In J. Cassidy, \& P.R. Shaver (Eds.), Handbook of attachment: Theory, research, and clinical applications (pp. 671-687). New York, NY: Guilford Press.

Iacobucci, D. (2009). Structural Equations Modelling: Fit indices, sample size, and advanced topics. Journal of Consumer Psychology, 20, 90-98.

Jacobsen, L.A., Mather, M., \& Dupuis, G. (2012). Household changes in the United States. Population Bulletin, 67. 
Keiley, M.K. (2002). The development and implementation of an affect regulation and attachment intervention for incarcerated adolescents and their parents. The Family Journal: Counselling and Therapy for Couples and Families, 10, 177-189.

Kenny, D.A. (2015). Measuring model fit. Retrieved from http://davidakenny.net/cm/fit.htm

Keskin, G., \& Çam, O. (2010). Adolescents' strengths and difficulties: Approach to attachment styles. Journal of Psychiatric and Mental Health Nursing, 17, 433-441.

Khalid, S., Ahmed, F., \& Imdad, M. (2012). Grandparenting and adolescents' personality development. International Proceedings of Economics Development and Research, 48, 143-147.

Kline, R.B. (2011). Principles and practice of structural equation modelling (3rd ed.). New York, NY: Guilford Press.

Kobak, R.R., Cole, H.E., Ferenz-Gillies, R., Fleming, W.S., \& Gamble, W. (1993). Attachment and emotion regulation during mother-teen problem solving: A control theory analysis. Child Development, 64, 231-245.

Kornhaber, A., \& Woodward, K.L. (1981). Grandparents/grandchildren: The vital connection. Garden City, NY: Anchor Press/Double Day

Kunce, L.J., \& Shaver, P.R. (1994). An attachment-theoretical approach to caregiving in romantic relationships. Advances in Personal Relationships, 5, 205-237.

Laible, D. (2007). Attachment with parents and peers in late adolescence: Links with emotional competence and social behaviour. Personality and Individual Differences, $43,1185-1197$.

Laible, D.J., Carlo, G., \& Roesch, S.C. (2004). Pathways to self-esteem in late adolescence: The role of parent and peer attachment, empathy, and social behaviours. Journal of Adolescence, 27, 703-716.

Laible, D.J., Carlo, G., \& Raffaelli, M. (2000). The differential relations of parent and peer attachment to adolescent adjustment. Journal of Youth and Adolescence, 29, 45-59.

Levin, H.S., Culhane, K.A., Hartmann, J., Evankovich, K., Mattson, A.J., Harward, H., Ringholz, G., Ewing-Cobbs, L., \& Fletcher, J.M. (1991). Developmental changes in performance on tests of purported frontal lobe functioning. Developmental Neuropsychology, 7, 377-395.

Levitt, M.J. (2005). Social relations in childhood and adolescence: The convoy model perspective. Human Development, 48, 28-47. 
Levitt, M. J., Bustos, G.L., Crooks, N. A., Hodgetts, J., Milevsky, A., \& Levitt, J. L. (2002). Multiple attachments and well-being in middle childhood and adolescence. Presented at the meeting of the American Psychological Association, Chicago, IL.

Levitt, M.J., Guacci-Franco, N., \& Levitt, J.L. (1993). Convoys of social support in childhood and early adolescence: Structure and function. Developmental Psychology, 29, 811-818.

Ludwig, K.B., \& Pittman, J.F. (1999). Adolescent prosocial values and self-efficacy in relation to delinquency, risky sexual behaviour, and drug use. Youth \& Society, 30, 461482.

Lussier, G., Deater-Deckard, K., Dunn, J., \& Davies, L. (2002). Support across two generations: Children's closeness to grandparents following parental divorce and remarriage. Journal of Family Psychology, 16, 363-376.

Maier, M.A., Bernier, A., Pekrun, R., Zimmermann, P., \& Grossmann, K.E. (2004). Attachment working models as unconscious structures: An experimental test. International Journal of Behavioural Development, 28, 180-189.

Main, M., \& Weston, D.R. (1982). Avoidance of the attachment figure in infancy: Descriptions and interpretations. In C.M. Parks, \& J. Stevenson-Hinde (Eds.), The place of attachment in human behaviour (pp. 31-59). London, England: Tavistock Publications.

Mardia, K.V. (1970). Measures of multivariate skewness and kurtosis with applications. Biometrika, 57, 519-530.

Markiewicz, D., Doyle, A.B., \& Brendgen, M. (2001). The quality of adolescents' friendships: Associations with mothers' interpersonal relationships, attachments to parents and friends, and prosocial behaviours. Journal of Adolescence, 24, 429-445.

Markiewicz, D., Lawford, H., Doyle, A.B., \& Haggart, N. (2006). Developmental differences in adolescents' and young adults' use of mothers, fathers, best friends, and romantic partners to fulfil attachment needs. Journal of Youth and Adolescence, 35, 127-140.

Marsh, H.W., Hau, K-T., Balla, J.R., \& Grayson, D. (1998). Is more ever too much? The number of indicators per factor in confirmatory factor analysis. Multivariate Behavioural Research, 33, 181-220.

McClure, M.J., Bartz, J.A., \& Lydon, J.E. (2013). Uncovering and overcoming ambivalence: The role of chronic and contextually activated attachment in two-person social dilemmas. Journal of Personality, 81, 103-117. 
Meeus, W., Oosterwegel, A., \& Vollebergh, W. (2002). Parental and peer attachment and identity development in adolescence. Journal of Adolescence, 25, 93-106.

Michalik, N.M., Eisenberg, N., Spinrad, T.L., Ladd, B., Thompson, M., \& Valiente, C. (2007). Longitudinal relations among parental emotional expressivity and sympathy and prosocial behaviour in adolescence. Social Development, 16, 286-309.

Mickelson, K.D., Kessler, R.C., \& Shaver, P.R. (1997). Adult attachment in a nationally representative sample. Journal of Personality and Social Psychology, 73, 1092-1106.

Mikulincer, M., \& Orbach, I. (1995). Attachment styles and repressive defensiveness: The accessibility and architecture of affective memories. Journal of Personality and Social Psychology, 68, 917-925.

Mikulincer, M., \& Shaver, P.R. (2003). The attachment behavioural system in adulthood: Activation, psychodynamics, and interpersonal processes. In P. Zanna (Ed.), Advances in experimental social psychology, Volume 35 (pp. 53-152). New York, NY: Academic Press.

Mikulincer, M., \& Shaver, P.R. (2009). An attachment and behavioural systems perspective on social support. Journal of Social and Personal Relationships, 26, 7-19.

Mikulincer, M., Dolev, T., \& Shaver, P.R. (2004). Attachment-related strategies during thought suppression: Ironic rebounds and vulnerable self-representations. Journal of Personality and Social Psychology, 87, 940-956.

Mikulincer, M., Gillath, O., Halevy, V., Avihou, N., Avidan, S., \& Eshkoli, N. (2001). Attachment theory and reactions to others' needs: Evidence that activation of the sense of attachment security promotes empathic responses. Journal of Personality and Social Psychology, 81, 1205-1224.

Mikulincer, M., Shaver, P.R., \& Pereg, D. (2003). Attachment theory and affect regulation: The dynamics, development, and cognitive consequences of attachment-related strategies. Motivation and Emotion, 27, 77-102.

Mikulincer, M., Shaver, P.R., Cassidy, J., \& Berant, E. (2009). Attachment-related defensive processes. In J.H. Obegi, \& E. Berant (Eds.), Attachment theory and research in clinical work with adults (293-327). New York, NY: Guilford Press.

Mikulincer, M., Shaver, P.R., Gillath, O., \& Nitzberg, R.A. (2005). Attachment, caregiving, and altruism: Boosting attachment security increases compassion and helping. Journal of Personality and Social Psychology, 89, 817-839. 
Miller, P.A., Eisenberg, N., Fabes, R.A., \& Shell, R. (1996). Relations of moral reasoning and vicarious emotion to young children's prosocial behaviour toward peers and adults. Developmental Psychology, 32, 210-219.

Milne, L.C., \& Lancaster, S. (2001). Predictors of depression in female adolescents. Adolescence, 36, 207-223.

Nevitt, J., \& Hancock, G.R. (2001). Performance of bootstrapping approaches to model test statistics and parameter standard error estimation in structural equation modelling. Structural Equation Modelling, 8, 353-377.

Newland, L.A., Chen, H-H., Coyl-Shepherd, D.D., Liang, Y-C., Carr, E.R., Dykstra, E., \& Gapp, S.C. (2013). Parent and child perspectives on mothering and fathering: The influence of ecocultural niches. Early Child Development and Care, 183, 534-552.

Newton, E.K., Laible, D., Carlo, G., Steele, J.S., \& McGinley, M. (2014). Do sensitive parents foster kind children, or vice versa? Bidirectional influences between children's prosocial behaviour and parental sensitivity. Developmental Psychology, 50, 18081816.

Nickerson, A.B., \& Nagle, R.J. (2005). Parent and peer attachment in late childhood and early adolescence. Journal of Early Adolescence, 25, 223-249.

Nickerson, A.B., Mele, D., \& Princiotta, D. (2008). Attachment and empathy as predictors of roles as defenders or outsiders in bullying interactions. Journal of School Psychology, 46, 687-703.

Pace, C.S., Martini, P.S., \& Zavattini, G.C. (2011). The factor structure of the Inventory of Parent and Peer Attachment (IPPA): A survey of Italian adolescents. Personality and Individual Differences, 51, 83-88.

Padilla-Walker, L.M., \& Carlo, G. (2014). The study of prosocial behaviour: Past, present, and future. In L.M. Padilla-Walker, \& G. Carlo (Eds.), Prosocial development: A multidimensional approach (pp. 3-15). New York, NY: Oxford University Press.

Padilla-Walker, L.M., \& Christensen, K.J. (2010). Empathy and self-regulation as mediators between parenting and adolescents' prosocial behaviour toward strangers, friends, and family. Journal of Research on Adolescence, 21, 545-551.

Padilla-Walker, L.M., \& Nelson, L.J. (2010). Parenting and adolescents' values and behaviour: The moderating role of temperament. Journal of Moral Education, 39, 491509 . 
Padilla-Walker, L.M. (2014). Parental socialization of prosocial behaviour. In L.M. PadillaWalker, \& G. Carlo (Eds.), Prosocial development: A multidimensional approach (pp. 131-149). New York, NY: Oxford University Press.

Padilla-Walker, L.M., Carlo, G., \& Nielson, M.G. (2015). Does helping keep teens protected? Longitudinal bidirectional relations between prosocial behaviour and problem behaviour. Child Development, 86, 1759-1772.

Parker, G., Tupling, H., \& Brown, L.B. (1979). A parental bonding instrument. British Journal of Medical Psychology, 52, 1-10.

Petersen, I. (2010). At the heart of development: An introduction to mental health promotion and the prevention of mental disorders in scarce-resource contexts. In I. Petersen, A. Bhana, A. J. Flisher, L. Swartz, \& L. Richter (Eds.), Promoting mental health in scarce-resource contexts: Emerging evidence and practice (pp. 3-20). Cape Town, South Africa: HSRC Press.

Poehlmann, J. (2003). An attachment perspective on grandparents raising their very young grandchildren: Implications for intervention and research. Infant Mental Health Journal, 24, 149-173.

Preston, C.C., \& Coleman, A.M. (2000). Optimal number of response categories in rating scales: Reliability, validity, discriminating power, and respondent preferences. Acta Psychologica, 104, 1-15.

Profe, W., \& Wild, L. (2015). Mother, father, and grandparent involvement: Associations with adolescent mental health and substance use. Journal of Family Issues, 1-22. DOI: $10.1177 / 0192513 X 15583069$.

Revelle, W. (2015). An overview of the psych package. Retrieved from https://cran.rproject.org/web/packages/psych/vignettes/overview.pdf

Rice, K.G., Cunningham, T.J., \& Young, M.B. (1997). Attachment to parents, social competence, and emotional well-being: A comparison of black and white late adolescents. Journal of Counselling Psychology,44, 89-101.

Rigdon, E.E. (1996). CFI versus RMSEA: A comparison of two fit indexes for structural equation modelling. Structural Equation Modelling: A Multidisciplinary Journal, 3, 369-379.

Rosseel, Y. (2012). Lavaan: An R package for Structural Equation Modelling. Journal of Statistical Software, 48. Retrieved from https://www.jstatsoft.org/article/view/v048i02/v48i02.pdf 
Rubin, K.H., Bowker, J.C., McDonald, K., \& Menzer, M. (2013). Peer relationships in childhood. In P. D. Zelazo (Ed.), The Oxford handbook of developmental psychology: Volume 2 (pp. 242-275). New York, NY: Oxford University Press.

Rubin, K.H., Dwyer, K.M., Booth-LaForce, C., Kim, A.H., Burgess, K.B., \& Rose-Krasnor, L. (2004). Attachment, friendship, and psychosocial functioning in early adolescence. Journal of Early Adolescence, 24, 326-356.

Ruiz, S.A., \& Silverstein, M. (2007). Relationships with grandparents and the emotional well-being of late adolescent and young adult grandchildren. Journal of Social Issues, 63, 793-808.

Sagi-Schwartz, A., \& Aviezer, O. (2005). Correlates of attachment to multiple caregivers in Kibbutz children from birth to emerging adulthood: The Haifa longitudinal study. In K.E. Grossmann, K. Grossmann, \& E. Waters (Eds.), Attachment from infancy to adulthood: The major longitudinal studies (pp. 165-197). New York, NY: Guilford Press.

Sameroff A.J., \& Chandler, M.J. (1975). Reproductive risk and the continuum of caretaking casualty. In: F.D. Horowitz, E.M. Hetherington, S. Scarr-Salapatek, \& G.M. Siegel (Eds.), Review of child development research. 4. (pp. 187-244). Chicago, IL: University of Chicago Press.

Sands, R.G., Goldberg-Glen, R.S., \& Shin, H. (2009). The voices of grandchildren of grandparent caregivers: A strengths-resilience perspective. Child Welfare, 88, 25-45.

Satorra, A., \& Bentler, P.M. (1994). Corrections to test statistics and standard errors on covariance structure analysis. In A. von Eye, \& C.C. Clogg (Eds.), Latent variables analysis (pp. 399-419). Thousand Oaks, CA: Sage.

Scourfield, J., John, B., Martin, N., \& McGuffin, P. (2004). The development of prosocial behaviour in children and adolescents: A twin study. Journal of Child Psychology and Psychiatry, 45, 927-935.

Seibert, A.C., \& Kerns, K.A. (2009). Attachment figures in middle childhood. International Journal of Behavioural Development, 33, 347-355.

Shaver, P.R., Mikulincer, M., \& Chun, D. (2008). Adult attachment theory, emotion regulation, and prosocial behaviour. In M. Vandekerckhove, C. von Scheve, S. Ismer, S. Jung, \& S. Kronast (Eds.), Regulating emotions: Culture, social necessity, and biological inheritance (pp. 121-145). Boston, MA: Wiley-Blackwell. 
Shomaker, L.B., \& Furman, W. (2009). Parent-adolescent relationship qualities, internal working models, and attachment styles as predictors of adolescents' interactions with friends. Journal of Social and Personal Relationships, 26, 579-603.

Sigelman, C. K., \& Rider, E. A. (2011). Human development across the life span ( $7^{\text {th }}$ ed.). Stamford, CT: Wadsworth, CENGAGE Learning.

Simons, K.J., Paternite, C.E., \& Shore, C. (2001). Quality of parent/adolescent attachment and aggression in young adolescents. Journal of Early Adolescence, 21, 182-203.

Simpson, J.A., Rholes, W.S., \& Nelligan, J.S. (1992). Support seeking and support giving within couples in an anxiety-provoking situation: The role of attachment styles. Journal of Personality and Social Psychology, 62, 434-446.

Sroufe, L.A. (1985). Attachment classification from the perspective of infant-caregiver relationships and infant temperament. Child Development, 56, 1-14.

Sroufe, L.A., Egeland, B., Carlson, E., \& Collins, W.A. (2005). Placing early attachment experiences in developmental context: The Minnesota longitudinal study. In K.E. Grossmann, K. Grossmann, \& E. Waters (Eds.), Attachment from infancy to adulthood: The major longitudinal studies (pp. 13-47). New York, NY: Guilford Press.

Statistics South Africa (2012). Census 2011 municipal report Western Cape. Pretoria: Statistics South Africa.

Statistics South Africa (2013a). South Africa's young children: Their family and home environment, 2012. Pretoria: Statistics South Africa.

Statistics South Africa (2013b). Social profile of vulnerable groups in South Africa, 20022012. Pretoria: Statistics South Africa.

Steinberg, L. (2005). Cognitive and affective development in adolescence. TRENDS in Cognitive Sciences, 9, 69-74.

Stone, L.L., Otten, R., Engels, R.C.M.E., Vermulst, A.A., \& Janssens, J.M.A.M. (2010). Psychometric properties of the parent and teacher versions of the Strengths and Difficulties Questionnaire for 4- to 12-year-olds: A review. Clinical Child and Family Psychology Review, 13, 254-274.

Thompson, K.L., \& Gullone, E. (2008). Prosocial and antisocial behaviours in adolescents: An investigation into associations with attachment and empathy. Anthrozoös, 21, 123137.

Thompson, R.A. (1994). Emotion regulation: A theme in search of definition. Monographs of the Society for Research in Child Development, 59, 25-52. 
Thompson, R.A. (1999). Early attachment and later development. In J. Cassidy, \& P.R. Shaver (Eds.), Handbook of attachment: Theory, research, and clinical applications (pp. 265-286). New York, NY: Guilford Press.

Thompson, R.A. (2006). The development of the person: Social understanding, relationships, conscience, self. In W. Damon, R.M. Lerner, \& N. Eisenberg (Eds.), Handbook of child psychology: Social, emotional and personality development: Volume 3 (6th ed.) (pp. 24-98). Hoboken, NJ: Wiley-Blackwell.

Van Emmichoven, I.A.Z., Van Ijzendoorn, M.H., De Ruiter, C., \& Brosschot, J.F. (2003). Selective processing of threatening information: Effects of attachment representation and anxiety disorder on attention and memory. Development and psychopathology, 15, 219-237.

Van Roy, B., Grøholt, B., Heyerdahl, S.,\& Clench-Aas, J. (2006). Self-reported strengths and difficulties in a large Norwegian population 10-19 years. European Child and Adolescent Psychiatry, 15, 189-198.

Van Widenfeld, B.M., Goedhart, A.W., Treffers, P.D.A., \& Goodman, R. (2003). Dutch version of the Strengths and Difficulties Questionnaire. European Child and Adolescent Psychiatry, 12, 281-289.

Villasenor-Alva, J.A., \& Gonzalez-Estrada, E. (2009). A generalization of Shapiro-Wilk's test for multivariate normality. Communications in Statistics: Theory and Methods, 38,1870-1883.

Vivona, J.M. (2000). Parental attachment styles of late adolescents: Qualities of attachment relationships and consequences for adjustment. Journal of Counselling Psychology, 47, 316-329.

Waters, E., Merrick, S., Treboux, D., Crowell, J., \& Albersheim, L. (2000). Attachment security in infancy and early adulthood: A twenty-year longitudinal study. Child Development, 71, 684-689.

Weiss, R.S. (1982). Attachment in adult life. In C.M. Parks, \& J. Stevenson-Hinde (Eds.), The place of attachment in human behaviour (pp. 171-184). London, England: Tavistock Publications.

Wentzel, K.R. (2014). Prosocial behaviour and peer relations in adolescence. In L.M. PadillaWalker, \& G. Carlo (Eds.), Prosocial development: A multidimensional approach (pp. 3-14). New York, NY: Oxford University Press.

Westmaas, J.L., \& Silver, R.C. (2001). The role of attachment in responses to victims of life crises. Journal of Personality and Social Psychology, 80, 425-438. 
Wild, L.G., \& Gaibie, F. (2014). Grandparental involvement and South African adolescents' psychological well-being. Journal of Intergenerational Relationships, 12, 425-441.

Woodward, L., Fergusson, D.M., \& Belsky, J. (2000). Timing of parental separation and attachment to parents in adolescence: Results of a prospective study from birth to age 16. Journal of Marriage and Family, 62, 162-174.

Yorgason, J.B., \& Gustafson, K.B. (2014). Linking grandparent involvement with the development of prosocial behaviour in adolescents. In L.M. Padilla-Walker, \& G. Carlo (Eds.), Prosocial development: A multidimensional approach (pp. 131-149). New York, NY: Oxford University Press.

Yorgason, J.B., Padilla-Walker, L., \& Jackson, J. (2011). Nonresidential grandparents' emotional and financial involvement in relation to early adolescent grandchild outcomes. Journal of Research on Adolescence, 21, 552-558.

Zimmer-Gembeck, M.J., Geiger, T.C., \& Crick, N.R. (2005). Relational and physical aggression, prosocial behaviour, and peer relations: Gender moderation and bidirectional associations. Journal of Early Adolescence, 25, 421-452.

Zimmermann, P. (1999). Structure and functions of internal working models of attachment and their role for emotion regulation. Attachment and Human Development, 1, 291-306. 
APPENDIX A: MY FAMILY, FRIENDS AND I QUESTIONNAIRE

My family, friends, and I

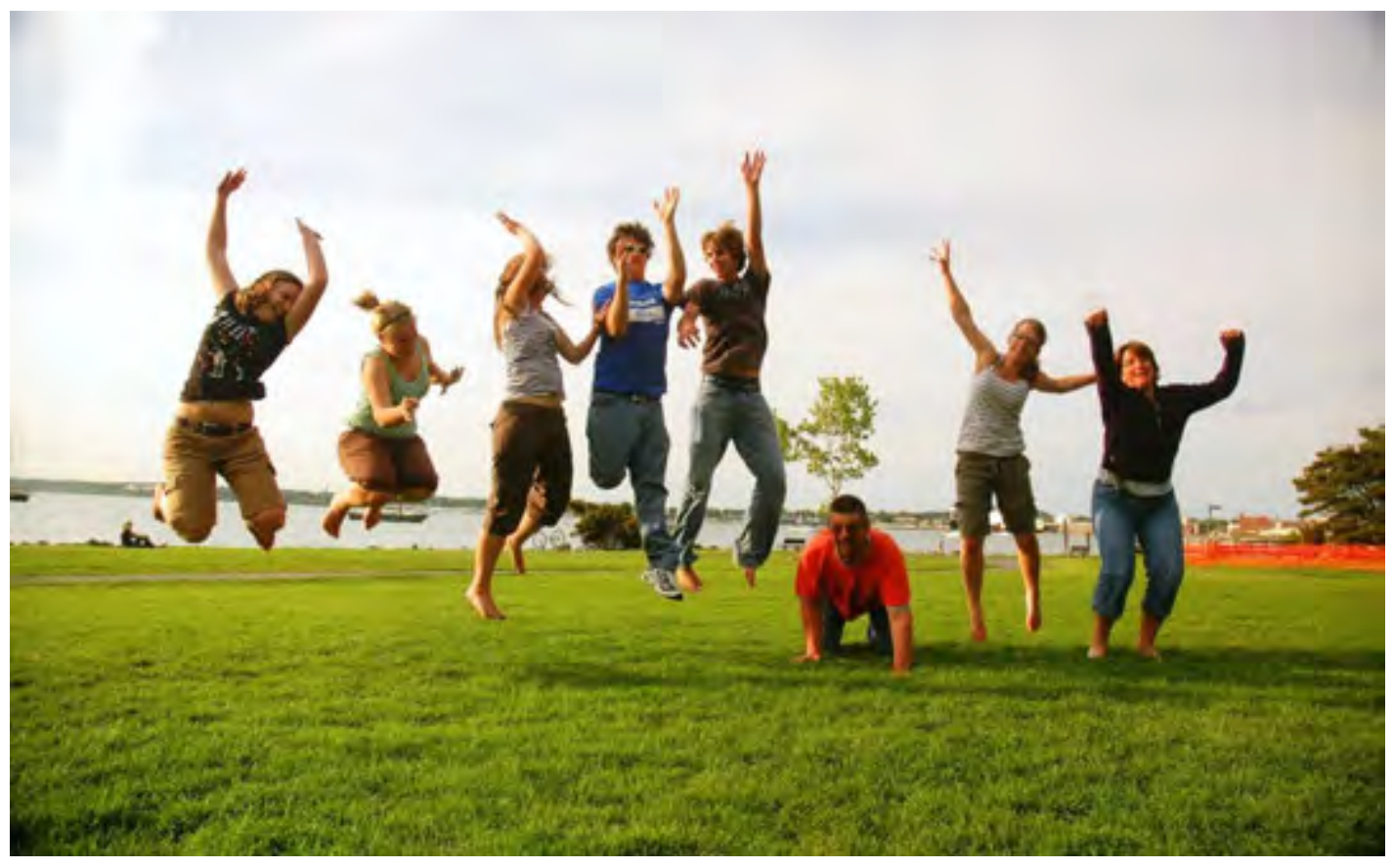

Tell us a little bit about yourself

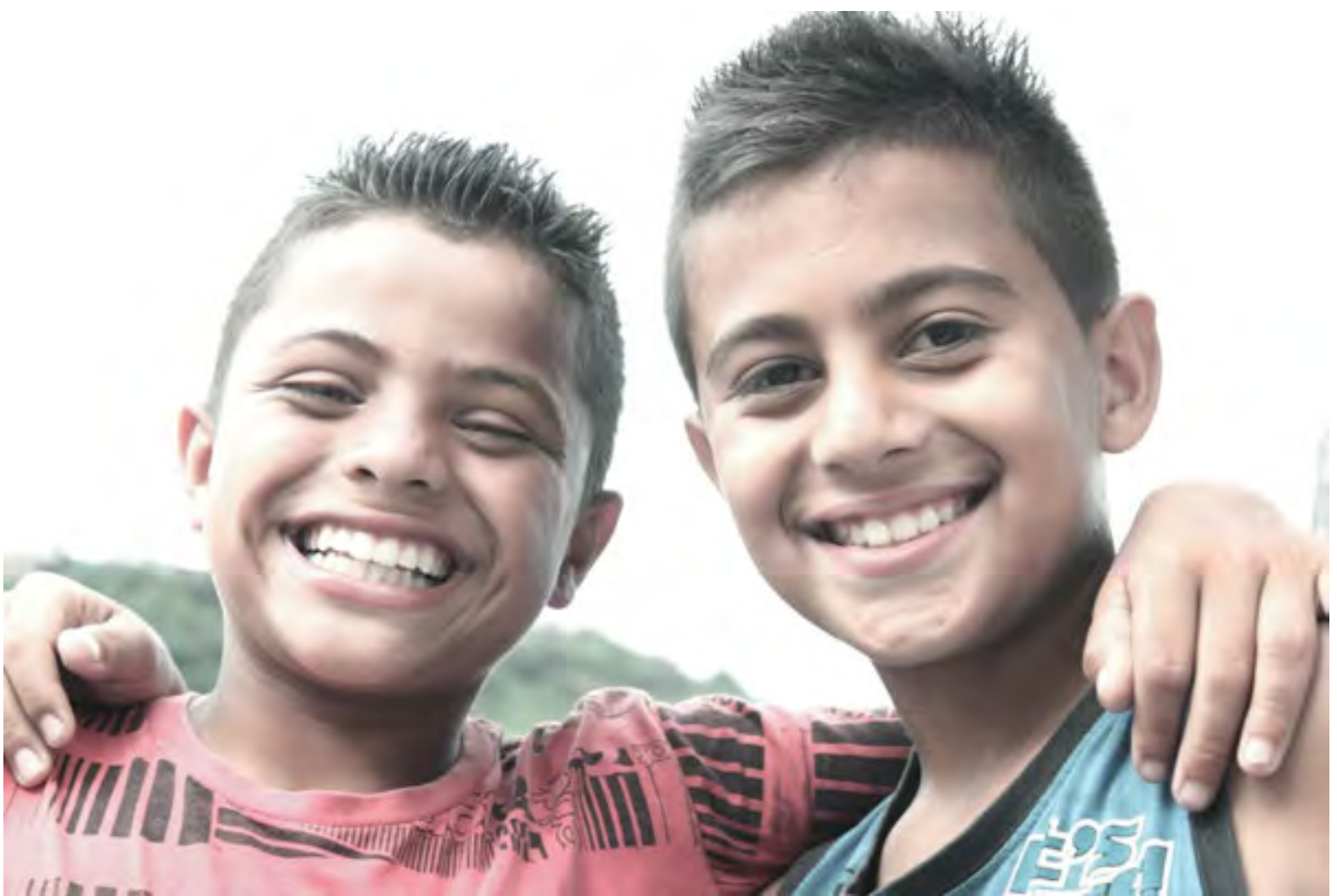


My Family, Friends and I survey

Hello. My name is Wade Profe, and I am from the Department of Psychology at the University of Cape Town. Please take time to read this sheet carefully and decide whether you do or don't want to take part. Ask the researcher if there is anything that is not clear, or if you have questions. Thank you for reading this.

\section{What is the study about?}

We would like to know more about young people, their feelings, and their relationships with their families and friends.

\section{What would I have to do?}

If you decide to take part, you will first sign an assent form (on the next page), and then spend about 30-45 minutes answering this questionnaire. The questions will ask about your feelings, behaviours and relationships.

\section{What are the risks?}

Some of the questions may talk about things that some people find quite personal. If any of the questions make you feel uncomfortable or you don't want to answer them, you do not have to. If any of the questions upset you, or if you would like to talk to someone about the feelings you experienced, please let your school counsellor know, or call Childline on 080 0055555 .

\section{What are the benefits?}

You will not benefit directly from participating in this study. However, we may learn something that will help other children at some point in the future. Your thoughts and opinions are very valuable.

\section{Do I have to take part?}

Not at all. It is up to you to decide whether or not to take part. You will not get in any trouble with your school or anyone else if you do not want to take part. If you decide to take part, you are still free to stop at any time. You don't have to give a reason.

\section{Will what I say be kept confidential?}

Anything you tell us about yourself will be kept strictly confidential. This means it will be private between you and the research team, and will not be told to anyone else. You will not be asked to put your name on the questionnaire. 


\section{Contact for further information}

If you have any questions about this study, you can contact Mr Wade Profe on 0724898077 orwadeizzel@gmail.com, or Dr Lauren Wild on 0216504607 or Lauren.Wild@uct.ac.za.

If you have any complaints about the study, please contact the Department of Psychology Postgraduate Administrator, Rosalind Adams on 0216504104.

Thank you for reading this sheet. If you have any questions, please raise your hand now. If you feel comfortable with everything, you can fill in the box below:

Tick

1. I have read and understand the information sheet for this study and have had the chance to ask questions.

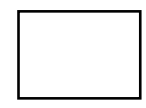

2. I understand that I have chosen to take part and that I am free to stop at any time, without giving any reason.

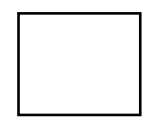

3. I agree to take part in the study

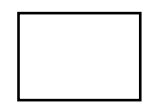

Signature

Date.

(You can just write your name if you don't have a signature) 
How old are you?

Are you a boy or a girl? (Please tick one)

$$
\text { Boy }
$$

Girl

Are you... (Please tick one)

Black African

$\square$ Coloured

$\square$ White

Indian

$\square$ Don't want to answer

$\square$ Other

At the house that you live in most of the time, who lives with you?

(Tick as many as necessary)

Mother

$\square$ Father

$\square$ Stepfather or your mother's partner

$\square$ Stepmother or your father's partner

Grandmother/s

$\square$ Grandfather/s

Aunt/s or Uncle/s

$\square$ Brother/s or sister/s

$\square$ Anyone else? Please tell us what their relationship is to you below. 
The questions below are all about you. Please tick whichever box most applies to you.

It will be really helpful to us if you answered all the questions as truthfully as possible.

\begin{tabular}{|c|c|c|c|}
\hline $\begin{array}{r}\text { Almost } \\
\text { never. }\end{array}$ & Sometimes. & $\begin{array}{l}\text { About half } \\
\text { the time }\end{array}$ & $\begin{array}{l}\text { Most of } \\
\text { the time }\end{array}$ \\
\hline
\end{tabular}

1.I am clear about my feelings.

2.I pay attention to how I feel.

3.I experience my emotions as overwhelming and out of control.

4.I have no idea how I am feeling.

5.I have difficulty making sense out of my feelings.

6.I am attentive to my feelings.

7.I know exactly how I am feeling.

8.I care about what I am feeling. 
Almost

never.
Sometimes.
About half the time

9.I am confused about how I am feeling.

10.When I'm upset, I

acknowledge my emotions.

11.When I'm upset, I become angry at myself for feeling that way.

12.When I'm upset, I become embarrassed.

13. When I'm upset, I have difficulty getting work done.

14.When I'm upset, I become out of control.

15.When I'm upset, I believe I'll remain that way for a long time.

16. When I'm upset, I believe that I'll end up very depressed.

17.When I'm upset, I believe that my emotions are valid and important.

18. When I'm upset, I have difficulty focusing on other things. 
Almost

never.
About half the time

19. When I'm upset, I feel out of control.

20.When I'm upset, I can still get things done.

21.When I'm upset, I feel ashamed of myself.

22.When I'm upset, I know

that I can find a way to feel better.

23.When I'm upset, I feel like I am weak.

24. When I'm upset, I feel I can remain in control over my behaviour.

25.When I'm upset, I feel guilty.

26. When I'm upset, I have difficulty concentrating.

27. When I'm upset, I have difficulty controlling my behaviour.

28. When I'm upset, I believe there is nothing I can do to feel better.

29. When I'm upset, I become irritated with myself. 


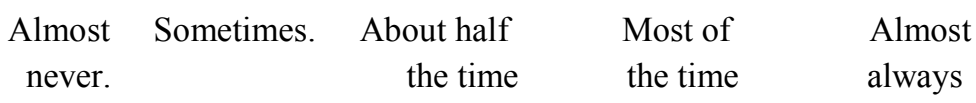

30. When I'm upset, I start to

feel very bad about myself.

31.When I'm upset, I believe

that wallowing in it is

all I can do.

32. When I'm upset, I lose

control over my behaviour.

33. When I'm upset, I have

difficulty thinking about

anything else.

34.I take time to figure out

what I am really feeling.

35. When I'm upset, it takes me

a long time to feel better.

36. When I'm upset, my

emotions feel overwhelming.

Tell us some more about yourself. Remember to answer all the questions as honestly as possible.

$\begin{array}{lcccc}\begin{array}{l}\text { Does not } \\ \text { describe me }\end{array} & \begin{array}{c}\text { Describes me } \\ \text { at all }\end{array} & \begin{array}{l}\text { Somewhat } \\ \text { describes me }\end{array} & \begin{array}{c}\text { Describes } \\ \text { me well }\end{array} & \begin{array}{l}\text { Describes } \\ \text { me greatly }\end{array}\end{array}$

1.It makes me

feel good when

I can comfort

someone who is

very upset. 


$\begin{array}{lclcc}\begin{array}{l}\text { Does not } \\ \text { describe me }\end{array} & \begin{array}{c}\text { Describes me } \\ \text { at all }\end{array} & \begin{array}{l}\text { Somewhat } \\ \text { a little }\end{array} & \begin{array}{c}\text { Describes } \\ \text { me well }\end{array} & \begin{array}{l}\text { Describes } \\ \text { me greatly }\end{array} \\ & & & & \end{array}$

2.I tend to help

people who are in a

real crisis or need.

3.I tend to help

$\square$

people when they

are hurt badly

4.I tend to help

others, especially when

they are really emotional.

5.It is easy for me

to help others when

they are in a bad situation.

6.I respond to

helping others best

when the situation is

highly emotional.

7.Emotional

situations make me want to

help others in need.

8.I usually help

others when they are

very upset. 
Now we're going to ask you some questions about your family and friends. Please answer all the questions. Remember, none of your family, friends or teachers will be allowed to look at your answers, so you can be completely honest.

Which of your parents are still alive?

Mother

Father

(Tick both boxes if both are still alive).

Please tell us a bit more about your relationship with your mother. (If your mother is no longer alive, please skip this section).

$\begin{array}{lcccc}\begin{array}{l}\text { Almost } \\ \text { never or } \\ \text { never true }\end{array} & \begin{array}{l}\text { Not very } \\ \text { often true }\end{array} & \begin{array}{c}\text { Sometimes } \\ \text { true }\end{array} & \begin{array}{c}\text { Often } \\ \text { true }\end{array} & \begin{array}{c}\text { Almost } \\ \text { always or } \\ \text { always true }\end{array}\end{array}$

1.My mother respects my feelings.

2.I feel my mother does a good job as my mother.

3.I wish I had a different mother.

4.My mother accepts me as I am.

5.I like to get my mother's point of view on things I'm concerned about.

6.I feel it's no use letting my feelings show around my mother. 


$\begin{array}{ccccc}\begin{array}{c}\text { Almost } \\ \text { never or } \\ \text { never true }\end{array} & \begin{array}{c}\text { Not very } \\ \text { often true }\end{array} & \begin{array}{c}\text { Sometimes } \\ \text { true }\end{array} & \begin{array}{l}\text { Often } \\ \text { true }\end{array} & \begin{array}{c}\text { Almost } \\ \text { always or } \\ \text { always true }\end{array}\end{array}$

7.My mother can tell when I'm upset about something.

8. Talking over my problems with my mother makes me feel ashamed or foolish.

9.My mother expects too much from me.

10.I get upset easily around my mother.

11.I get upset a lot more than my mother knows about.

12.When we discuss things, my mother cares about my point of view.

13.My mother trusts my judgment.

14.My mother has her own problems, so I don't bother her with mine.

15.My mother helps me to understand myself better.

16.I tell my mother about my problems and troubles. 


$\begin{array}{lcccc}\begin{array}{l}\text { Almost } \\ \text { never or } \\ \text { never true }\end{array} & \begin{array}{l}\text { Not very } \\ \text { often true }\end{array} & \begin{array}{c}\text { Sometimes } \\ \text { true }\end{array} & \begin{array}{c}\text { Often } \\ \text { true }\end{array} & \begin{array}{c}\text { Almost } \\ \text { always or } \\ \text { always true }\end{array}\end{array}$

17.I feel angry with my mother.

18.I don't get much attention from my mother.

19. My mother helps me to talk about my difficulties.

20.My mother understands me.

21.When I am angry about something, my mother tries to be understanding.

22.I trust my mother.

23.My mother doesn't understand what I'm going through these days.

24.I can count on my mother when I need to get something off my chest.

25.If my mother knows something is bothering me, she asks me about it. 
Please tell us a bit more about your relationship with your father.

(If your father is no longer alive, please skip this section).

$\begin{array}{lcccc}\begin{array}{l}\text { Almost } \\ \text { never or } \\ \text { never true }\end{array} & \begin{array}{c}\text { Not very } \\ \text { often true }\end{array} & \begin{array}{c}\text { Sometimes } \\ \text { true }\end{array} & \begin{array}{c}\text { Often } \\ \text { true }\end{array} & \begin{array}{c}\text { Almost } \\ \text { always or } \\ \text { always true }\end{array}\end{array}$

1.My father respects

my feelings.

2.I feel my father does a good job as my father.

3.I wish I had a different father.

4.My father accepts me as I am.

5.I like to get my father's point of view on things I'm concerned about.

6.I feel it's no use letting my feelings show around my father.

7.My father can tell when I'm upset about something.

8. Talking over my problems with my father makes me feel ashamed or foolish.

9.My father expects too much from me. 


$\begin{array}{lcccc}\begin{array}{l}\text { Almost } \\ \text { never or } \\ \text { never true }\end{array} & \begin{array}{l}\text { Not very } \\ \text { often true }\end{array} & \begin{array}{c}\text { Sometimes } \\ \text { true }\end{array} & \begin{array}{c}\text { Often } \\ \text { true }\end{array} & \begin{array}{c}\text { Almost } \\ \text { always or } \\ \text { always true }\end{array}\end{array}$

10.I get upset easily around my father.

11.I get upset a lot more than my father knows about.

12.When we discuss things, my father cares about my point of view.

13.My father trusts my judgment.

14.My father has his own problems, so I don't bother him with mine.

15.My father helps me to understand myself better.

16.I tell my father about my problems and troubles.

17.I feel angry with my father.

18.I don't get much attention from my father.

19.My father helps me to talk about my difficulties.

20.My father understands me. 


$\begin{array}{lcccc}\begin{array}{l}\text { Almost } \\ \text { never or } \\ \text { never true }\end{array} & \begin{array}{l}\text { Not very } \\ \text { often true }\end{array} & \begin{array}{c}\text { Sometimes } \\ \text { true }\end{array} & \begin{array}{c}\text { Often } \\ \text { true }\end{array} & \begin{array}{c}\text { Almost } \\ \text { always or } \\ \text { always true }\end{array}\end{array}$

21. When I am angry about something, my father tries to be understanding.

22.I trust my father.

23.My father doesn't understand what I'm going through these days.

24.I can count on my father when I need to get something off my chest.

25.If my father knows something is bothering me, he asks me about it.

Which of your grandparents are still alive?

Mother's mother Mother's father Father's mother Father's father 
Which of your grandparents do you have the closest relationship with?

(Please tick only one)

Mother's mother Mother's father Father's mother Father's father

$\begin{array}{llll}\square & \square & \square & \square\end{array}$

\section{Please tell us a bit more about your relationship with your closest}

grandparent.

(If none of your grandparents are still alive, please skip this section).

$\begin{array}{lcccc}\begin{array}{l}\text { Almost } \\ \text { never or } \\ \text { never true }\end{array} & \begin{array}{l}\text { Not very } \\ \text { often true }\end{array} & \begin{array}{c}\text { Sometimes } \\ \text { true }\end{array} & \begin{array}{c}\text { Often } \\ \text { true }\end{array} & \begin{array}{c}\text { Almost } \\ \text { always or } \\ \text { always true }\end{array}\end{array}$

1.My grandparent respects

my feelings.

2.I feel my grandparent does a good job as my grandparent.

3.I wish I had a different grandparent.

4.My grandparent accepts me as I am.

5.I like to get my grandparent's point of view on things I'm concerned about.

6.I feel it's no use letting my feelings show around my grandparent. 


$\begin{array}{lcccc}\begin{array}{l}\text { Almost } \\ \text { never or } \\ \text { never true }\end{array} & \begin{array}{l}\text { Not very } \\ \text { often true }\end{array} & \begin{array}{c}\text { Sometimes } \\ \text { true }\end{array} & \begin{array}{c}\text { Often } \\ \text { true }\end{array} & \begin{array}{c}\text { Almost } \\ \text { always or } \\ \text { always true }\end{array}\end{array}$

7.My grandparent can tell when I'm upset about something.

8. Talking over my problems with my grandparent makes me feel ashamed or foolish.

9.My grandparent expects too much from me.

10.I get upset easily around my grandparent.

11.I get upset a lot more than my grandparent knows about.

12.When we discuss things, my grandparent cares about my point of view.

13.My grandparent trusts my judgment.

14.My grandparent has his/her own problems, so I don't bother him/her with mine.

15.My grandparent helps me to understand myself better.

16.I tell my grandparent about my problems and troubles. 


$\begin{array}{lcccc}\begin{array}{l}\text { Almost } \\ \text { never or } \\ \text { never true }\end{array} & \begin{array}{l}\text { Not very } \\ \text { often true }\end{array} & \begin{array}{c}\text { Sometimes } \\ \text { true }\end{array} & \begin{array}{c}\text { Often } \\ \text { true }\end{array} & \begin{array}{c}\text { Almost } \\ \text { always or } \\ \text { always true }\end{array}\end{array}$

17.I feel angry with my grandparent.

18.I don't get much attention from my grandparent.

19.My grandparent helps me to talk about my difficulties.

20.My grandparent understands me.

21. When I am angry about something, my grandparent tries to be understanding.

22.I trust my grandparent.

23. My grandparent doesn't understand what I'm going through these days.

24.I can count on my grandparent when I need to get something off my chest.

25.If my grandparent knows something is bothering me, he/she asks me about it. 
Now please tell us about your relationship with your close friends.

Almost finished. Well done for getting this far!

$\begin{array}{lcccc}\begin{array}{l}\text { Almost } \\ \text { never or } \\ \text { never true }\end{array} & \begin{array}{c}\text { Not very } \\ \text { often true }\end{array} & \begin{array}{c}\text { Sometimes } \\ \text { true }\end{array} & \begin{array}{c}\text { Often } \\ \text { true }\end{array} & \begin{array}{c}\text { Almost } \\ \text { always or } \\ \text { always true }\end{array}\end{array}$

1.I like to get my friends' point of view on things I'm concerned about.

2.My friends can tell when I'm upset about something.

3.When we discuss things, my friends care about my point of view.

4.Talking over my problems with friends makes me feel ashamed or foolish.

5.I wish I had different friends.

6.My friends understand me.

7.My friends encourage me to talk about my difficulties.

8.My friends accept me as I am. 


$\begin{array}{lcccc}\begin{array}{l}\text { Almost } \\ \text { never or } \\ \text { never true }\end{array} & \begin{array}{l}\text { Not very } \\ \text { often true }\end{array} & \begin{array}{c}\text { Sometimes } \\ \text { true }\end{array} & \begin{array}{c}\text { Often } \\ \text { true }\end{array} & \begin{array}{c}\text { Almost } \\ \text { always or } \\ \text { always true }\end{array}\end{array}$

9.I feel the need to be in touch

with my friends more often.

10.My friends don't understand what I'm going through these days.

11.I feel alone or apart when I am with my friends.

12.My friends listen to what I have to say.

13.I feel my friends are good friends.

14.My friends are fairly easy to talk to.

15. When I am angry about something, my friends try to be understanding.

16.My friends help me understand myself better.

17.My friends care about how I am feeling.

18.I feel angry with my friends. 


$\begin{array}{llccc}\begin{array}{l}\text { Almost } \\ \text { never or } \\ \text { never true }\end{array} & \begin{array}{l}\text { Not very } \\ \text { often true }\end{array} & \begin{array}{c}\text { Sometimes } \\ \text { true }\end{array} & \begin{array}{c}\text { Often } \\ \text { true }\end{array} & \begin{array}{c}\text { Almost } \\ \text { always or } \\ \text { always true }\end{array} \\ & & & & \end{array}$

19.I can count on my friends when I need to get something off my chest.

20.I trust my friends.

21.My friends respect my feelings.

22.I get upset a lot more than my friends know about.

23.It seems as if my friends are irritated with me for no reason.

24.I can tell my friends about my problems and troubles.

25.If my friends know something is bothering me, they ask me about it. 
And now just a final few questions about yourself.

$\begin{array}{ccccc}\text { Does not } & \text { Describes me } & \begin{array}{c}\text { Somewhat } \\ \text { describes me }\end{array} & \begin{array}{c}\text { Describes } \\ \text { me well }\end{array} & \begin{array}{c}\text { Describes } \\ \text { me very well }\end{array} \\ \text { well } & \text { a little } & \text { dello } & & \end{array}$

1.I often have

tender, concerned

feelings for people less

fortunate than me.

2.I sometimes find

it difficult to see things

from the "other guy's"

point of view.

3.Sometimes I don't

feel very sorry for

other people when

they are having problems.

4.I try to look at

everybody's side of

a disagreement before

I make a decision.

5.When I see

someone being taken

advantage of, I feel

kind of protective

towards them.

6.I sometimes try

to understand my friends

better by imagining how

things look from their

perspective. 


$\begin{array}{ccccc}\text { Does not } & \text { Describes me } & \text { Somewhat } & \text { Describes } & \text { Describes } \\ \text { describe me } & \text { a little } & \text { describes me } & \text { me well } & \text { me very well } \\ \text { well } & & & & \end{array}$

7.Other people's misfortunes do not usually disturb me a great deal.

8.If I'm sure I'm right about something, I don't waste much time listening to other people's arguments.

9.When I see someone being treated unfairly, I sometimes don't feel very much pity for them.

10.I am often quite touched by things that I see happen.

11.I believe that there are two sides to every question and try to look at them both.

12.I would describe myself as a pretty soft-hearted person.

13. When I'm upset at someone, I usually try to "put myself in his shoes" for a while.

14.Before I criticize somebody, I try to imagine how I would feel if I were in their place. 


\section{APPENDIX B: TEACHER'S QUESTIONNAIRE}

Learner's participant number:

Please answer the following questions about the participant indicated above, by ticking the appropriate boxes. Please answer each question as accurately and honestly as possible.

Not true Somewhat true Certainly true

1. Considerate of other people's feelings.

2. Shares readily with other young people, for example CDs, games, food.

3. Helpful if someone is hurt, upset or feeling ill.

4. Kind to younger children.

5. Often volunteers to help others (parents, teachers, children)

Thank you very much for completing this survey! 


\title{
APPENDIX C: PERMISSION FROM THE WESTERN CAPE EDUCATION DEPARTMENT TO CONDUCT THE STUDY
}

\author{
Audrey.wyngaard@westerncape.gov.za \\ tel: +27021 4679272 \\ Fax: 0865902282 \\ Private Bag x9114, Cape Town, 8000 \\ wced.wcape.gov.za
}

REFERENCE: $20151202-5864$

\section{ENQUIRIES: Dr A T Wyngaard}

Mr Wade Profe

13 Kestel Street

Plumstead

7800

Dear Mr Wade Profe

RESEARCH PROPOSAL: THE INFLUENCE OF MULTIPLE ATTACHMENT FIGURES ON ADOLESCENT EMOTION REGULATION, SYMPATHY AND PROSOCIAL BEHAVIOUR

Your application to conduct the above-mentioned research in schools in the Western Cape has been approved subject to the following conditions:

1. Principals, educators and learners are under no obligation to assist you in your investigation.

2. Principals, educators, learners and schools should not be identifiable in any way from the results of the investigation.

3. You make all the arrangements concerning your investigation.

4. Educators' programmes are not to be interrupted.

5. The Study is to be conducted from 01 February 2016 till 18 March 2016

6. No research can be conducted during the fourth term as schools are preparing and finalizing syllabi for examinations (October to December).

7. Should you wish to extend the period of your survey, please contact Dr A.T Wyngaard at the contact numbers above quoting the reference number?

8. A photocopy of this letter is submitted to the principal where the intended research is to be conducted.

9. Your research will be limited to the list of schools as forwarded to the Western Cape Education Department.

10. A brief summary of the content, findings and recommendations is provided to the Director: Research Services.

11. The Department receives a copy of the completed report/dissertation/thesis addressed to:

The Director: Research Services

Western Cape Education Department

Private Bag X9114

CAPE TOWN

8000

We wish you success in your research.

Kind regards.

Signed: Dr Audrey T Wyngaard

Directorate: Research

DATE: 02 December 2015 


\title{
APPENDIX D: PERMISSION FROM THE UNIVERSITY OF CAPE TOWN RESEARCH ETHICS COMMITTEE OF THE FACULTY OF HUMANITIES TO CONDUCT THE STUDY
}

\section{UNIVERSITY OF CAPE TOWN}

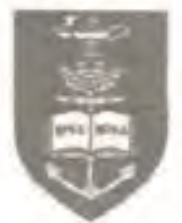

\section{Department of Psychology}

\author{
University of Cape Town Rondebosch 7701 South Africa \\ Telephone (021) 6503414

Mr W. Profe

Department of Psychology

University of Cape Town

Rondebosch 7701

Dear Mr Profe,

I am pleased to inform you that ethical clearance has been given by an Ethics Review Committee of the Faculty of Humanities for conducting a survey and interviews as part of your study. The influence of multiple attachment figures on adolescent emotion regulation, sympathy and prosocial behaviour. The reference number is PSY2015-047.

I wish you all the best for your study.

Yours sincerely,

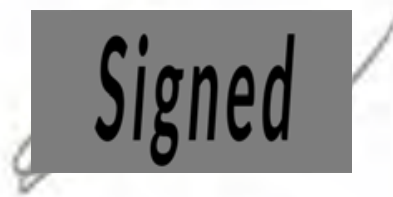

Johann Louw PhD

Professor

Chair: Ethics Review Committee 


\section{APPENDIX E: PARENT CONSENT FORM}

\section{UNIVERSITY OF CAPE TOWN}

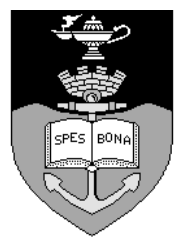

Department of Psychology

University of Cape Town, Rondebosch, 7701, South Africa

Telephone (021) 650-4605

Fax: (021) 650-4104

Dear Parent

\section{My family, Friends and I: Research study at your child's school}

I am a Masters student from the Department of Psychology at the University of Cape Town. I have arranged to conduct a study about children's helping behaviours at your child's school.

We would like to invite your child to fill in a questionnaire during an ordinary school period. Using this questionnaire, we would like to find out more about children's relationships with their family and friends, how they deal with their feelings, and how they respond to others in need. This is a voluntary exercise and your child will be able to choose whether or not to participate. If they do not participate, they will not suffer any negative consequences of any sort. If they do participate, they will be free to withdraw from the study at any time, or to leave out certain questions. All information provided by your child will be anonymous and confidential. They will not be asked to put their name on the questionnaire, and the information from all learners who participate will be combined in the presentation of the results. As a result, no child who participates in the research will be personally identifiable. In addition, your child's teacher will complete a short questionnaire about your child's helping behaviours, using your child's unique, confidential participant number.

If you are at all unhappy about your child's participation in this study, please fill in the reply slip below and return it to school within 5 days. No response will be regarded as permission for your child to participate.

Thank you for your cooperation.

Yours sincerely

Mr Wade Profe

Principal Investigator 
If you have any questions or complaints about this study, please contact:

Mr Wade Profe

Psychology Masters Student

Tel.: 0724898077

Email: wadeizzel@gmail.com
Dr. Lauren Wild

Supervisor

Tel: (021) 6504607

Email: lauren.wild@uct.ac.za

If you wish to speak to the Chair of the Research Ethics Committee, please contact:

Mrs Rosalind Adams

Department of Psychology Postgraduate Coordinator

0216504104

Email: Rosalind.Adams@uct.ac.za

I do not want my son / daughter to participate in the research study being conducted by the UCT Psychology Department at my child's school.

Child's Name:

Class:

Parent's / Guardian's Name:

Signature:

Date: 


\section{APPENDIX F: TEACHER CONSENT FORM}

\section{My Family, Friends and I survey: Teacher's consent form}

My name is Wade Profe, a Masters student from the Department of Psychology at the University of Cape Town. Please take time to read this sheet carefully and decide whether you do or don't want to take part. Do not hesitate to ask the researcher if there is anything that is not clear, or if you have questions. Thank you for reading this.

\section{What is the study about?}

We would like to know more about young people, their feelings, and their relationships with their family and friends.

\section{What would you have to do?}

If you decide to take part, you will first sign the consent form on the next page, and then complete the attached questionnaires for each learner in your class. The questionnaire contains only 5 short questions regarding the helping behaviour of the learner.

\section{What are the risks?}

We trust that you will find the questionnaire very easy and quick to complete, and therefore it will not have a detrimental effect on your time schedule.

\section{What are the benefits?}

By completing these questionnaires for each child in your class, you will be entered into a lucky draw. If your name is drawn, you will win a R500 Pick n' Pay shopping voucher. Additionally, we may learn something that will help other learners at some point in the future. The information you provide is very valuable.

\section{Do you have to take part?}

No. It is up to you to decide whether or not to take part. You are free to withdraw your participation at any time before or during the study process, without any negative consequences (except that you will not be eligible to win the shopping voucher).

\section{Will what I say be kept confidential?}

Anything that you say will be kept strictly confidential, and will not be shared with the learners' relatives or friends, or any other persons not directly involved in the collection of research data. As you will see, for the purposes of matching your completed questionnaires with each learner's respective questionnaire, you have been given a class list assigning a participant number to each learner. Once the research has been completed, these lists will be destroyed to ensure that none of the information provided can be traced back to you or any learner. 


\section{Contact for further information}

If you have any questions about this study, you can contact Mr Wade Profe on (Tel.) 072489 8077 or (Email)wadeizzel@gmail.com, or Dr Lauren Wild on (Tel.)021 6504607 or (Email) Lauren.Wild@uct.ac.za.

If you wish to speak to the Chair of the Research Ethics Committee, please contact the Department of Psychology Postgraduate Administrator, Rosalind Adams. (Tel.) 021650 4104.

Thank you for reading this sheet. If you have any questions, please feel free to raise them with the researcher. If you feel comfortable with everything, you can fill in the box below:

\section{Tick}

1. I have read and understand the information sheet for this study and have had the chance to ask questions.

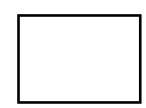

2. I understand that I have chosen to take part and that I am free to stop at any time, without giving any reason.

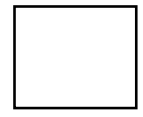

3. I agree to take part in the study

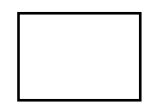

Name of participant

Signature

Date...... 


\section{APPENDIX G: INSTRUCTIONS FOR TEACHERS}

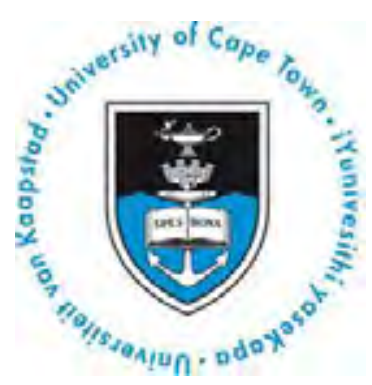

Department of Psychology Master's candidate

Wade Byron Profe

13 Kestel Street

Plumstead

Cape Town

7800

Tel: $+27(0) 724898077$

E-mail: wadeizzel@gmail.com

Internet: www.uct.ac.za

\section{Dear Teacher}

\section{RE: Research to be conducted at your school on ...}

Attached are documents pertaining to the research to be conducted among your Grade 7 learners by Mr Wade Profe from the University of Cape Town on ...

Attached herein are the following documents:

1. A parent consent form for each child in your class, to be taken home by each child to their parents as soon as possible. If any parents return the reply slip indicating that they do not want their child to participate, please take note of these and notify the researcher on the day of survey administration.

2. A teacher's consent form. Please read through this and sign where appropriate before filling in the learner questionnaires.

3. A short, 5-question survey for each child in your class. Please fill out one of these surveys for each child in your class as honestly and accurately as you can, by the end of the survey administration on ... Please indicate the child for whom you are answering on each questionnaire by filling in their participant number in the space provided. Please keep all the completed surveys for your class together and hand them to the researcher on the day of survey administration.

4. A class list containing the names and participant numbers for each learner in your class. Please use each child's participant number only when completing the 5-item questionnaire.

If you have any questions or require any assistance, please do not hesitate to contact $\mathrm{Mr}$ Wade Profe on 0724898077 or via email on wadeizzel@gmail.com.

Yours sincerely

Wade Profe 